Final Report for DOE grant \# DE-FG03-02ER54686

Roger Raman - PL, University of Washington, Seattle, WA 98195

Grant ending: July 14,2004

The CT injector originally used for injecting CTs into $1 \mathrm{~T}$ toroidal field discharges in the TdeV tokamak was shipped PPPL from the Affiliated Customs Brokers storage facility in Montreal during Navember 2002. All components were transported safely, without damage, and are currently in storage at PPPL, waiting for further funding in order to begin advanced fueling experinents on NSTX. The components are currently insured through the University of Washington.

Several technical presentations were made to investigate the feasibility of the CT injector installation on NSTX. These technical presentations, attached to this document, were:

[1] Motivation for Compact Toroid Injection in NSTX, NSTX Physics Seminar, April 7, 2003 by R Raman (attached). Also attached as STI File: Raman_040703.pdf

[2] Assessment of the Engineering Feasibility of Installing CTF-II on NSTX. April 22, 2003, by R. Raman (attached).

[3] Assessment of the Cost for CT Installation on NSTX - A Peer Review, May 20, 2003 , H.W. Kugel, R. Raman, L. Dudek, F. Jones, L. Roquemore (attached).

[4] CT Fueling for NSTX Fy 04-08 steady-state operation needs, NSTX Fy 04-08 plans meeting, June 24-26, 2002, R. Raman, T.R. Jarboe, H.W. Kugel.

At the ITPA meeting on Steady-State operations held at GA during October 2003, a presentation was made on CT Fueling [S, also attached as STI Filc: Raman_100803.pdt]. The summary from this meeting stated: "R. Raman made a presentation on the injection of compact toroids (CT) for fuelling advanced scenarios. The approach appears interesting and a plan for developing this technique was proposed, the first step being a full test on NSTX, which appears essential before considering such a technique for ITER. The group is in favor of this proposal." [6]. The ITPA steady state group, thus, endorsed the proposal to conduct a CT Fueling test on NSTX.

As suggested by the ITPA neeting summary, CT injection experiments on NSTX will make a unique and very important contribution to ITER, while developing needed systems for the ST concept (fueling requirements for steady state high-beta operation and momentum injection capability). This is because no other large machine is at present engaged in such an experiment mainly because no one else has the capability to conduct such an experiment on a near-time scale.

Wo are at present investigating, through PPPL, the possibility of re-assembling the CT hardware in a test lab at PPPL.

The US is currently the world leader in CT Fueling technology and because of NSTX, is in a unique position to conduct the required next-step experiments on a near time scale, as reflected by the endorsement from the ITPA summary [6]. Eventually such a system is also needed for the ST concept. 


\section{Recent References:}

[1] Motivation for Compact Toroid Injection in NSTX, NSTX Physics Seminar, April 7. 2003 by R. Raman (atrached).

[2] Assessment of the Engineering Feasibility of Installing CTF-II on NSTX, April 22, 2003, by R. Raman (attached).

[3] Assessment of Cost for CT Installation on NSTX - A Peer Review, May 20, 2003, H.W. Kugel, R. Raman, L. Dudek, F. Jones, L. Roquemore (attached).

[4] CT Fueling for NSTX Fy 04-08 stcady-statc operation needs, NSTX Fy 04-08 plans meeting, June 24-26, 2002, R. Raman, T.R. Jarboe, H.W. Kugel.

[5] R. Raman, Fueling requirements for stendy-state, high bootstrap current fraction discharges, TTPA Meeting on Steady State and Energetic Particles Working Group, General Atomics, October 8-10, 2003.

[6] Annual report of the ITPA Steady State and Energetic Particles Working Group (2003), Page 9, section 9 of the file ITPATGSSO\&EP_2003_annual_rep.d 


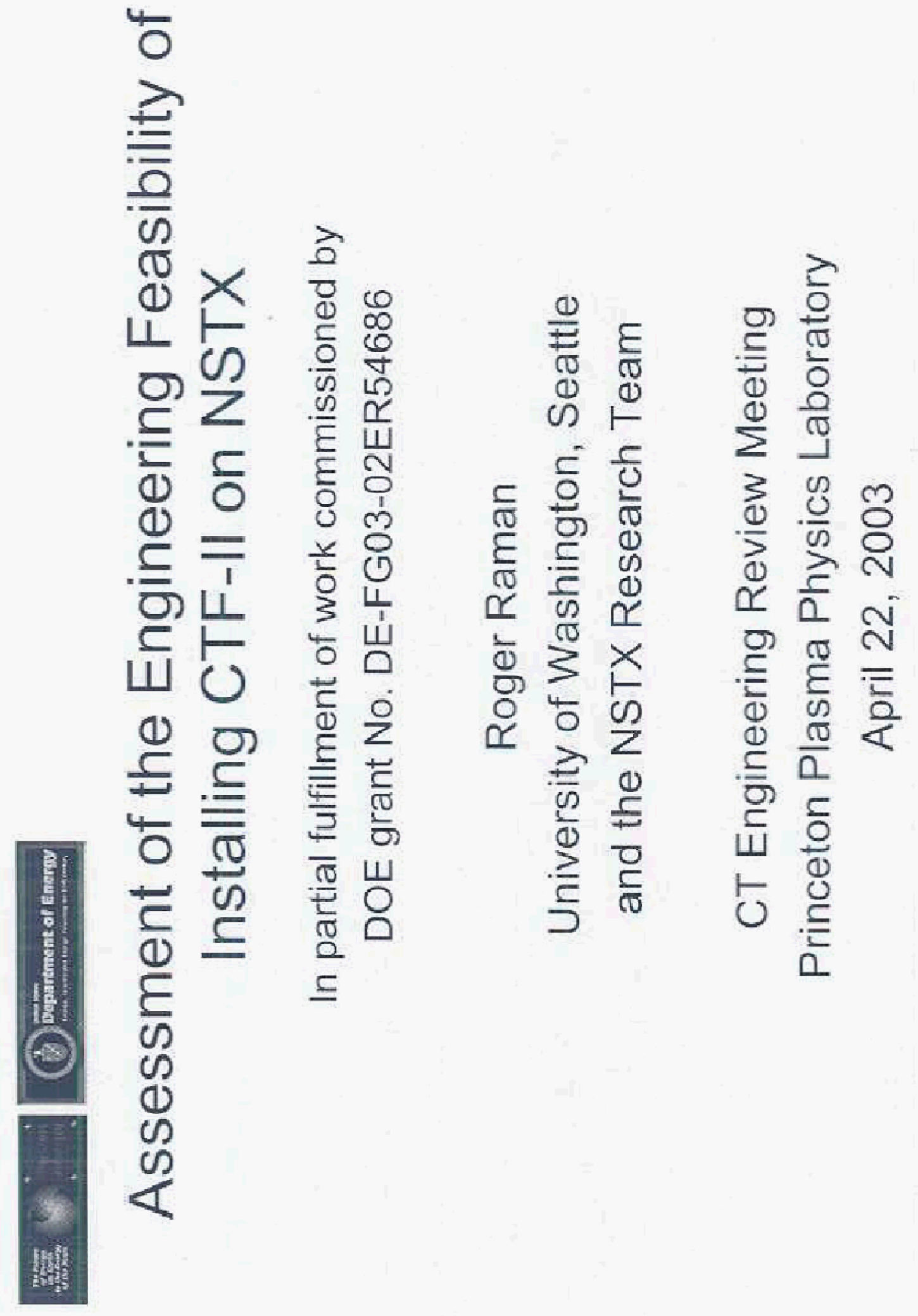




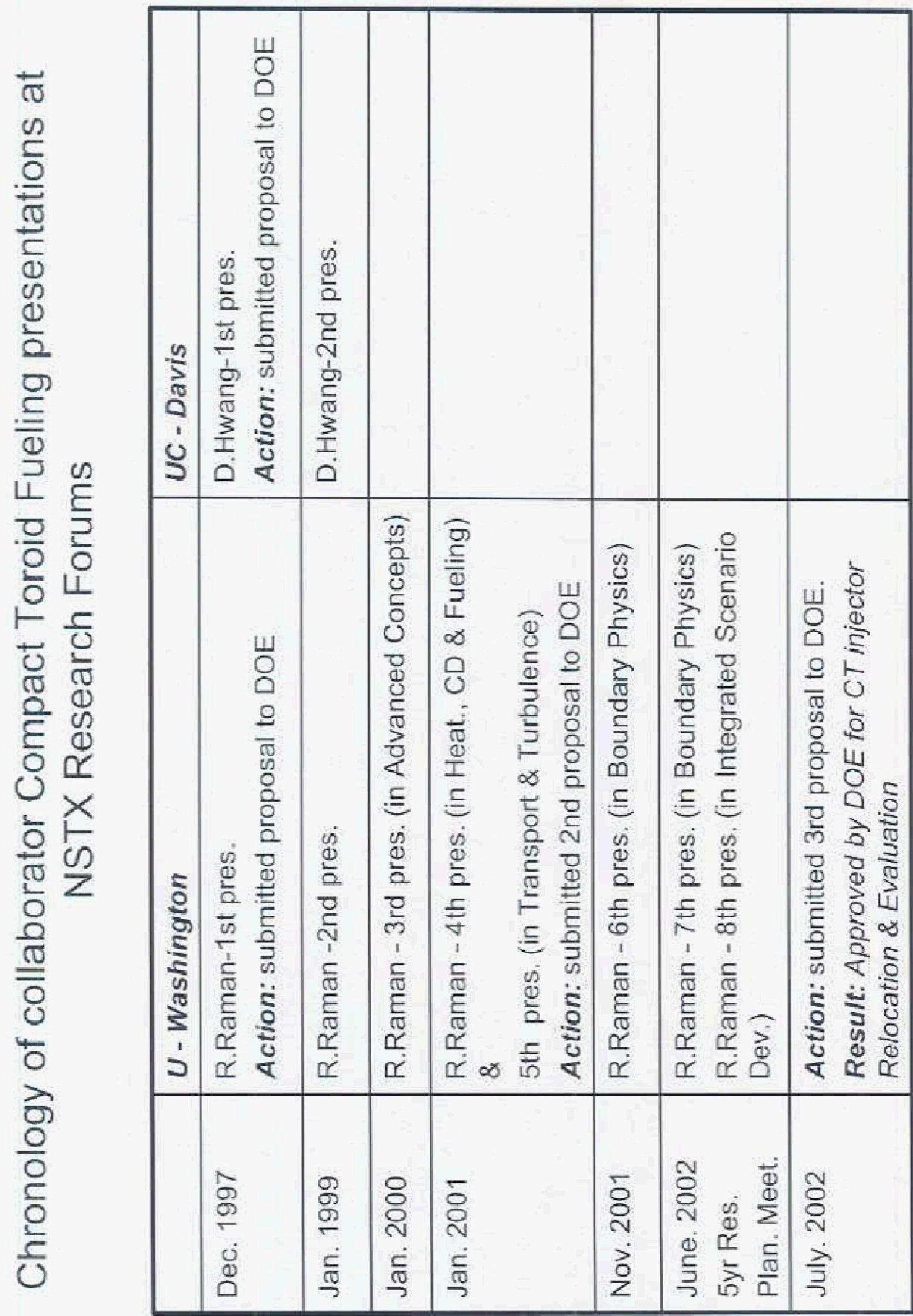




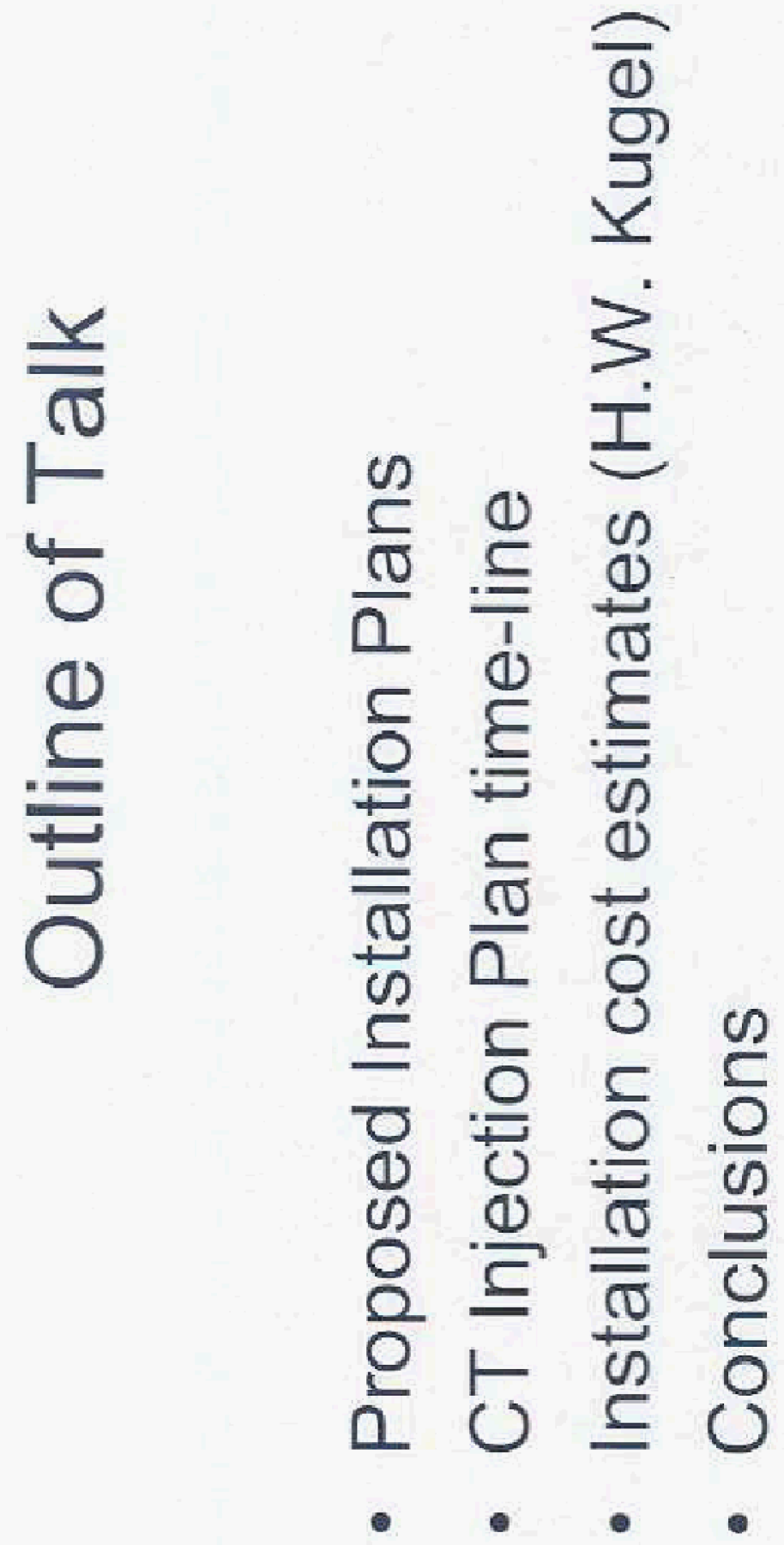



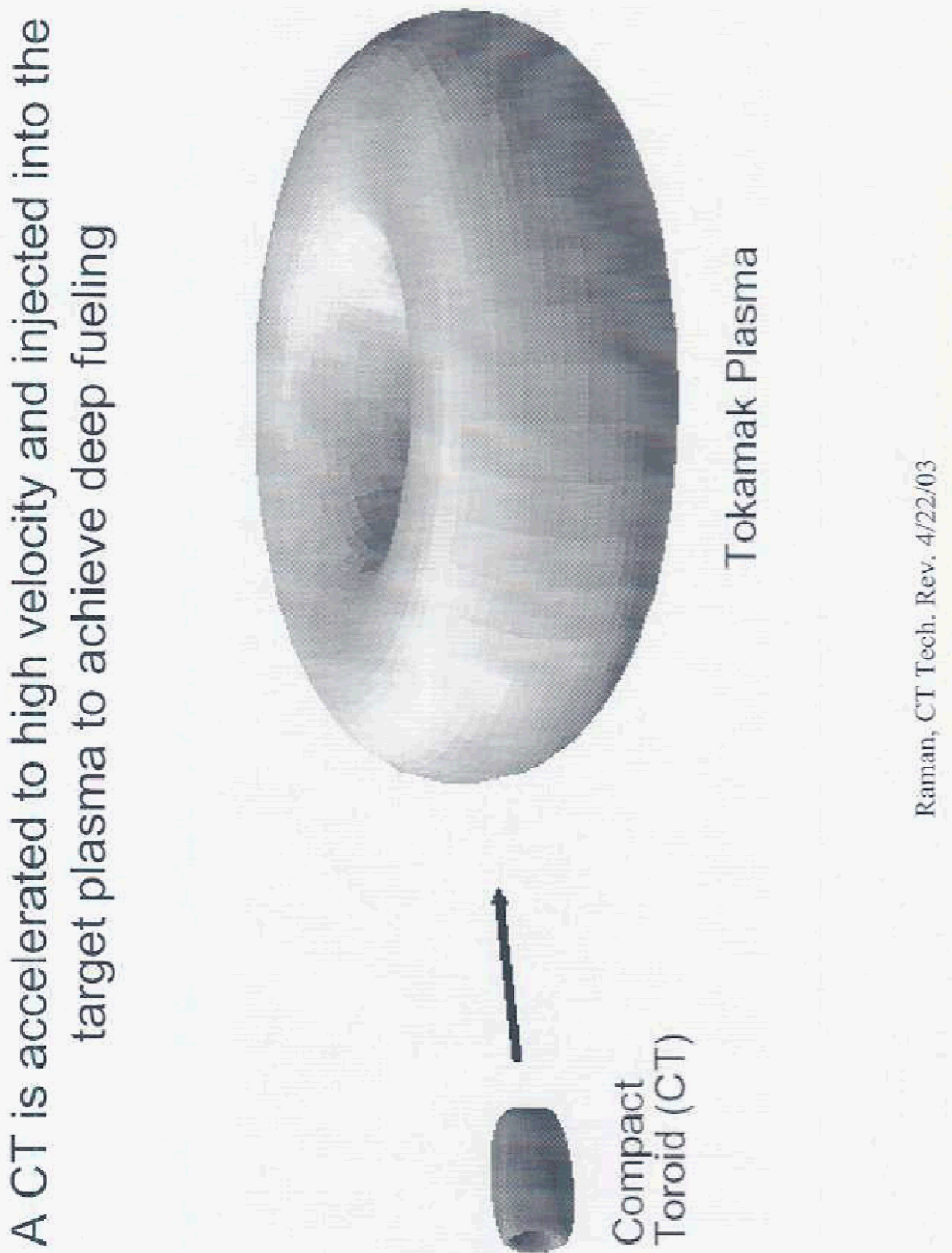


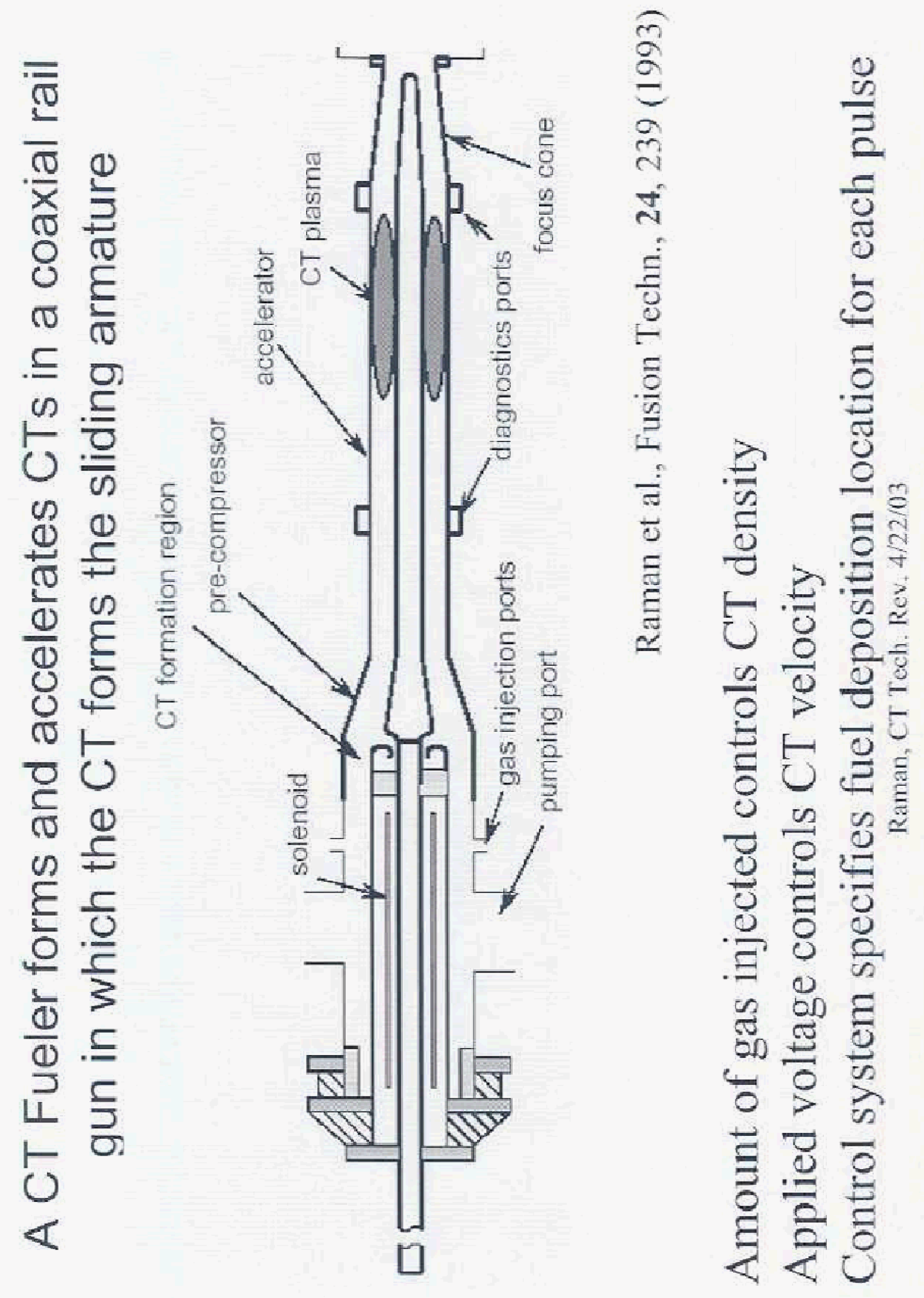




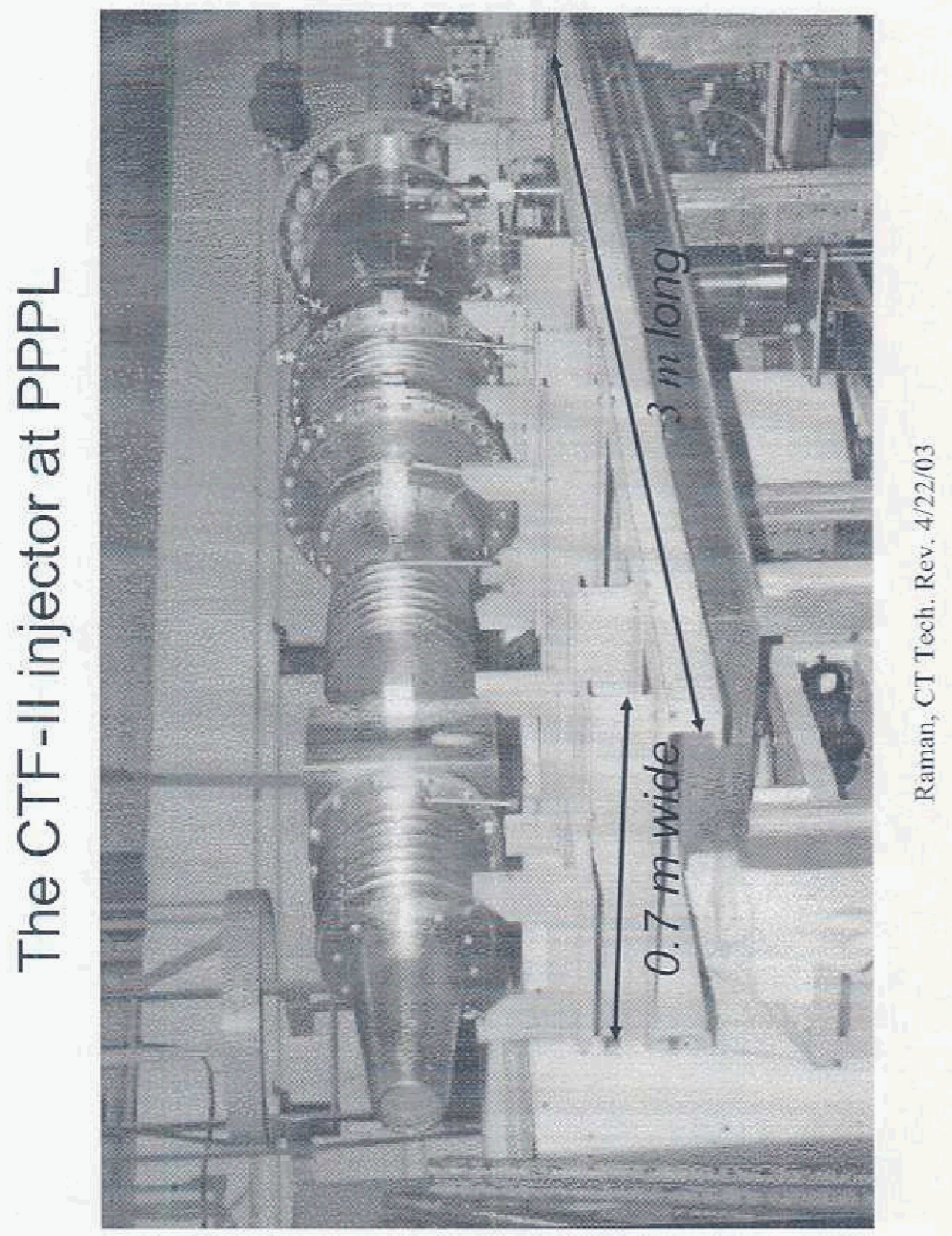




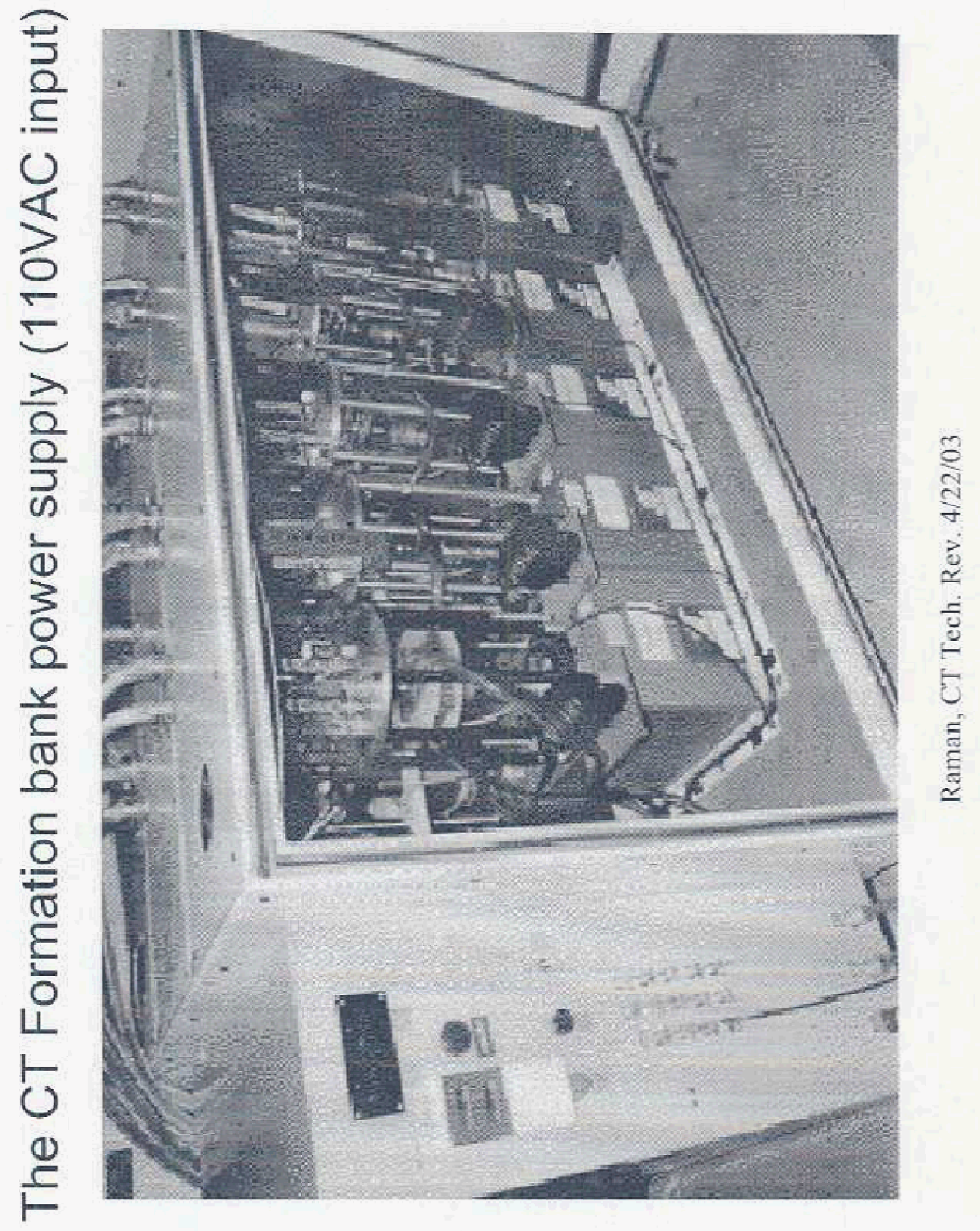




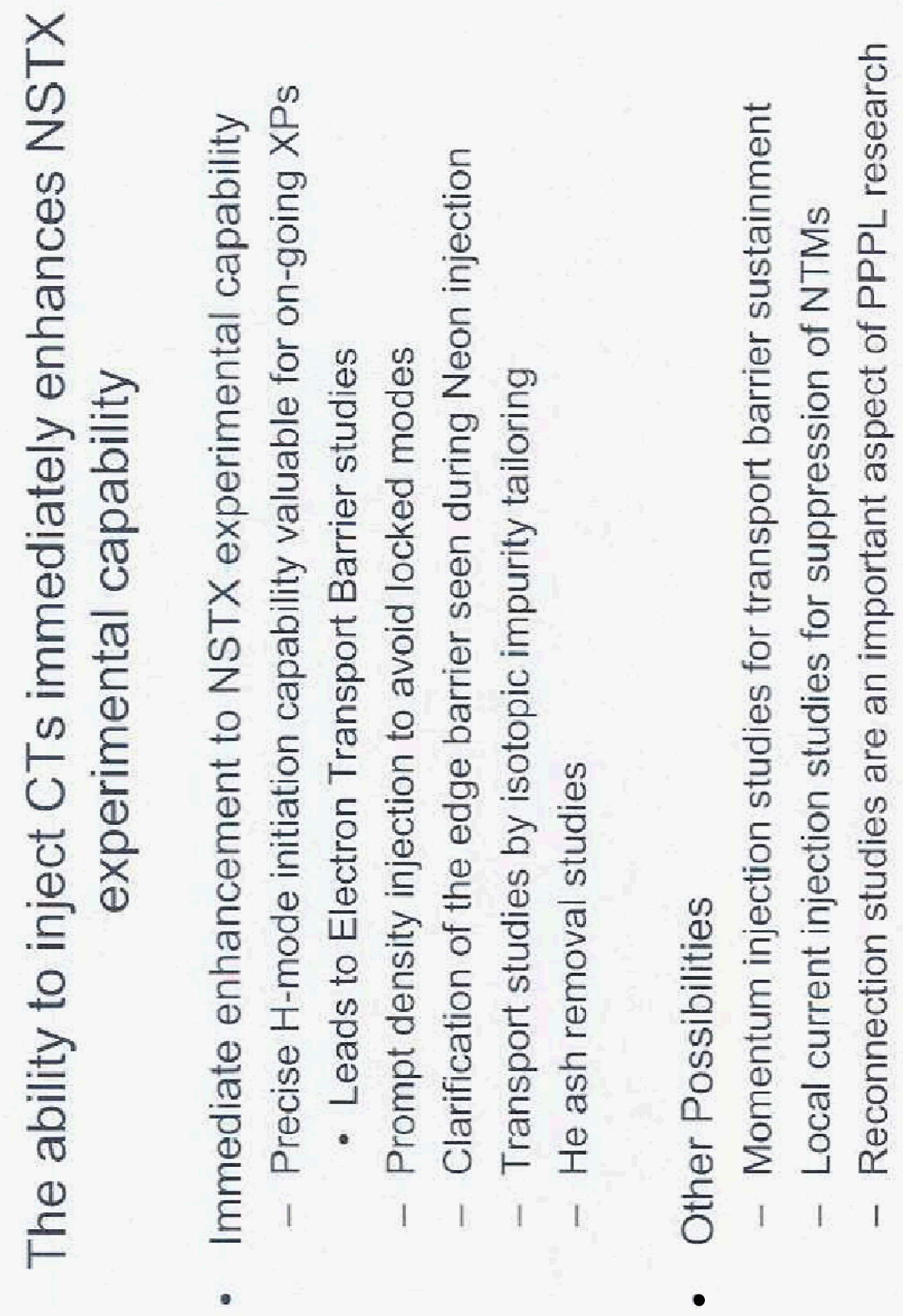




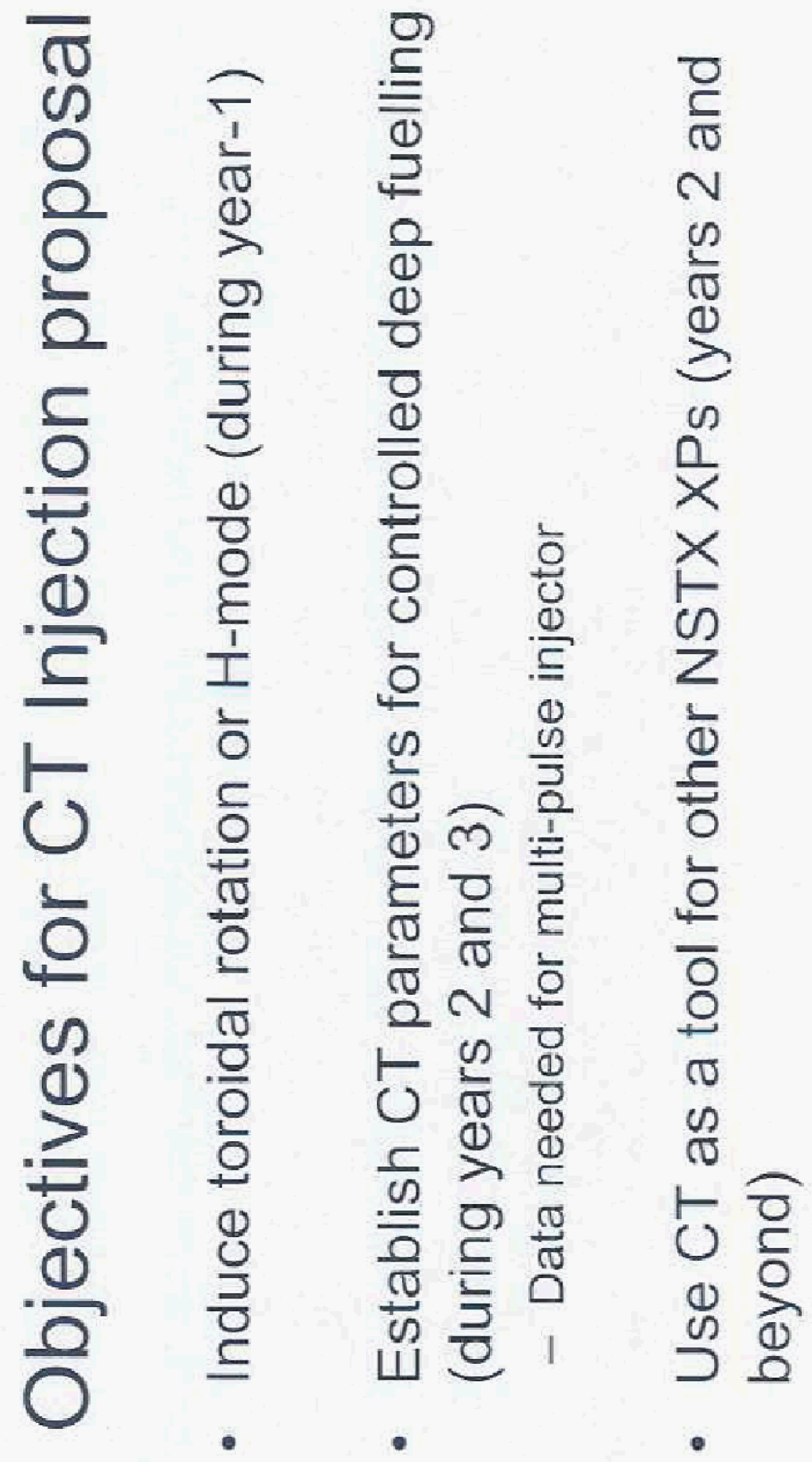



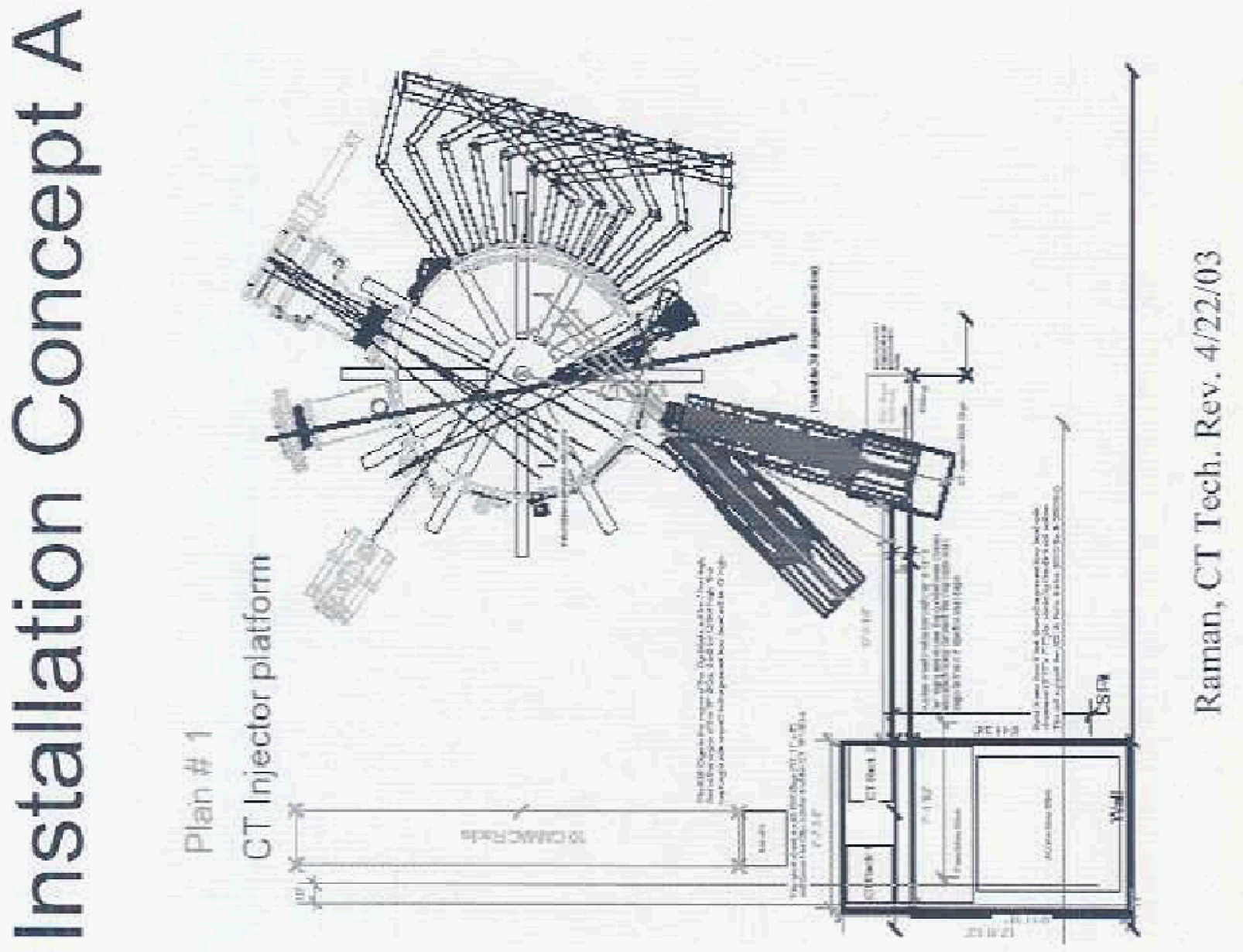


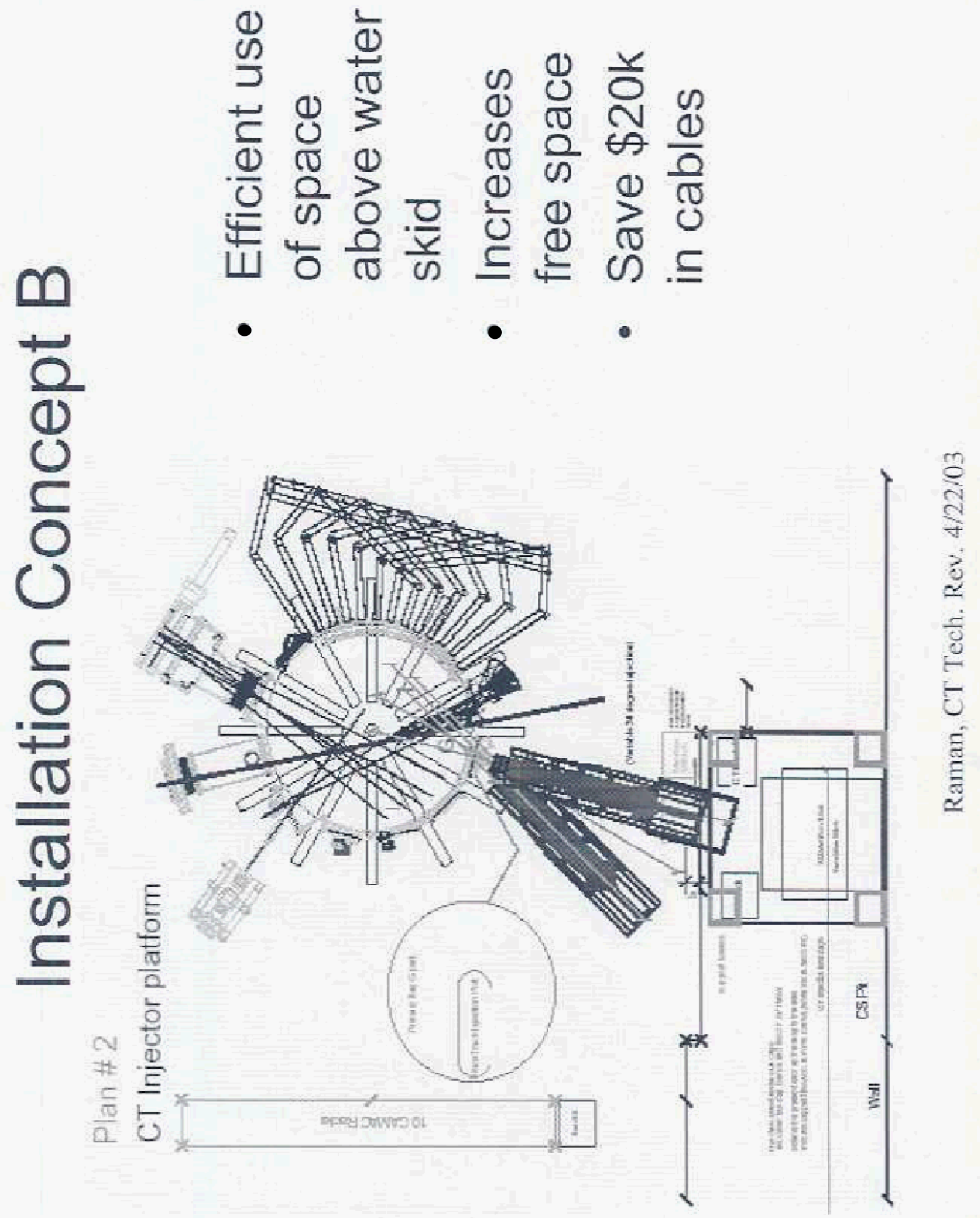




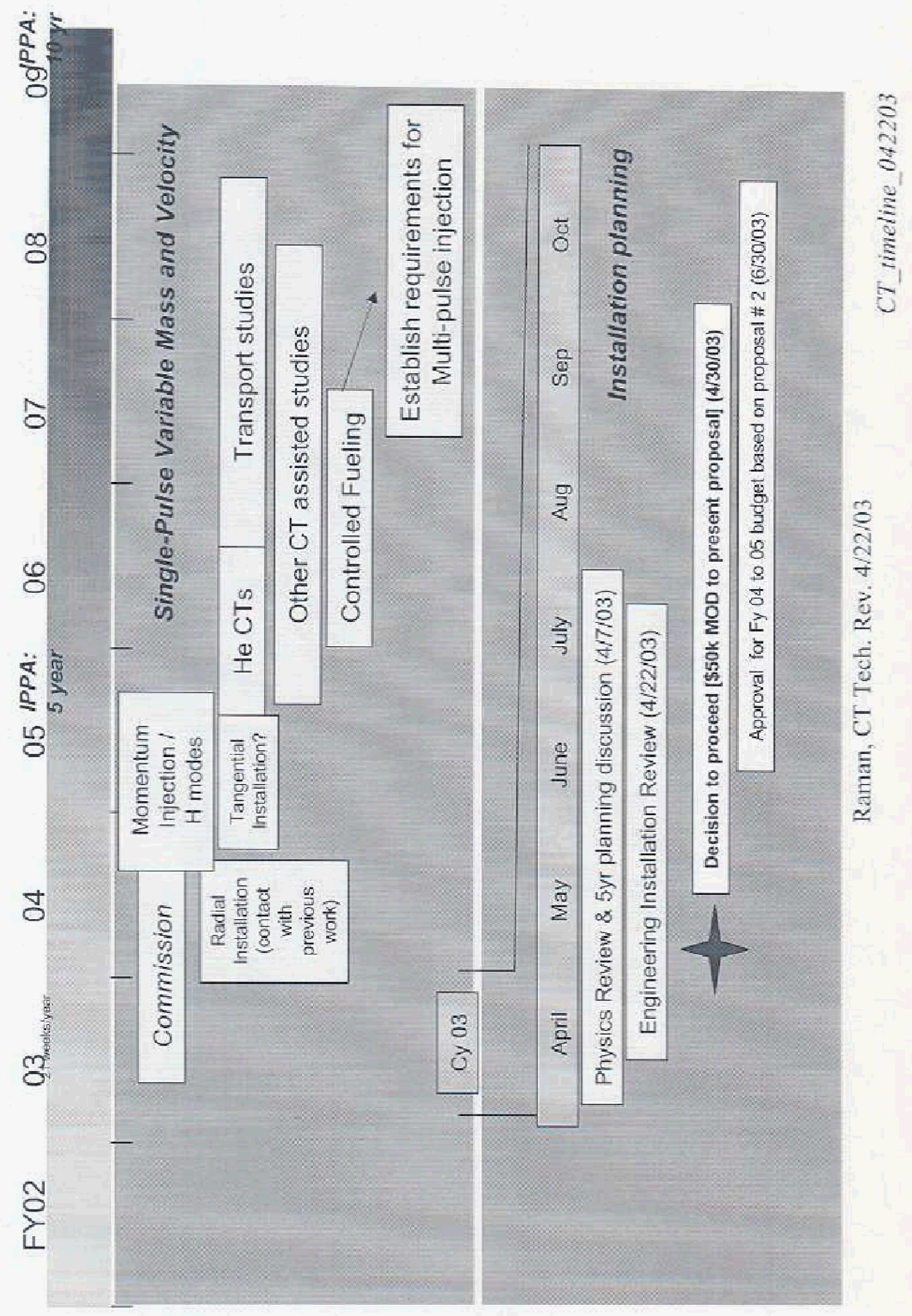




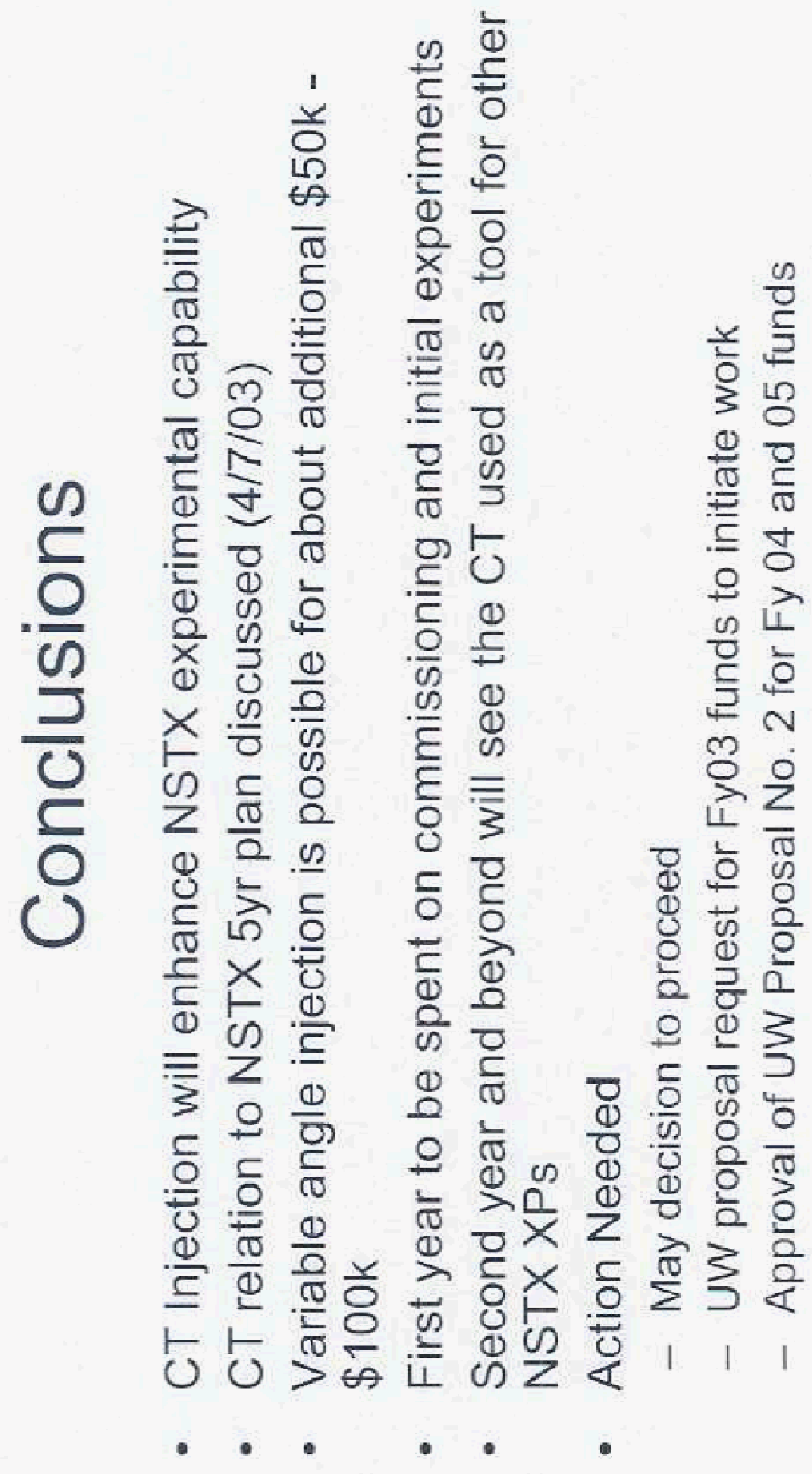

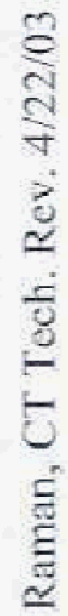




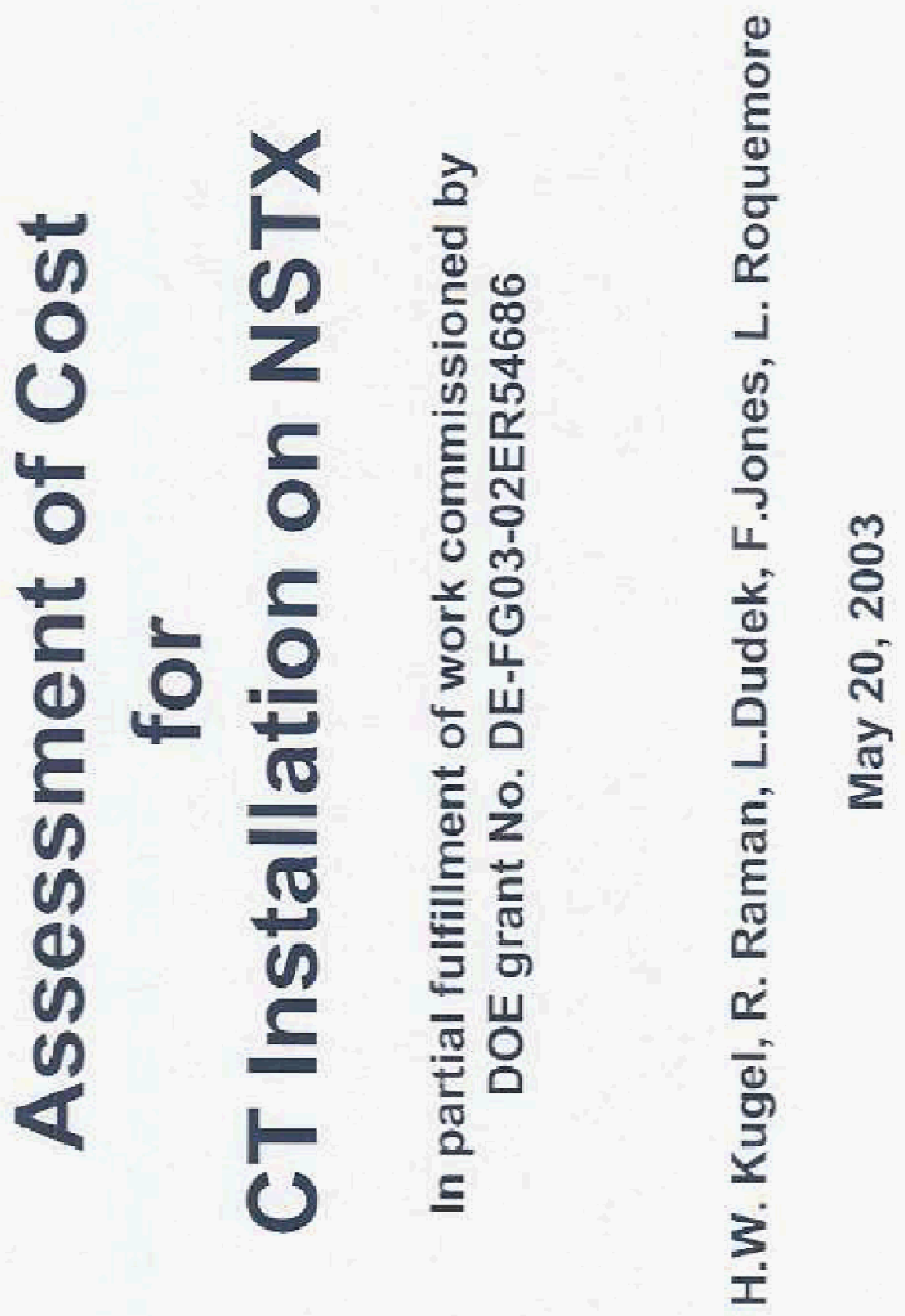




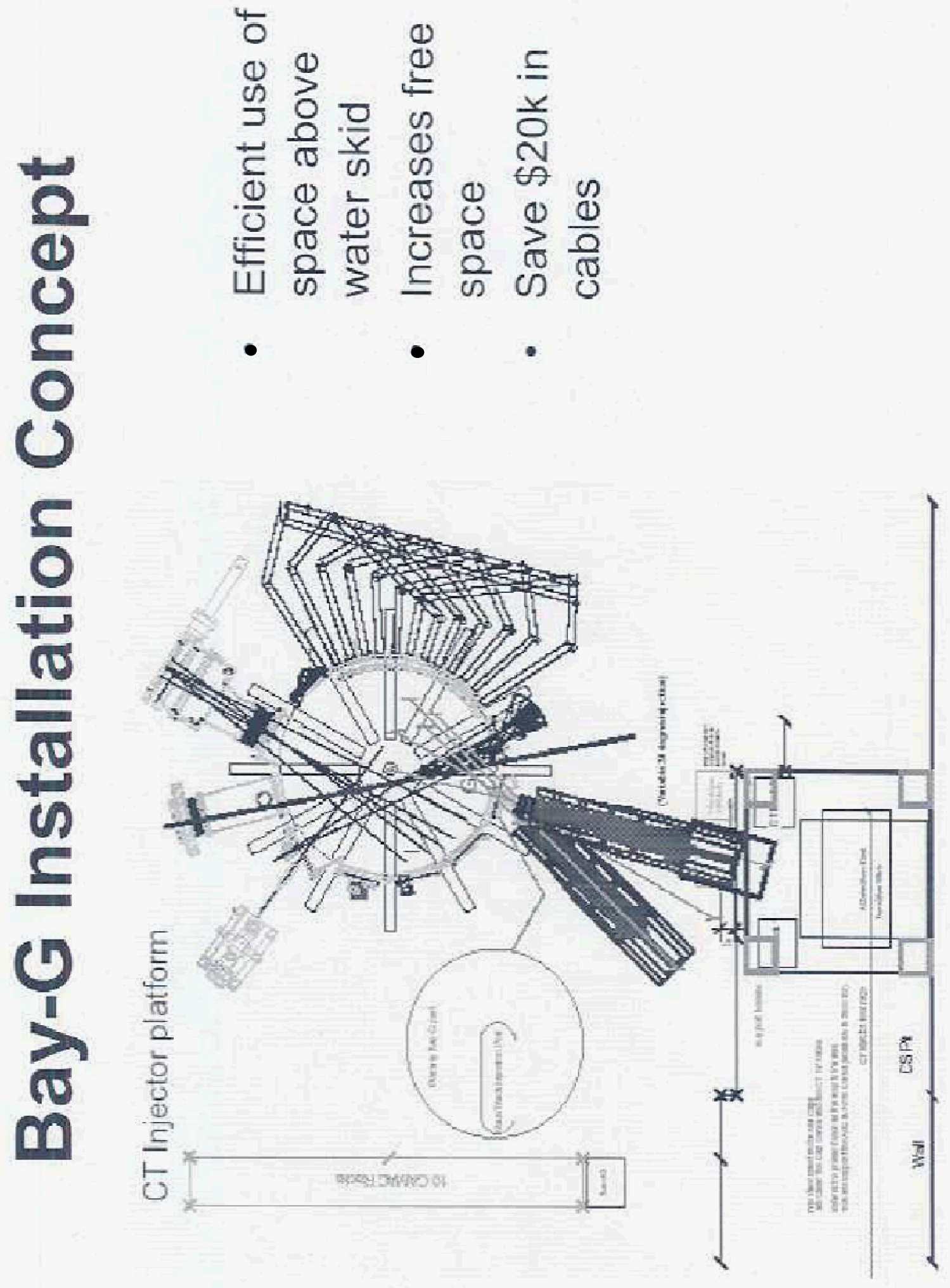



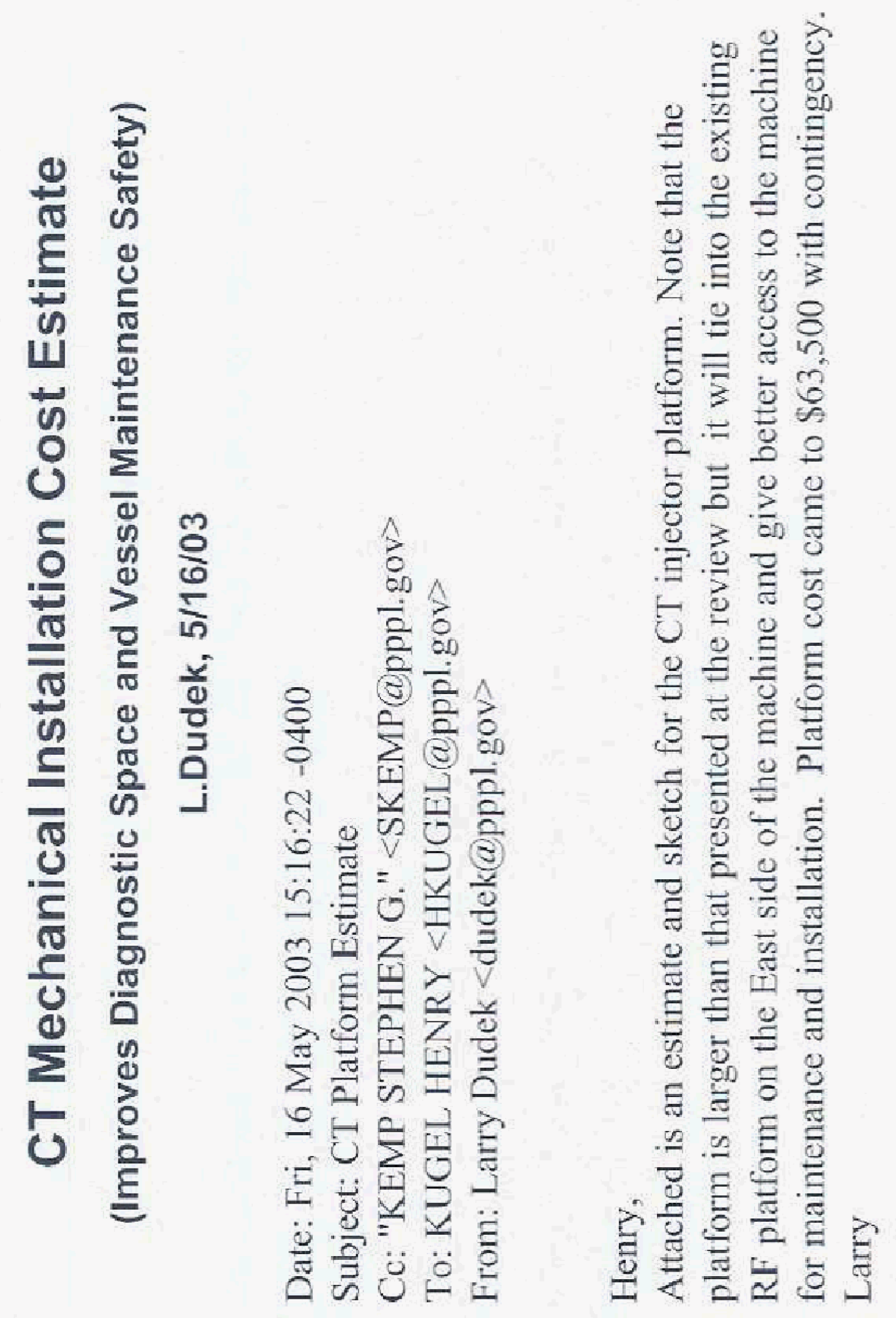


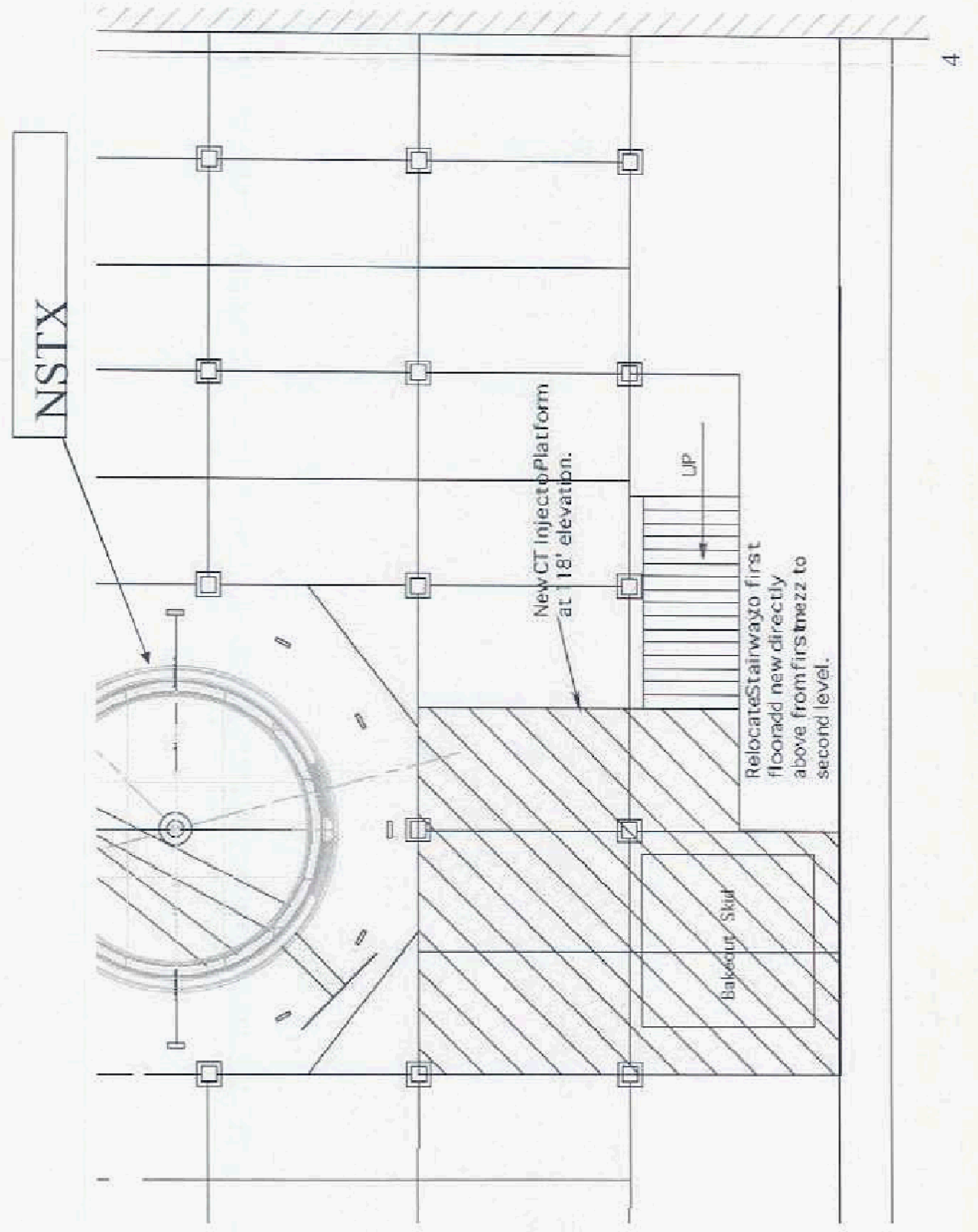




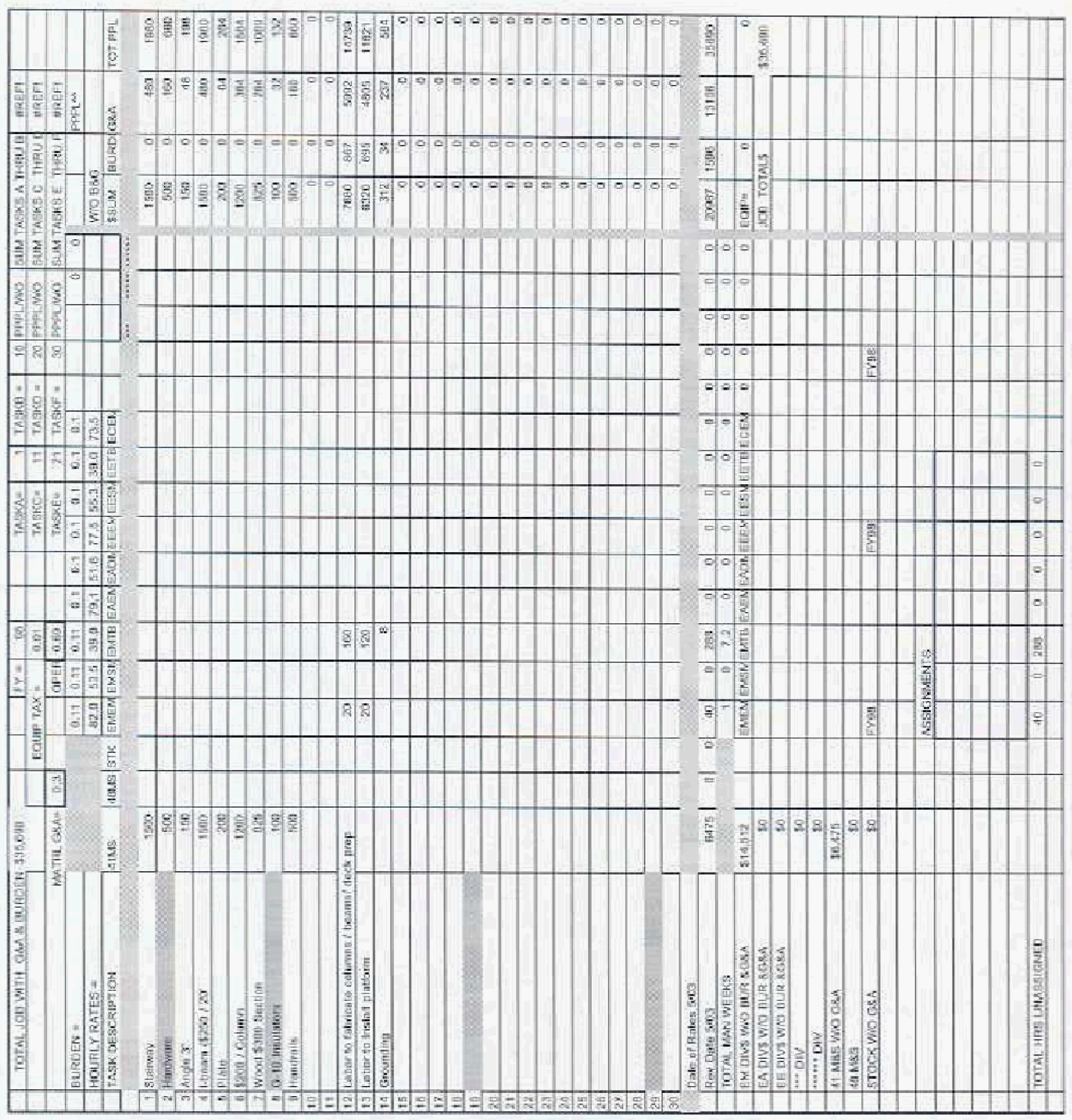




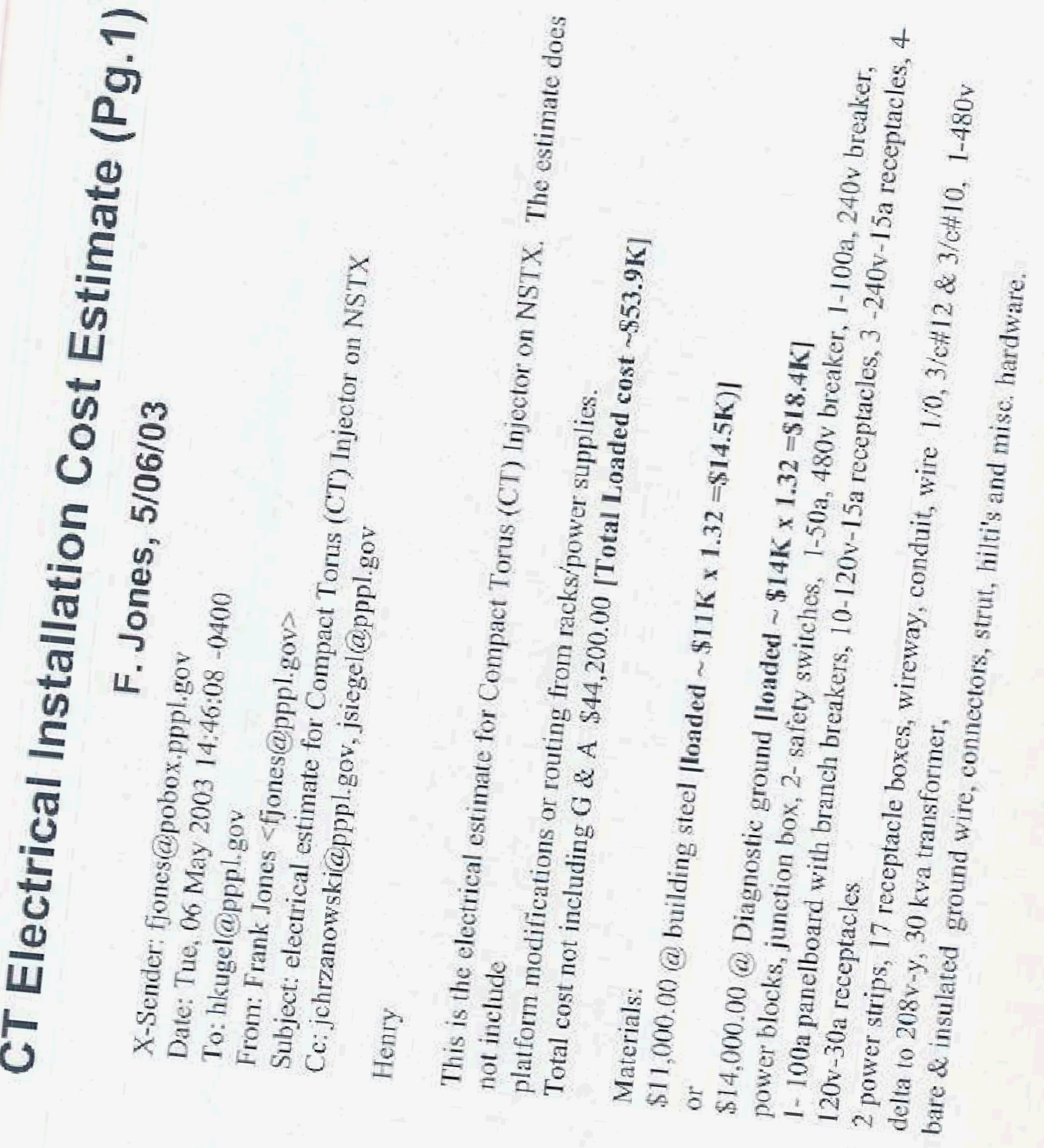




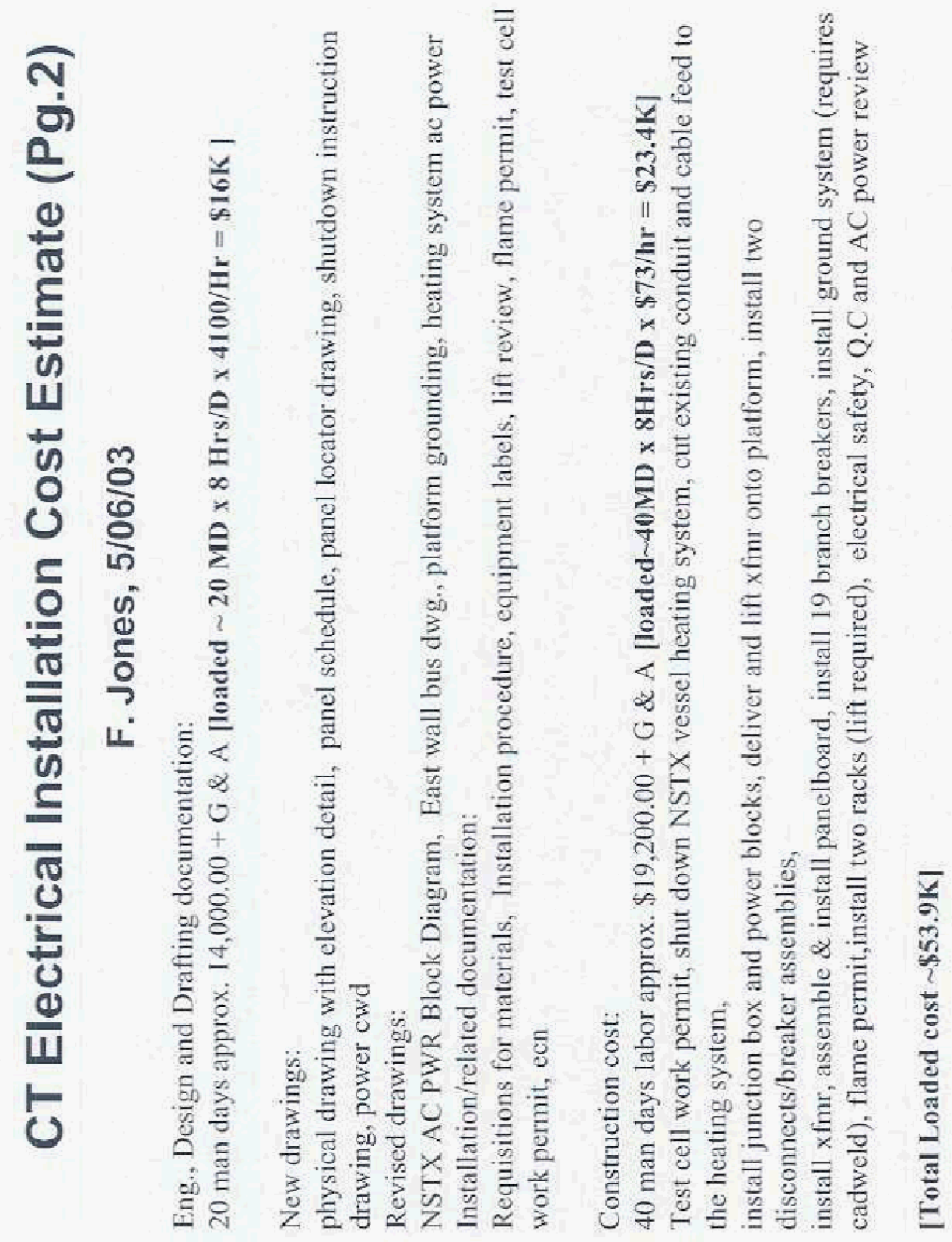



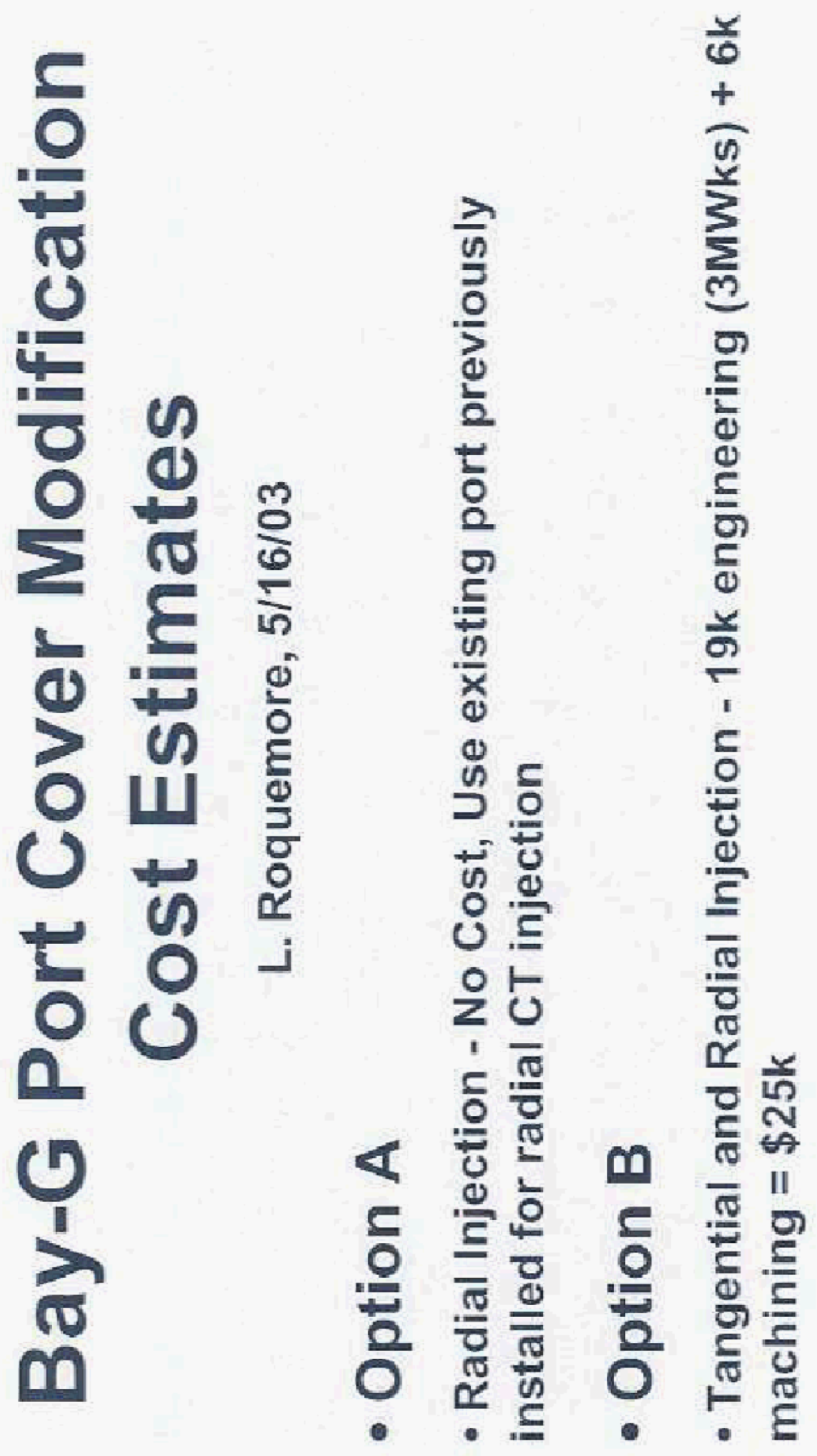


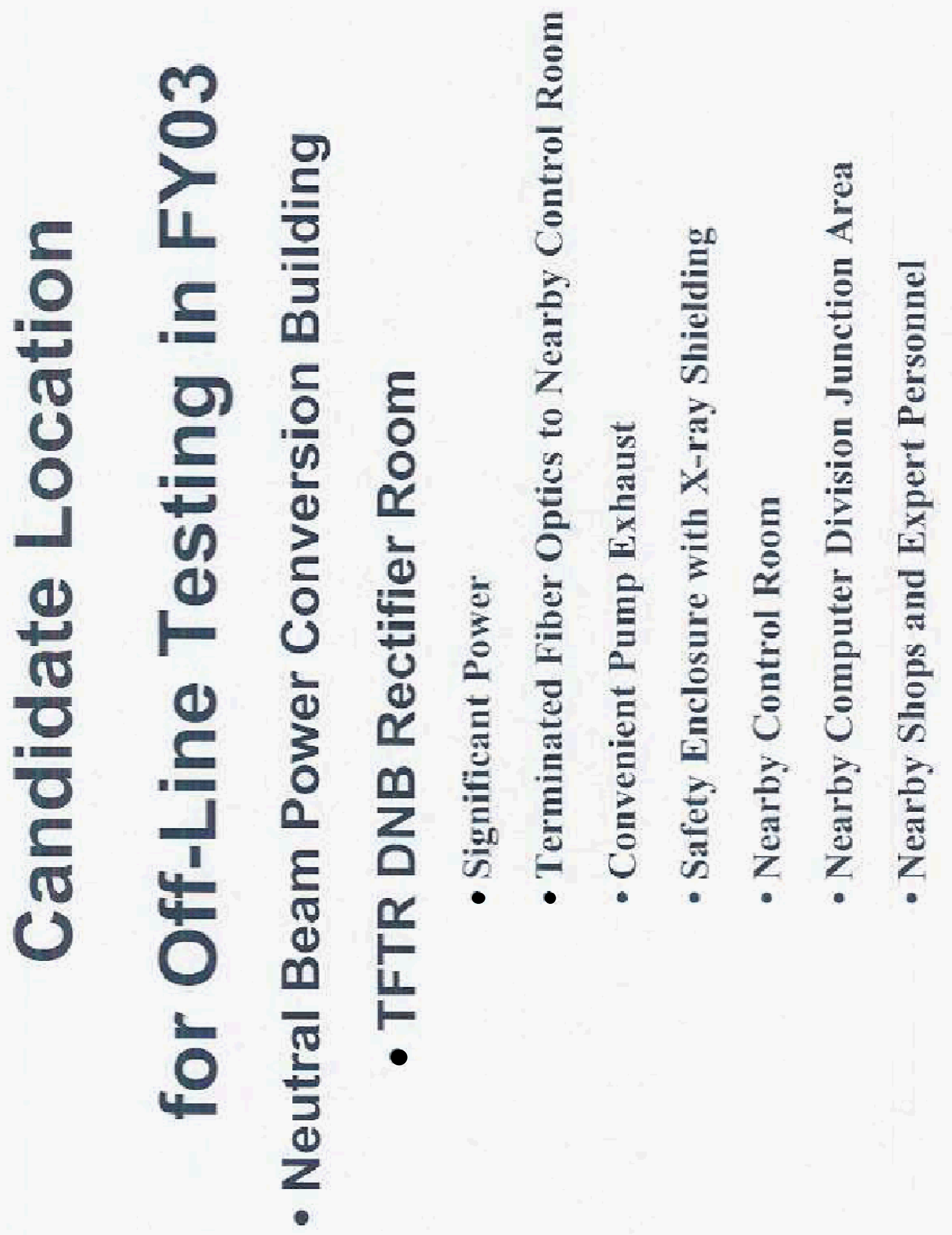




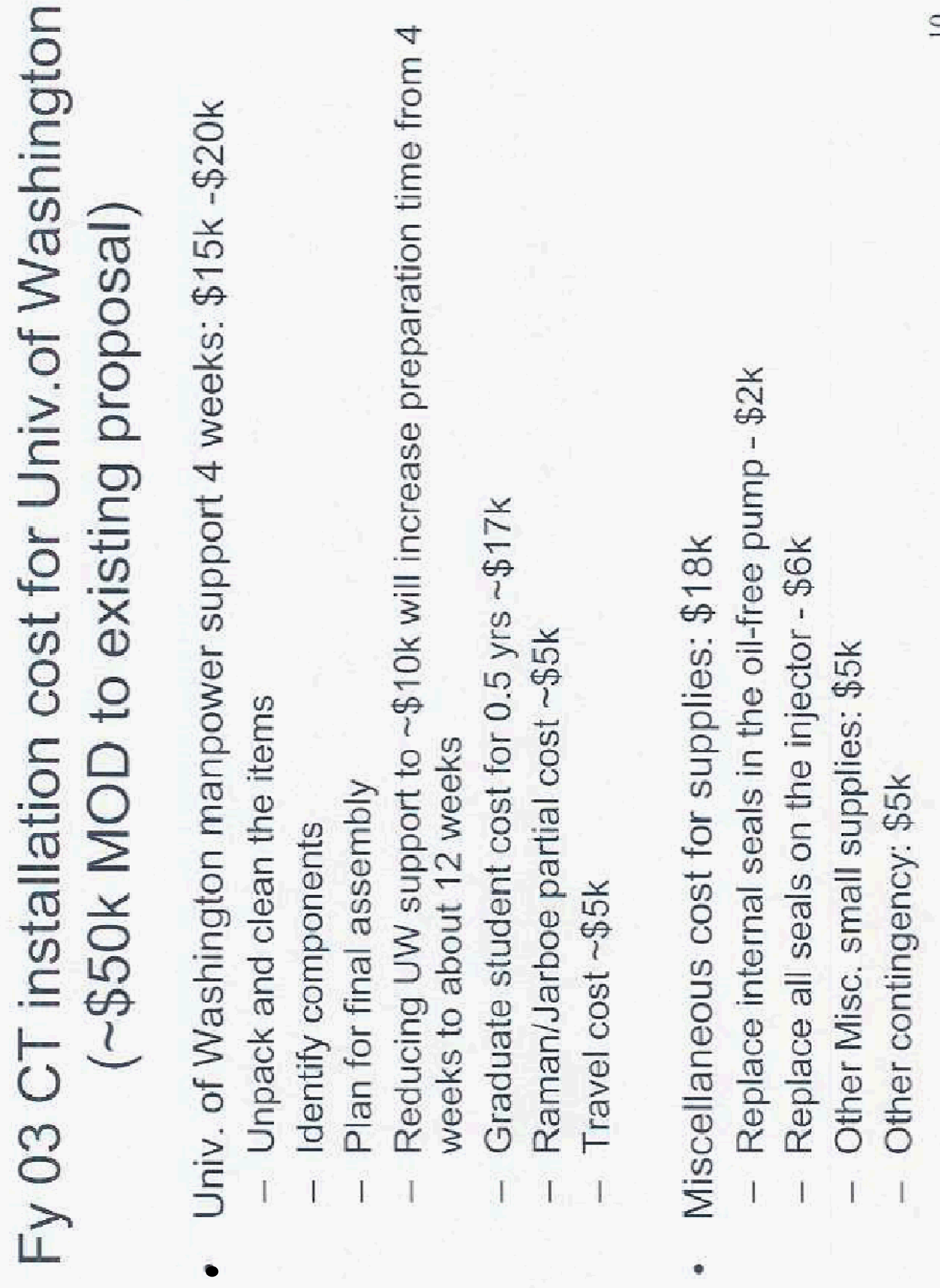




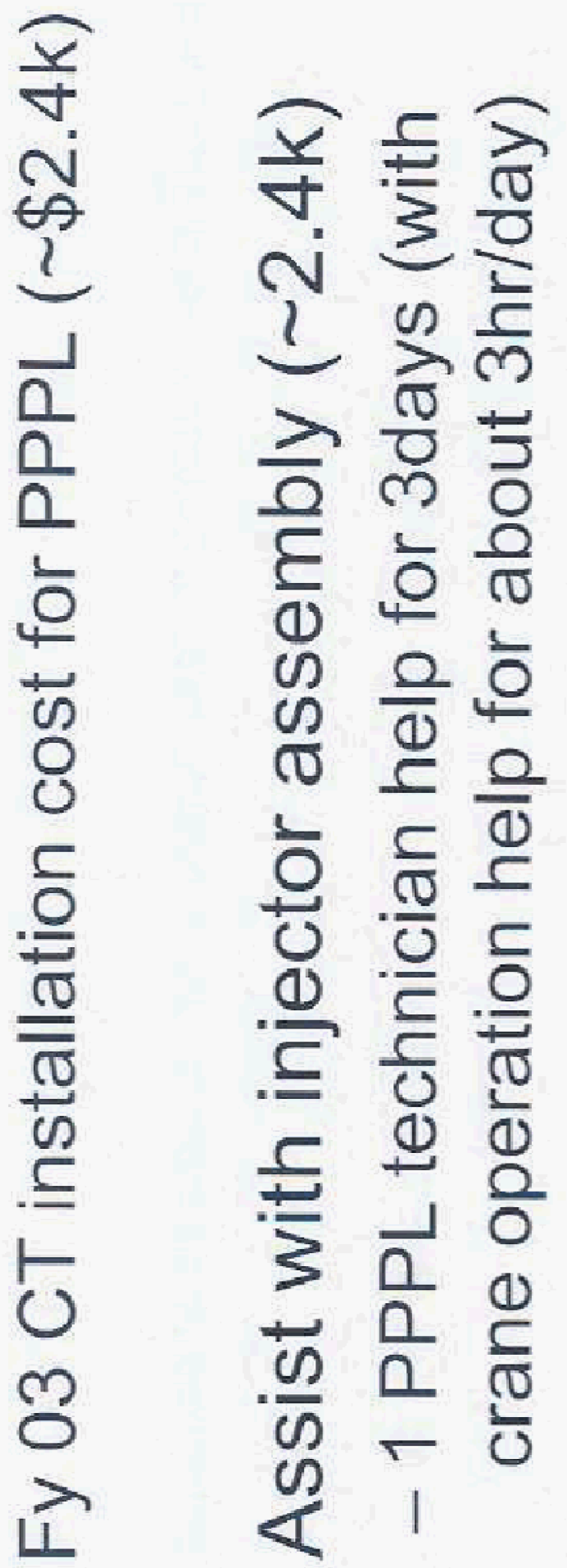




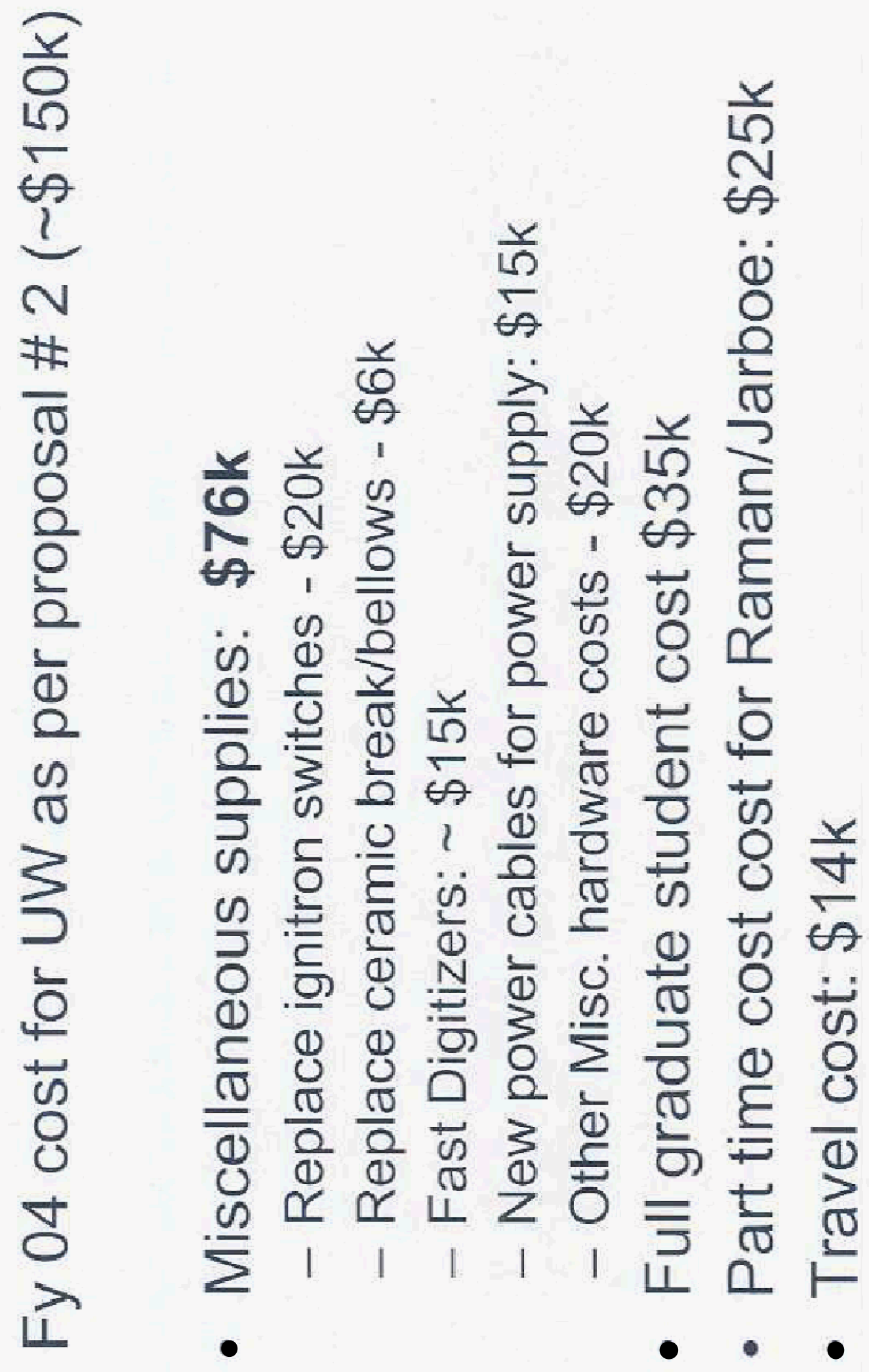




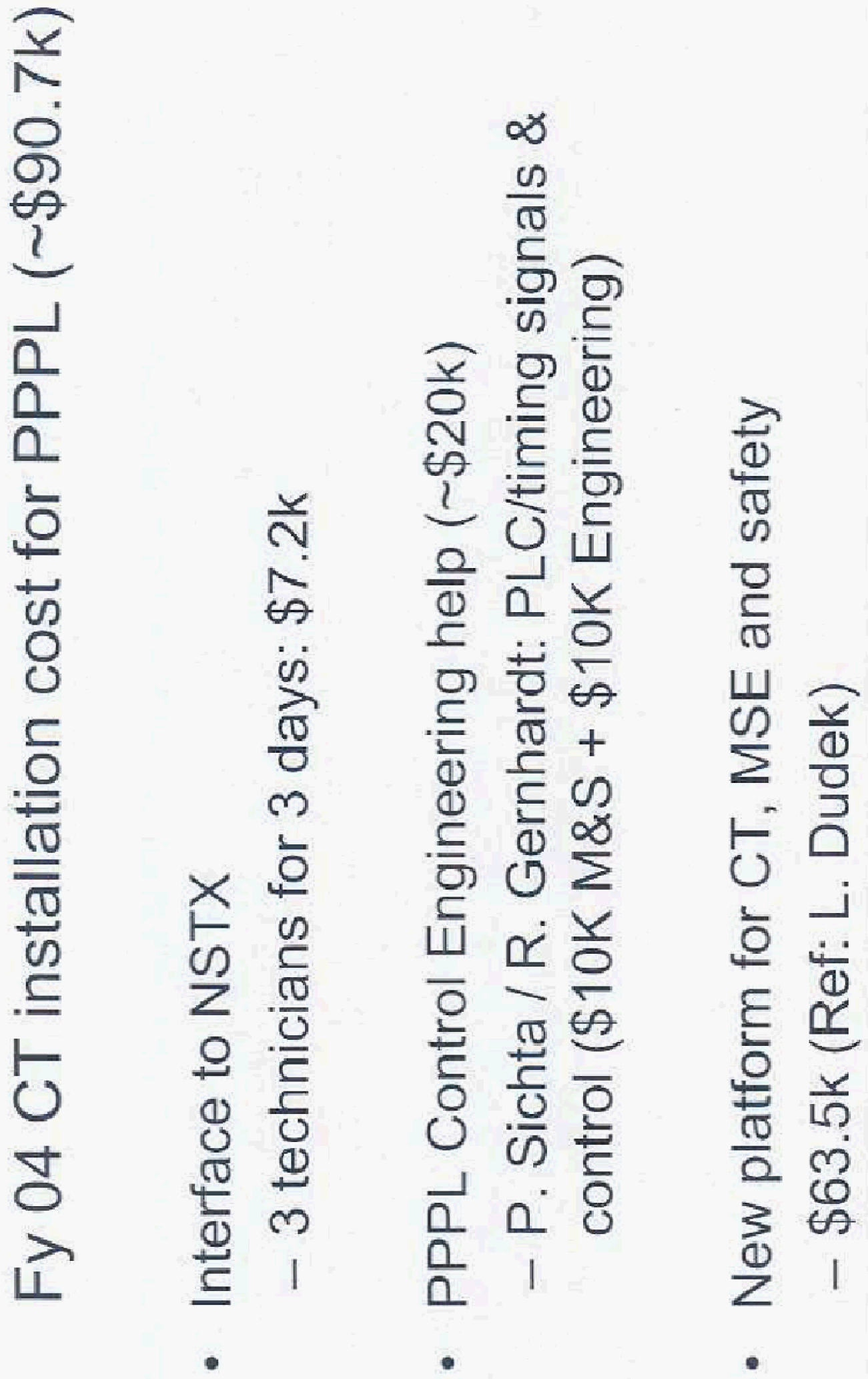



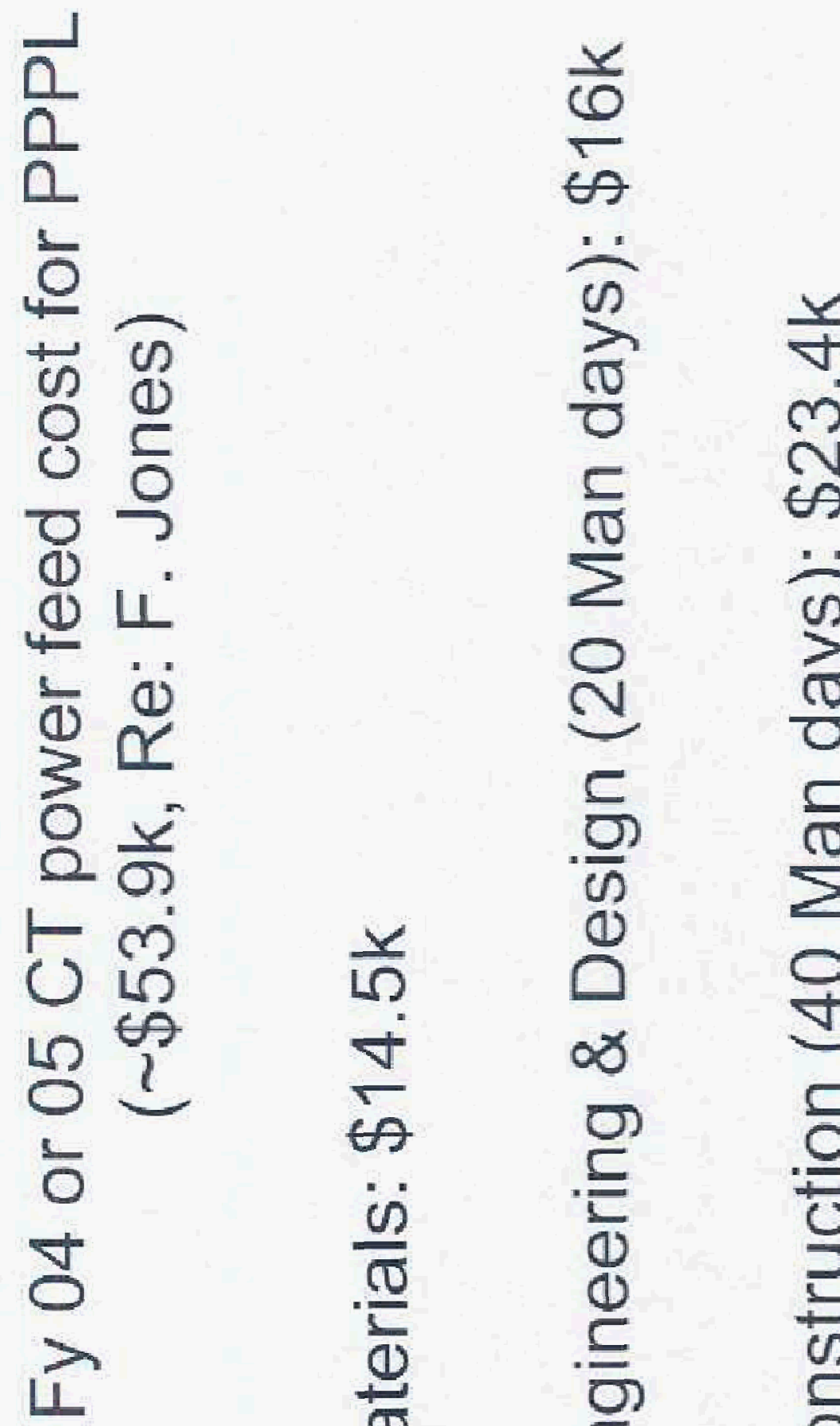

$\frac{R}{40}$

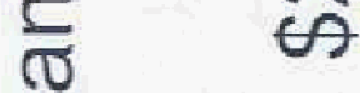

$\sum$

○

v

$\frac{1}{6}$

3

त

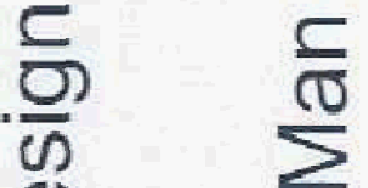

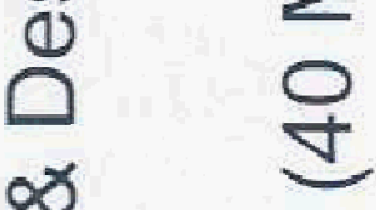

Uก

(0)

(1)

$+$

$\sum$

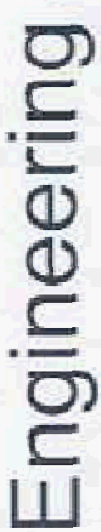

$\frac{5}{0}$

-

단

- 
(D)

(1)

ర

(1)

0

(1)

(1)

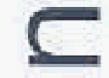

$\infty$

(1)

○

(V)

ह

(2)

0

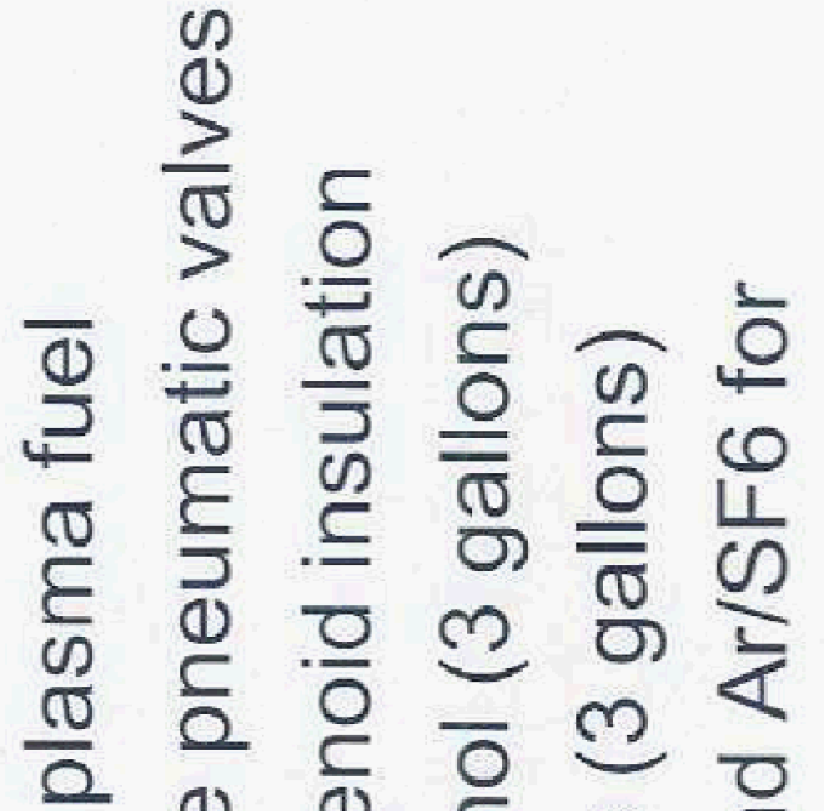

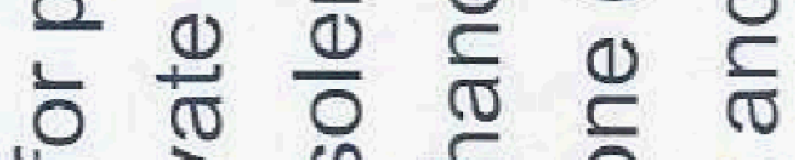

$4 \geq \infty \stackrel{5}{5}$ ○

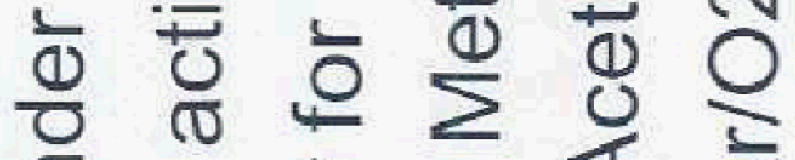

ఏ으 인

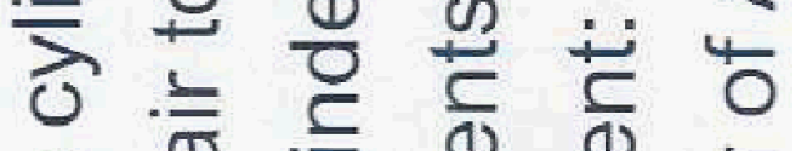

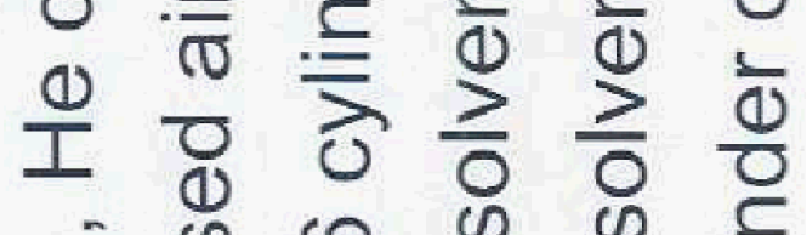

N क 0 क ज

๙

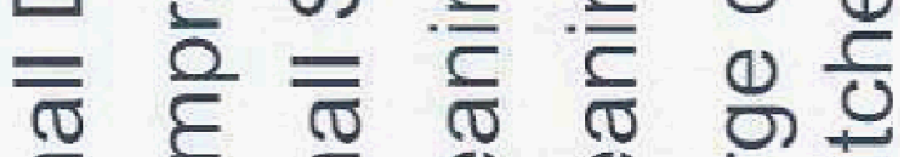

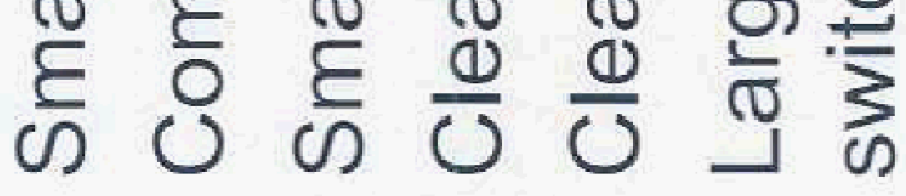

- $\bullet \circ \div$ 


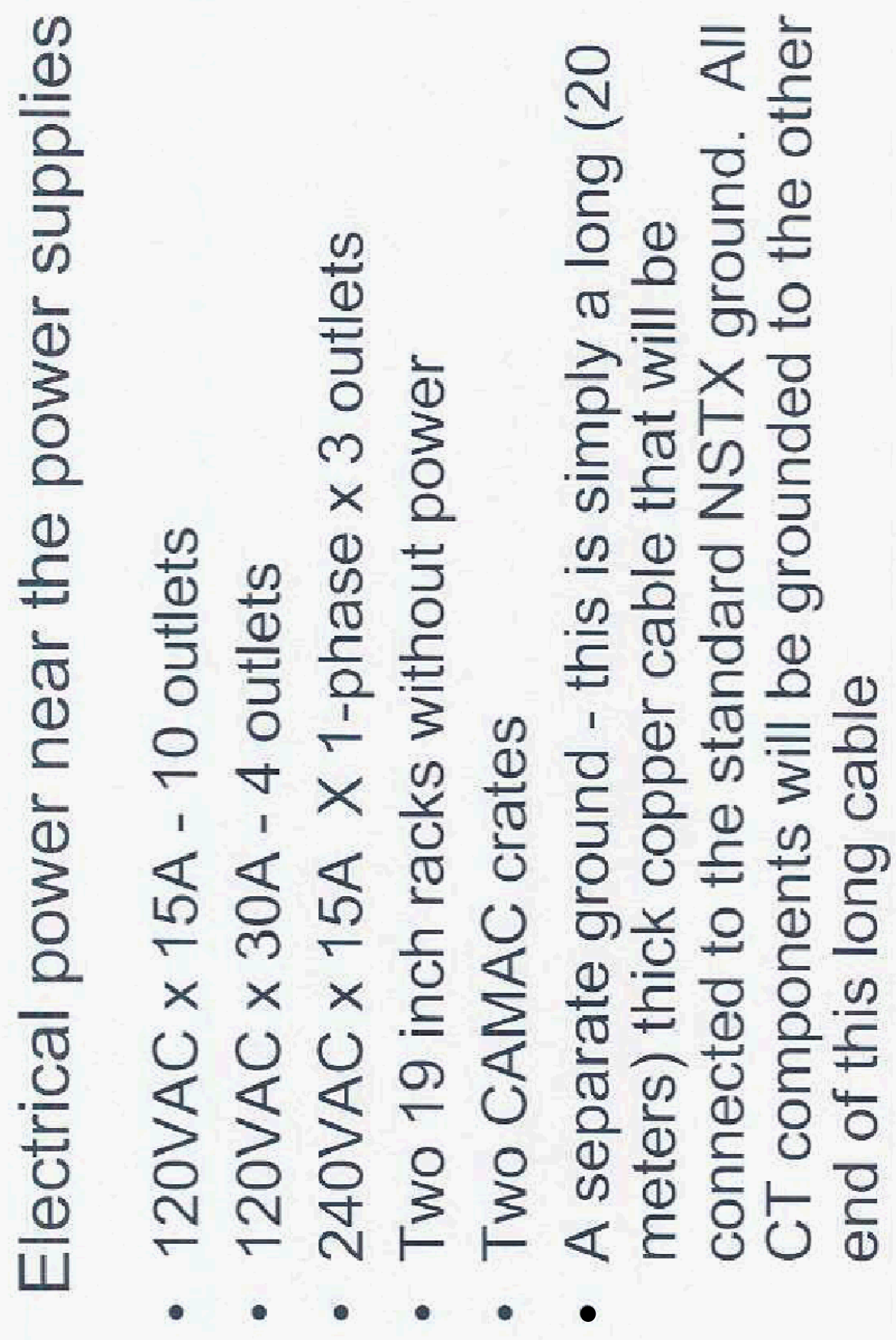



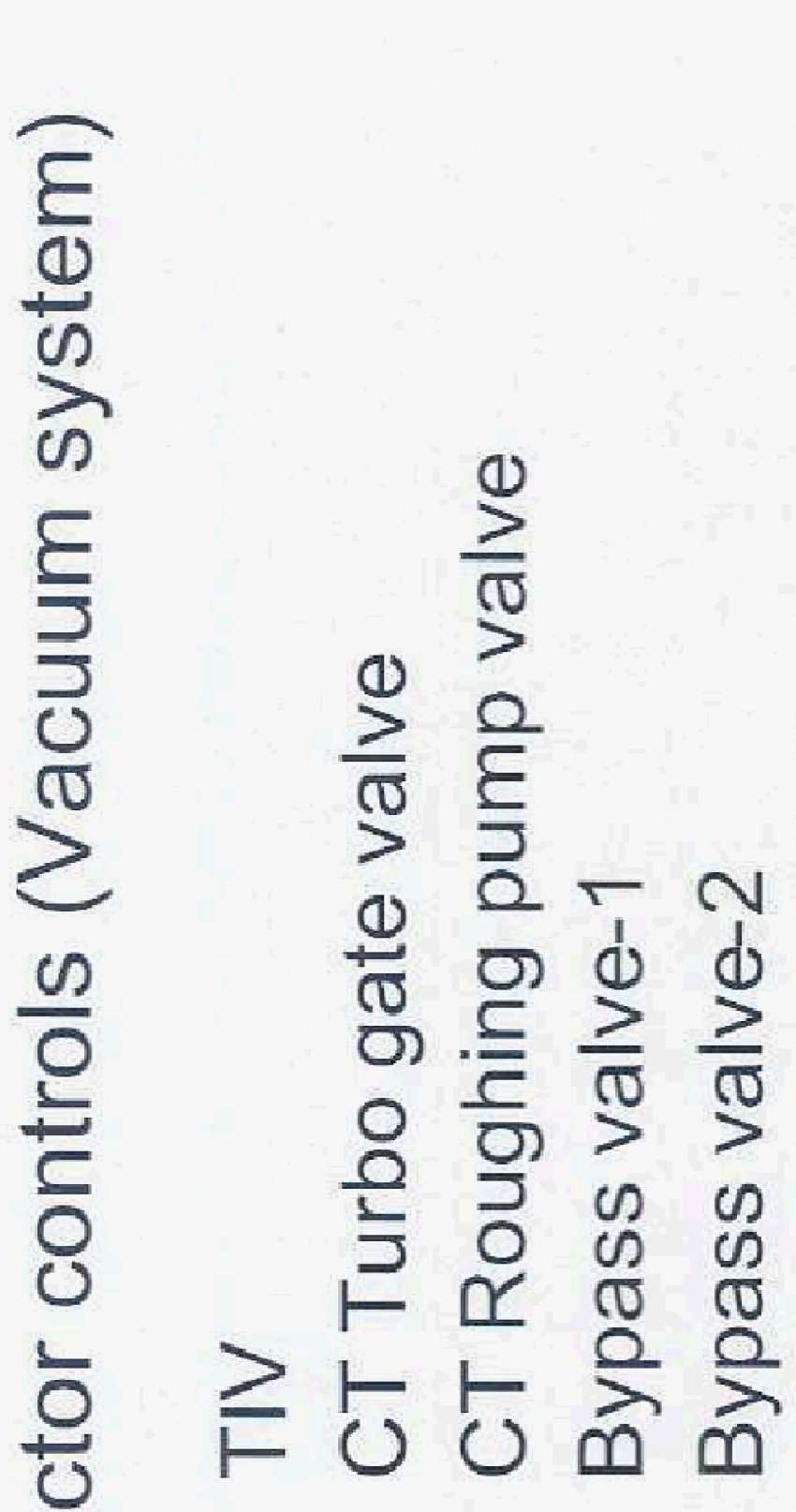

- I -
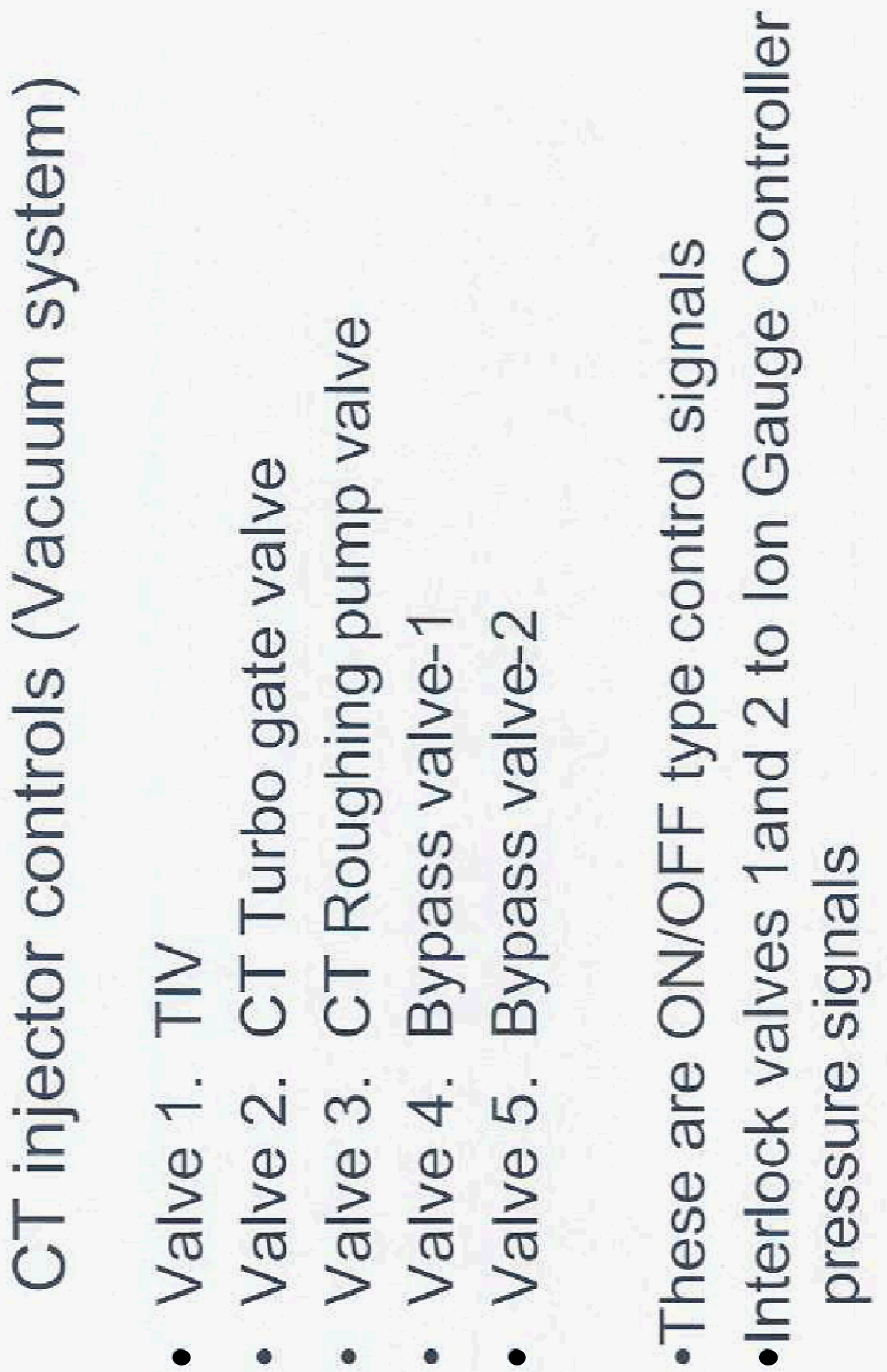


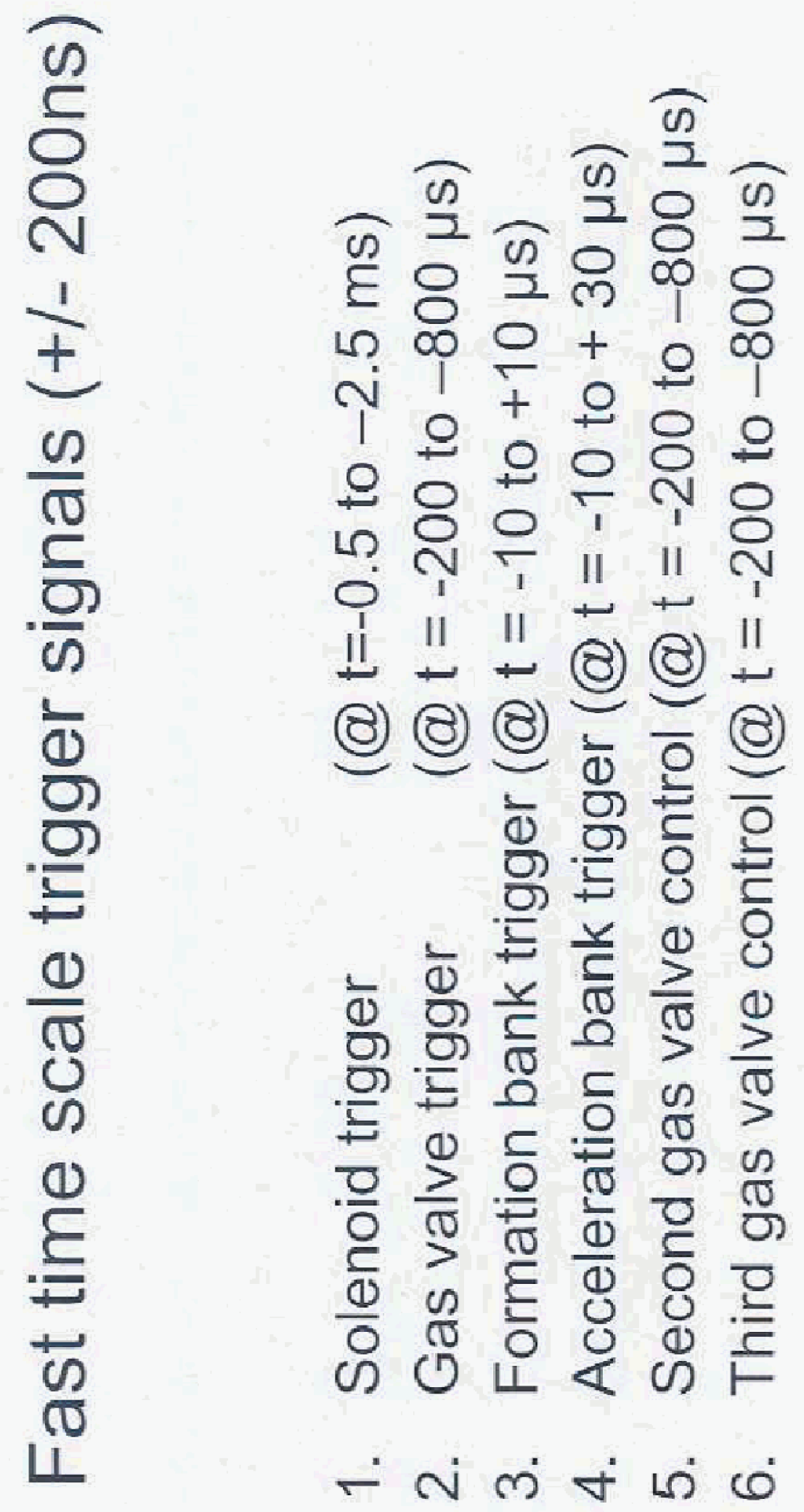



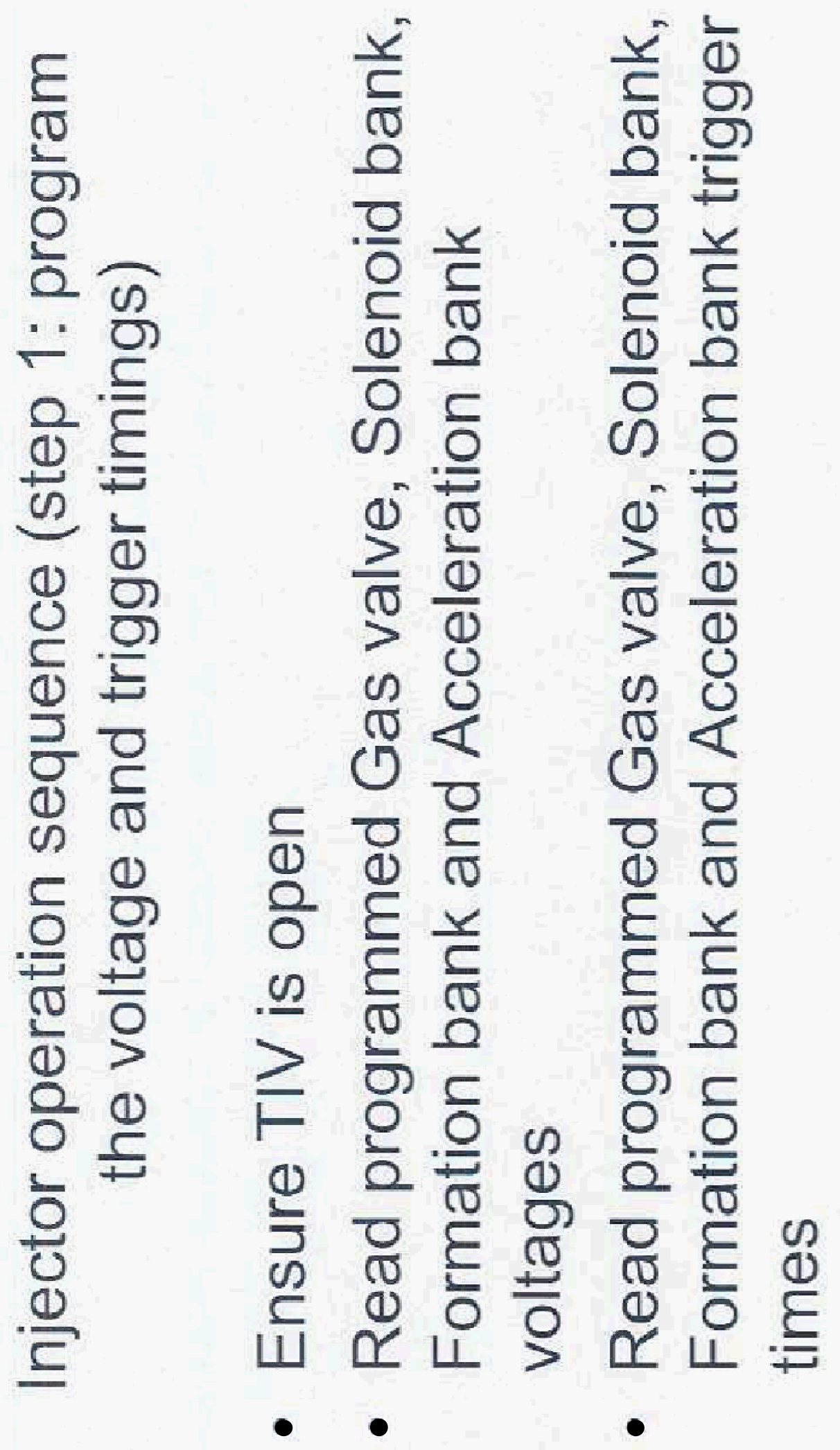


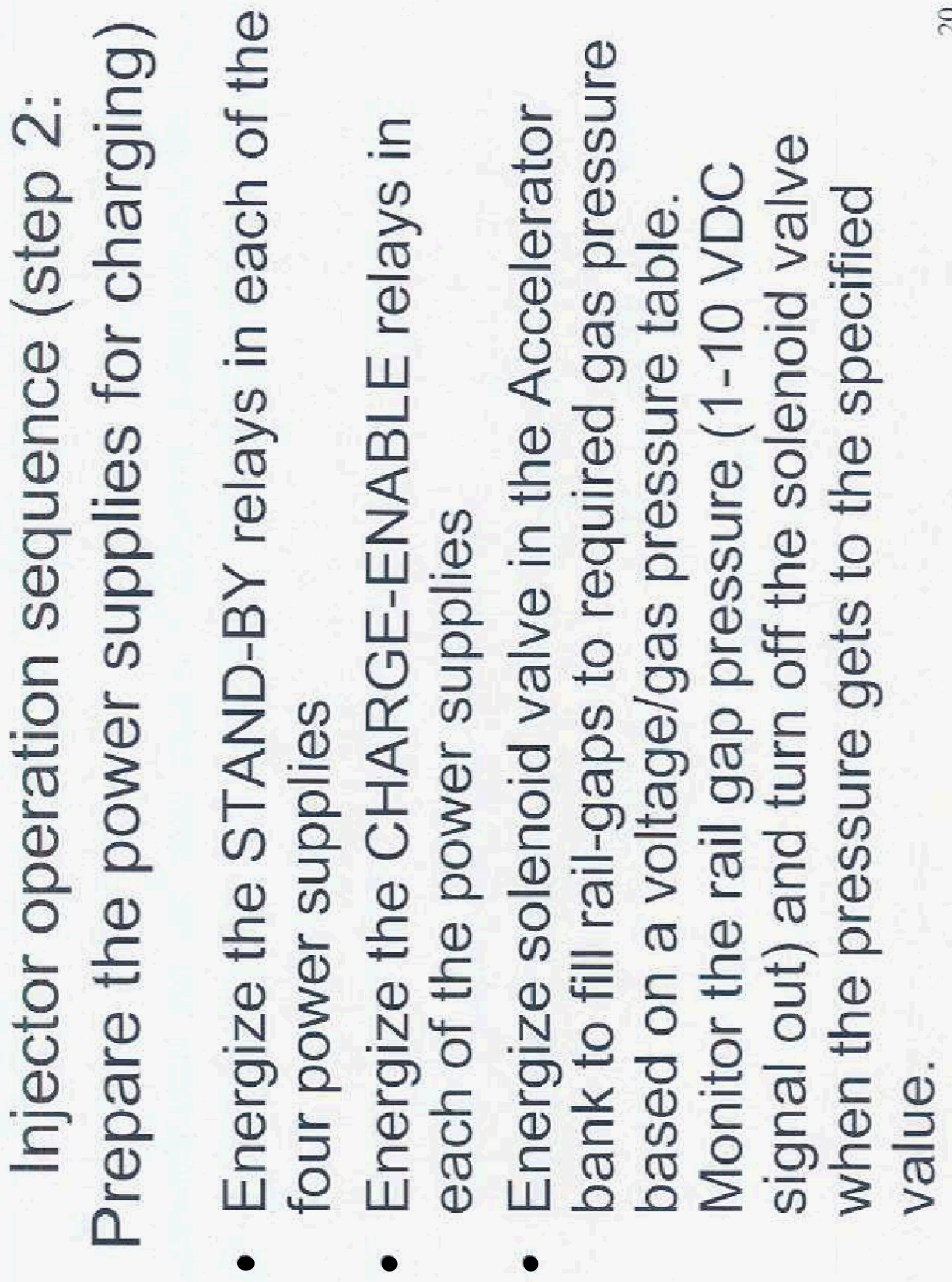




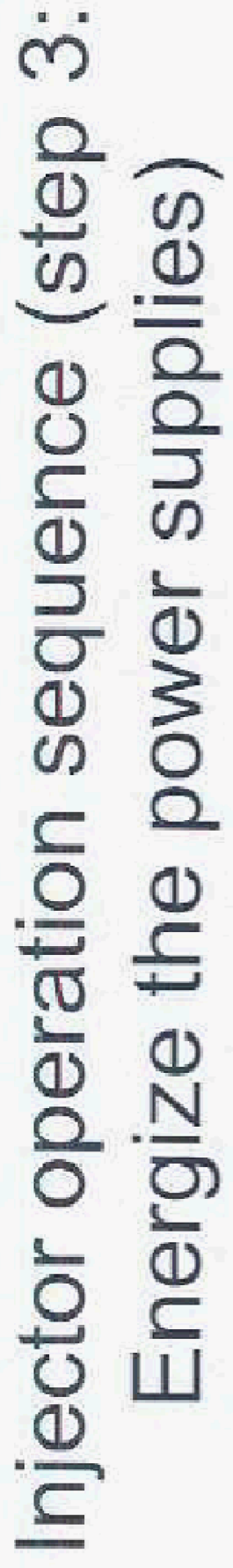

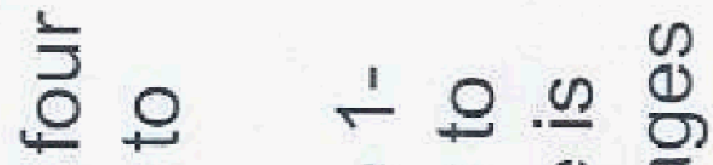

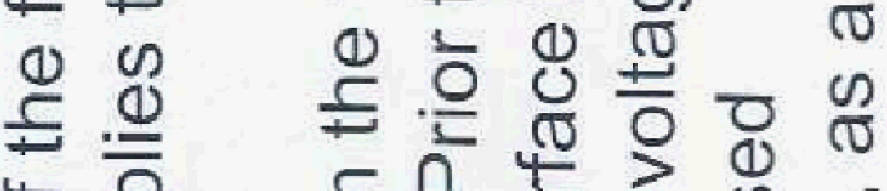

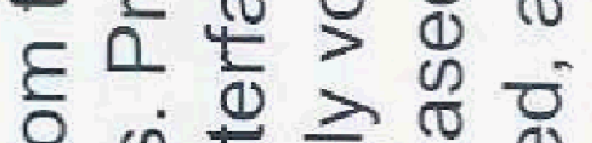

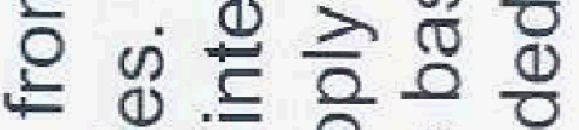

(1) $\frac{0}{0}, 0$ (1)

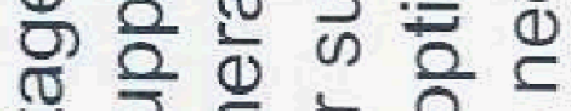

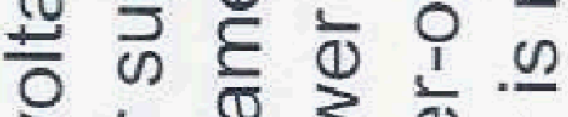

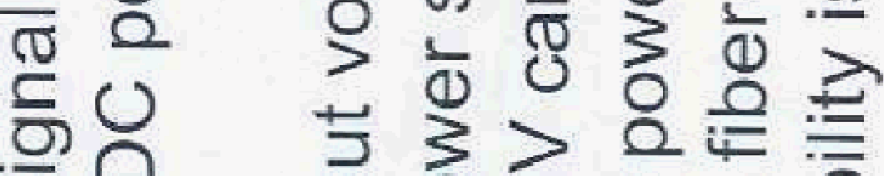

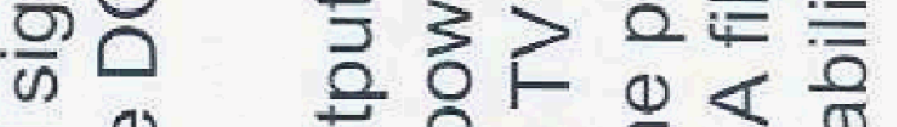

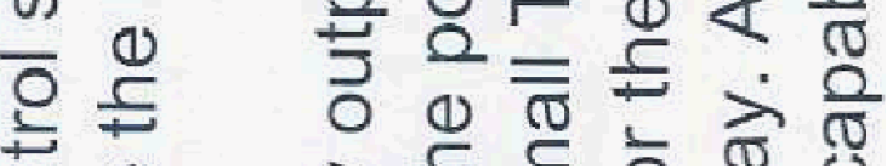

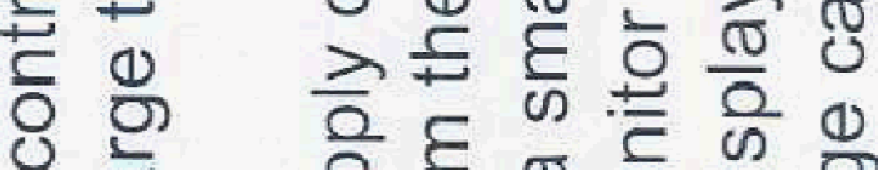

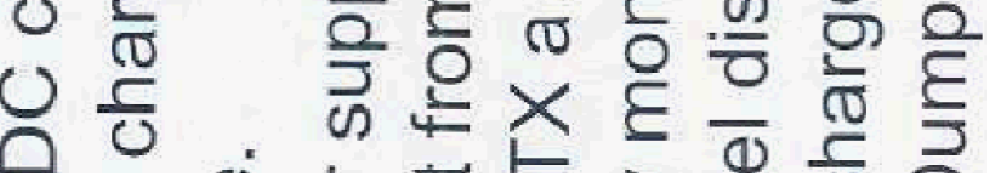

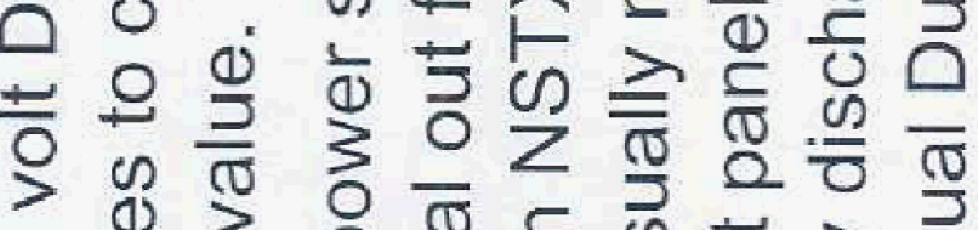

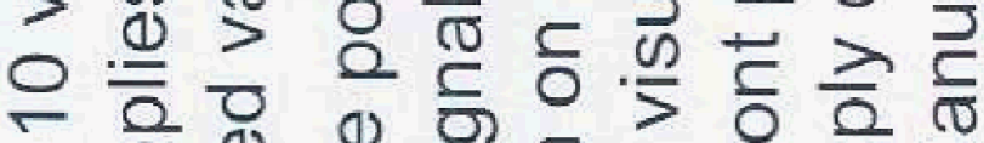

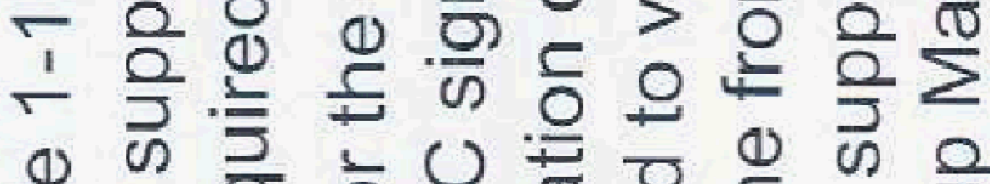

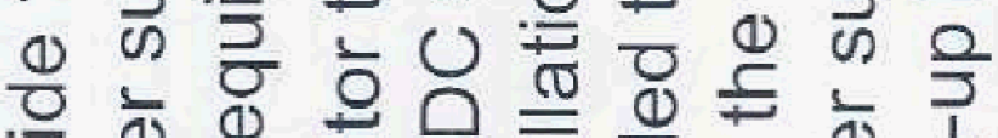

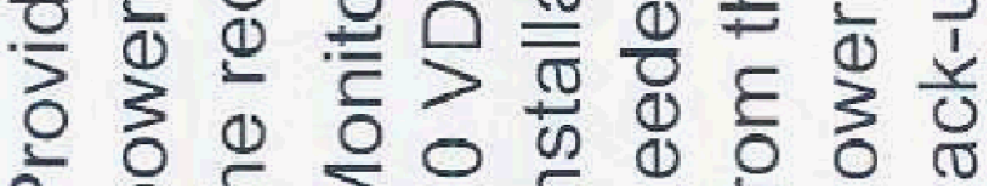

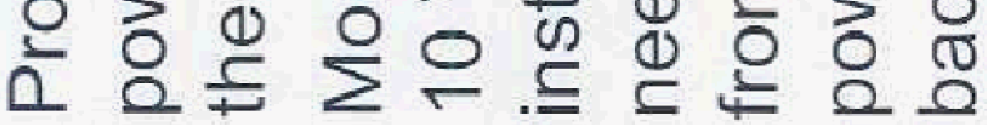




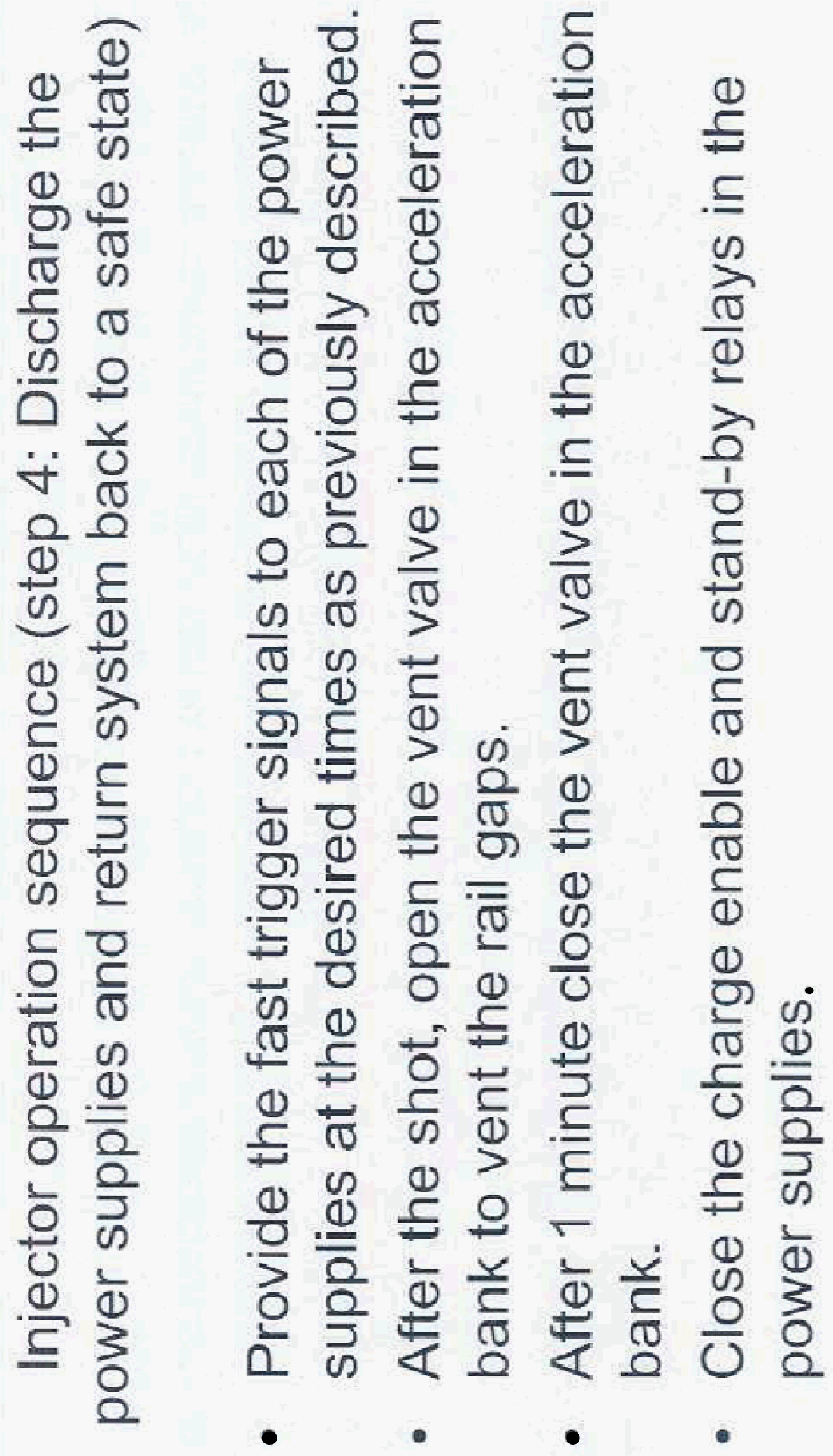




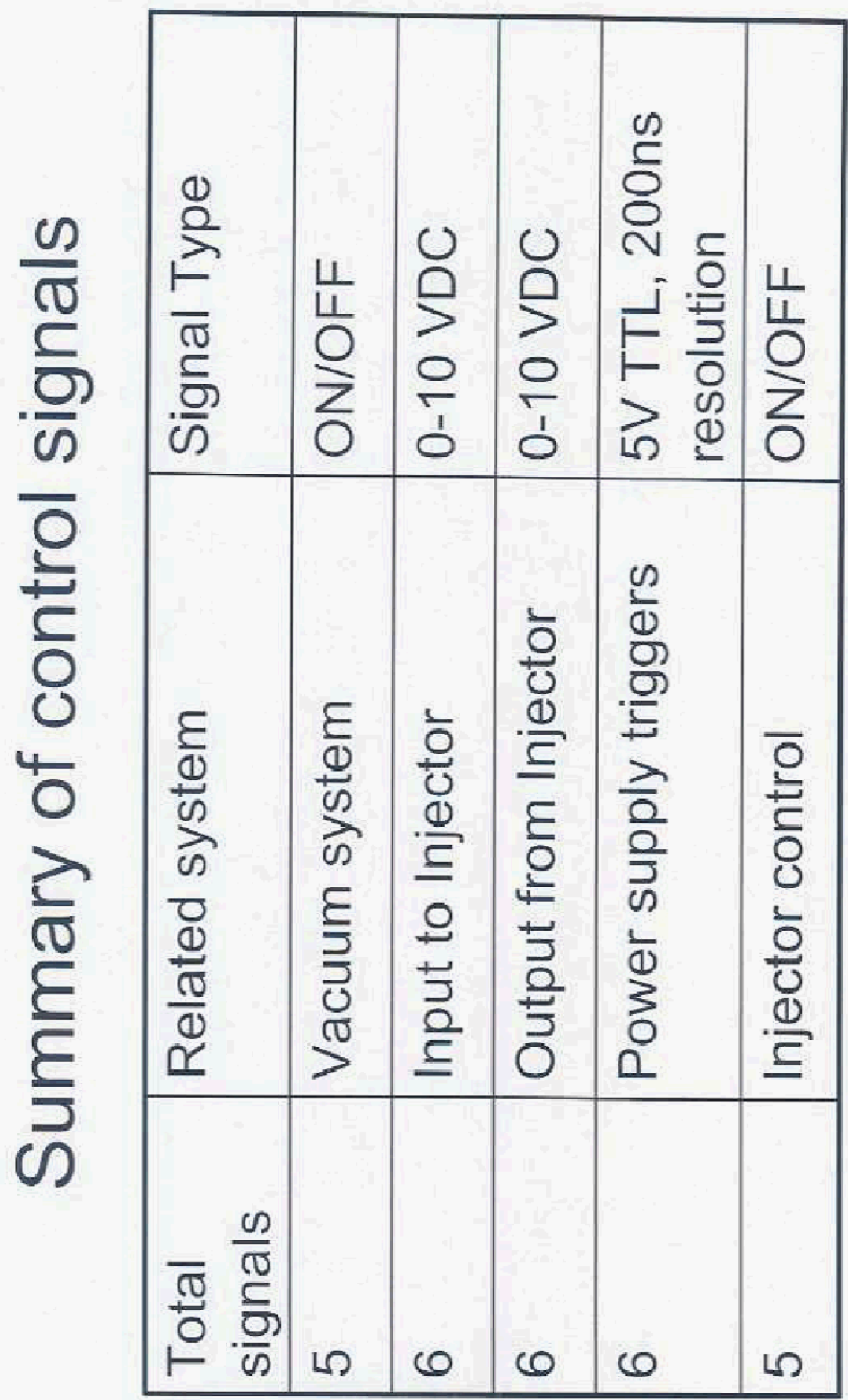


$\frac{4}{6}$

등

10

18

N

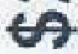

I

$\frac{1}{10} \times \frac{*}{6}$

$\underset{6}{x} \stackrel{*}{\frac{*}{6}}$

तु

든

क ष

แ $\leftrightarrow ~ N$

음

党

है

ㄴㄴ?

政

อ गु

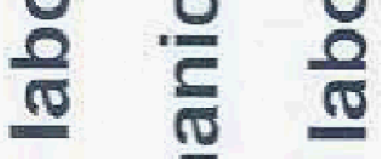

등 등

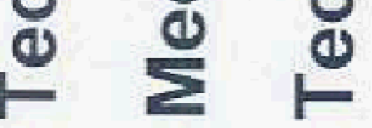

ㄴ

$\stackrel{1}{1}$

त

m

- $\infty$

$\widehat{\overline{\text { जิ }}}$

응

त)

\& $\overline{\mathrm{T}}$

즘

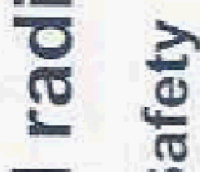

$\nabla$ क

등

兑

त

당

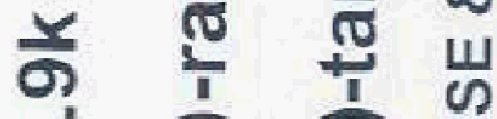

กิ่ $\frac{1}{4} \frac{1}{m}$

$\leftrightarrow$ ᄃ

เ่ 은 음

닫

तิ

ํำ

닿

웅 응 응

둥

$\pi$

ت্

ก

\&

$\varangle m$

๔

응

은

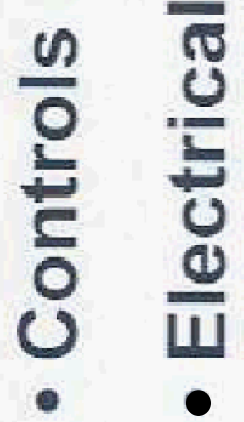

о

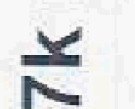

$\stackrel{x}{N}$

$\Phi$

量

들

F

$\dot{i}$ is

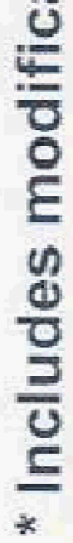



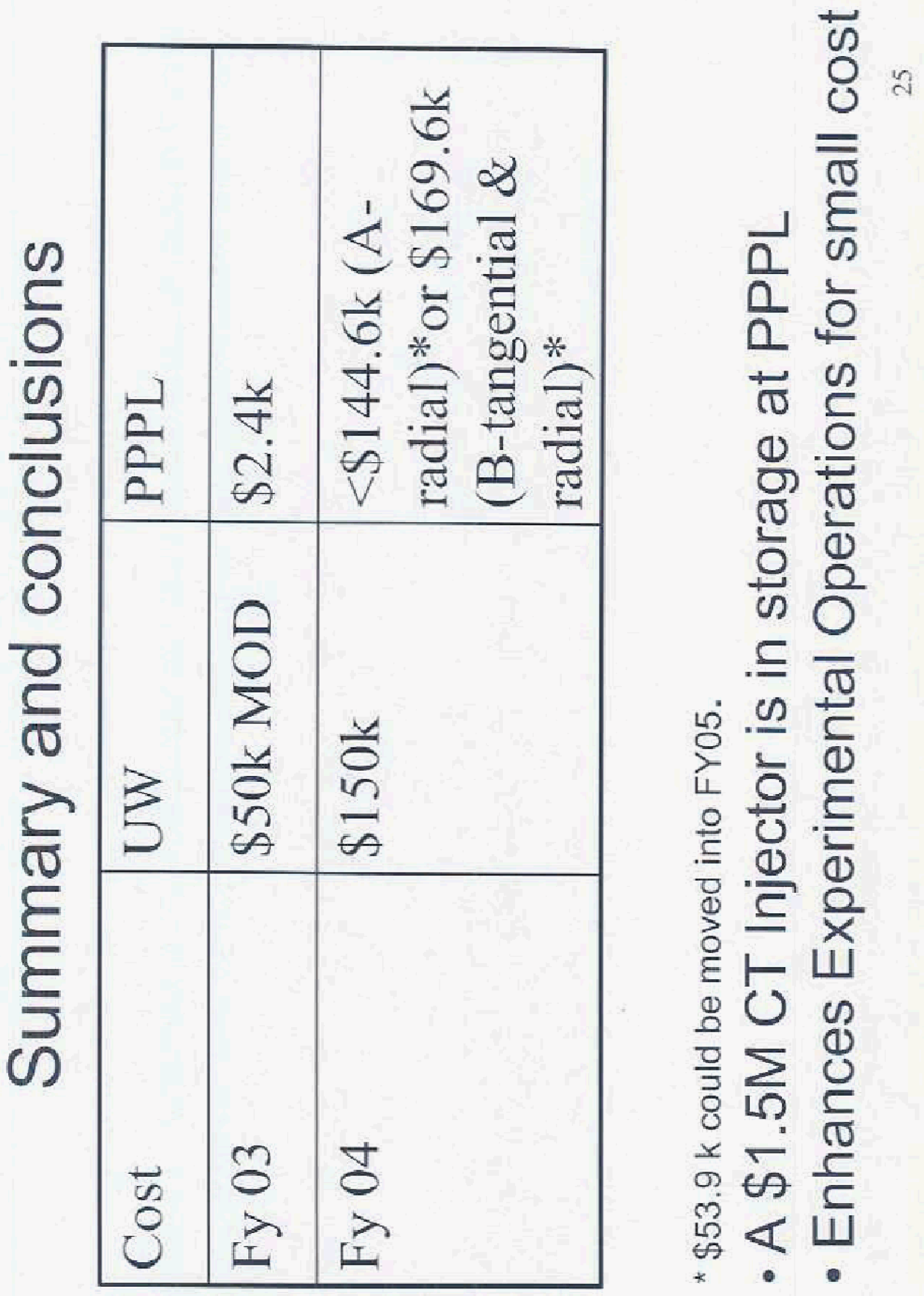


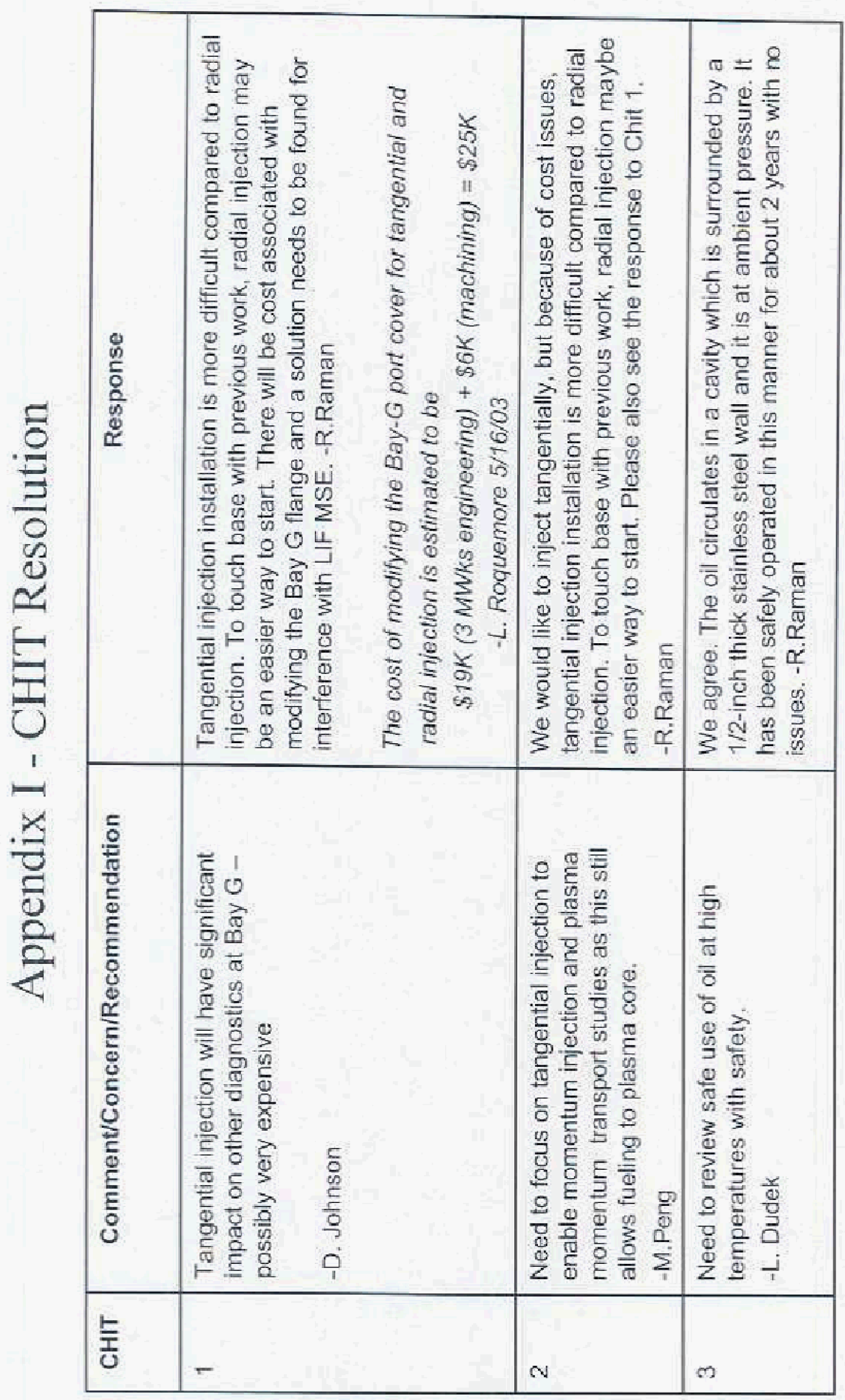




\begin{tabular}{|c|c|c|c|}
\hline 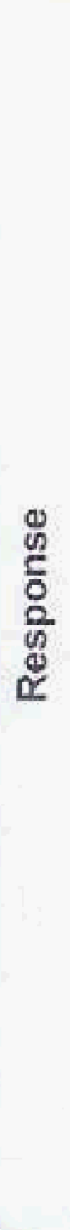 & 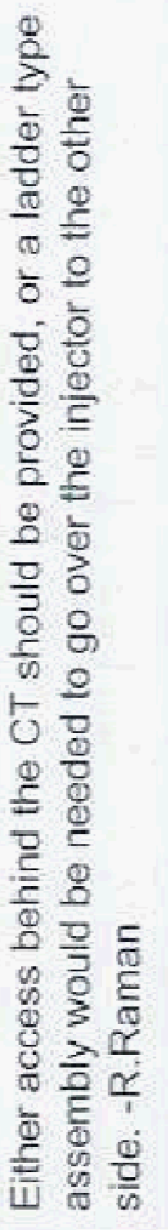 & 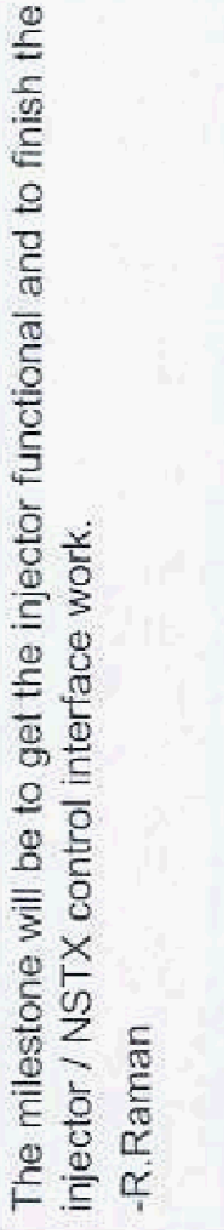 & 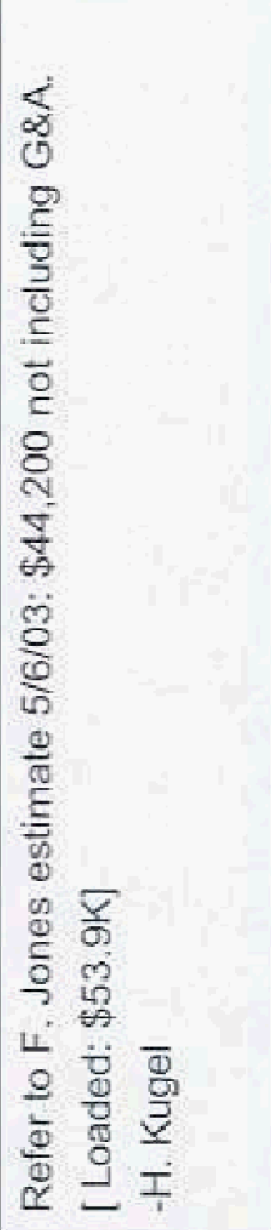 \\
\hline 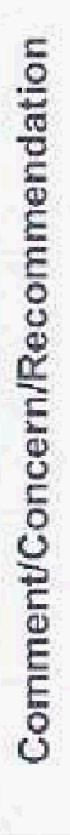 & 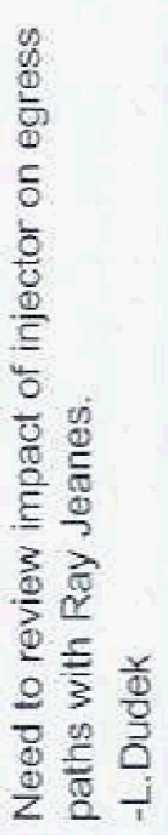 & 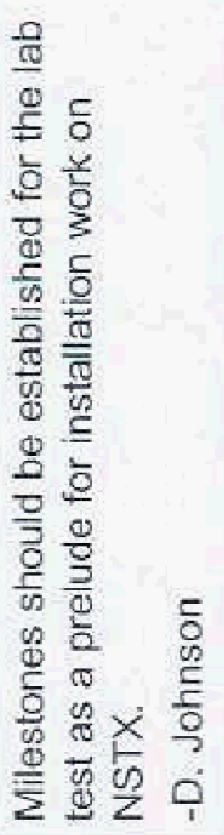 & 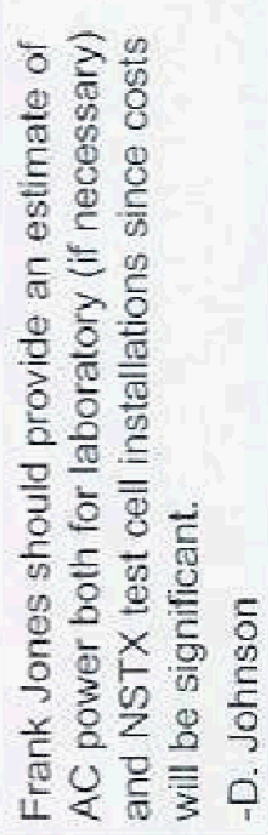 \\
\hline$\frac{\text { 嵉 }}{\frac{T}{0}}$ & ष & 10 & 6 \\
\hline
\end{tabular}




\begin{tabular}{|c|c|c|}
\hline$\frac{0}{0}$ & 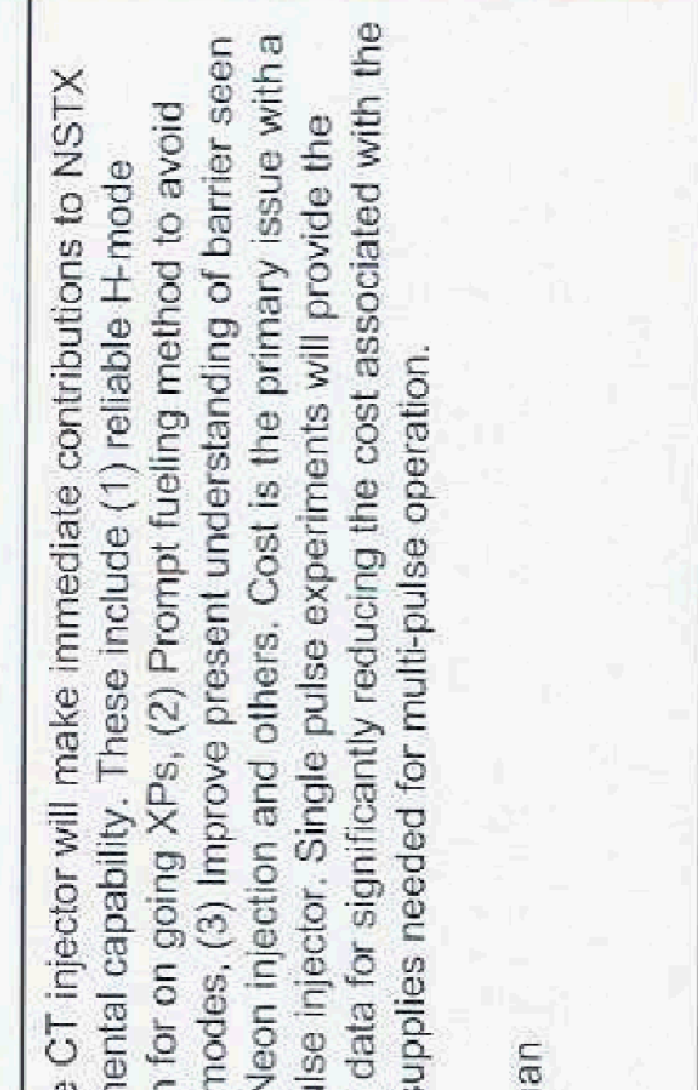 & 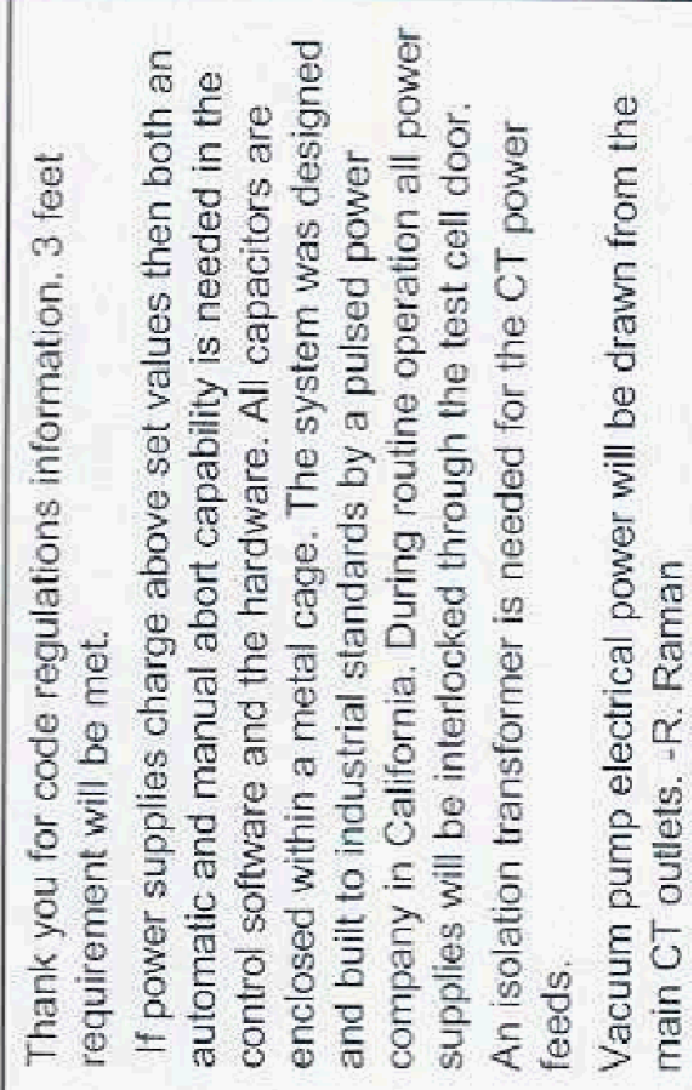 \\
\hline & 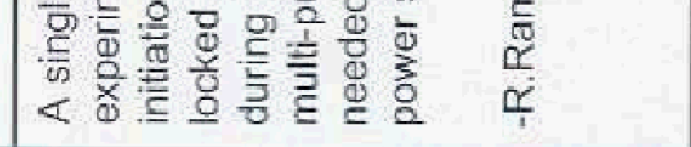 & बi \\
\hline & 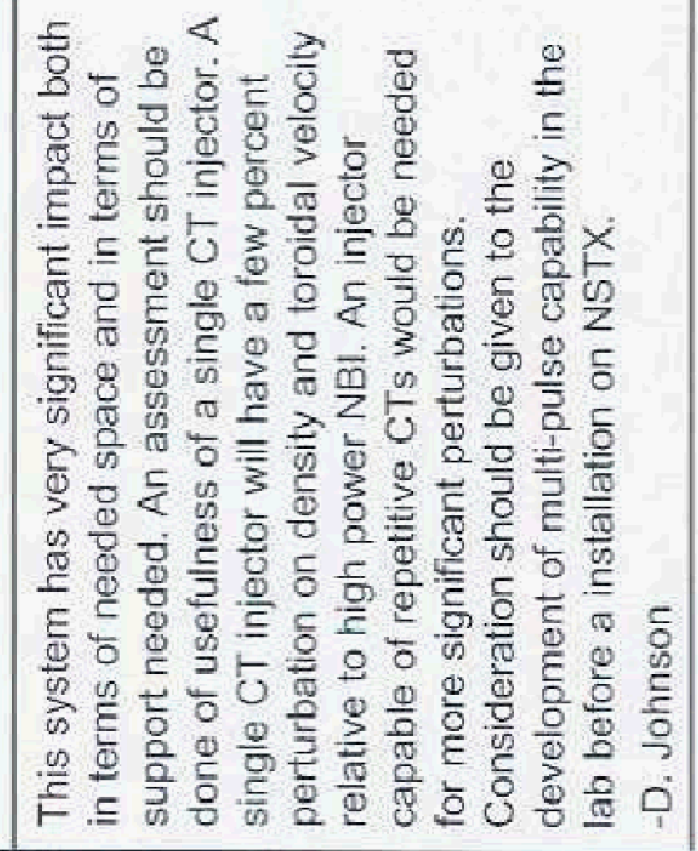 & 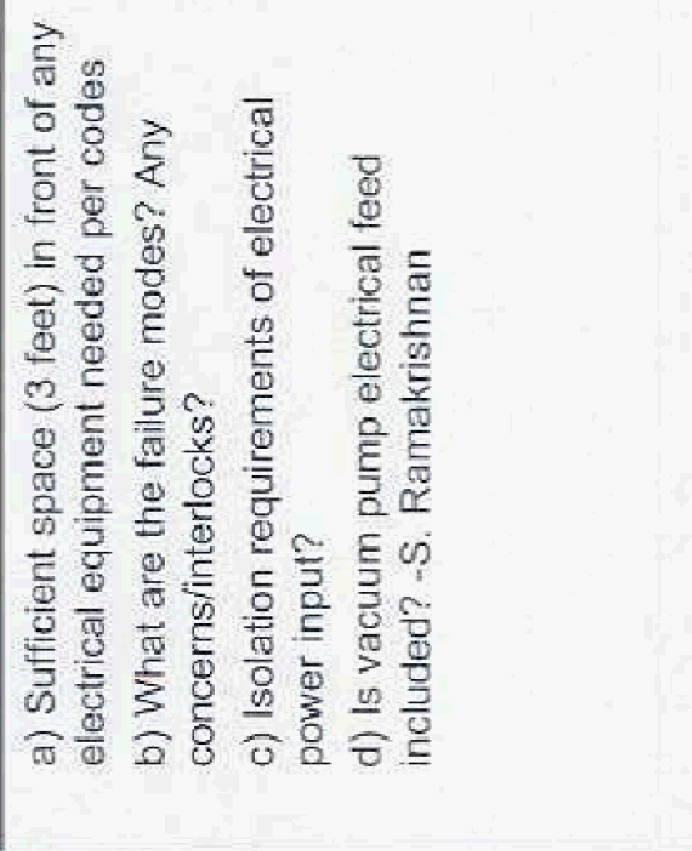 \\
\hline & $r$ & $\infty$ \\
\hline
\end{tabular}




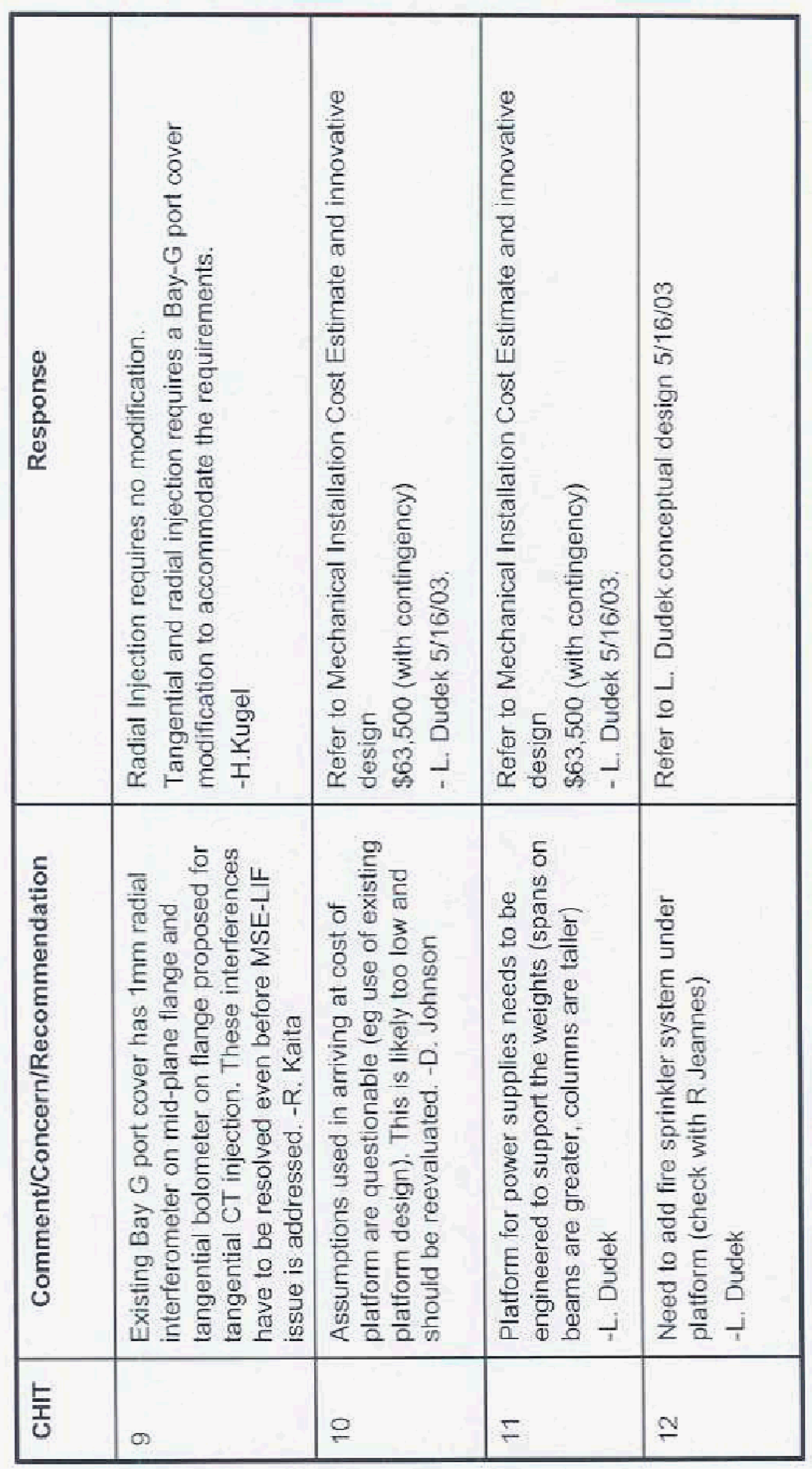




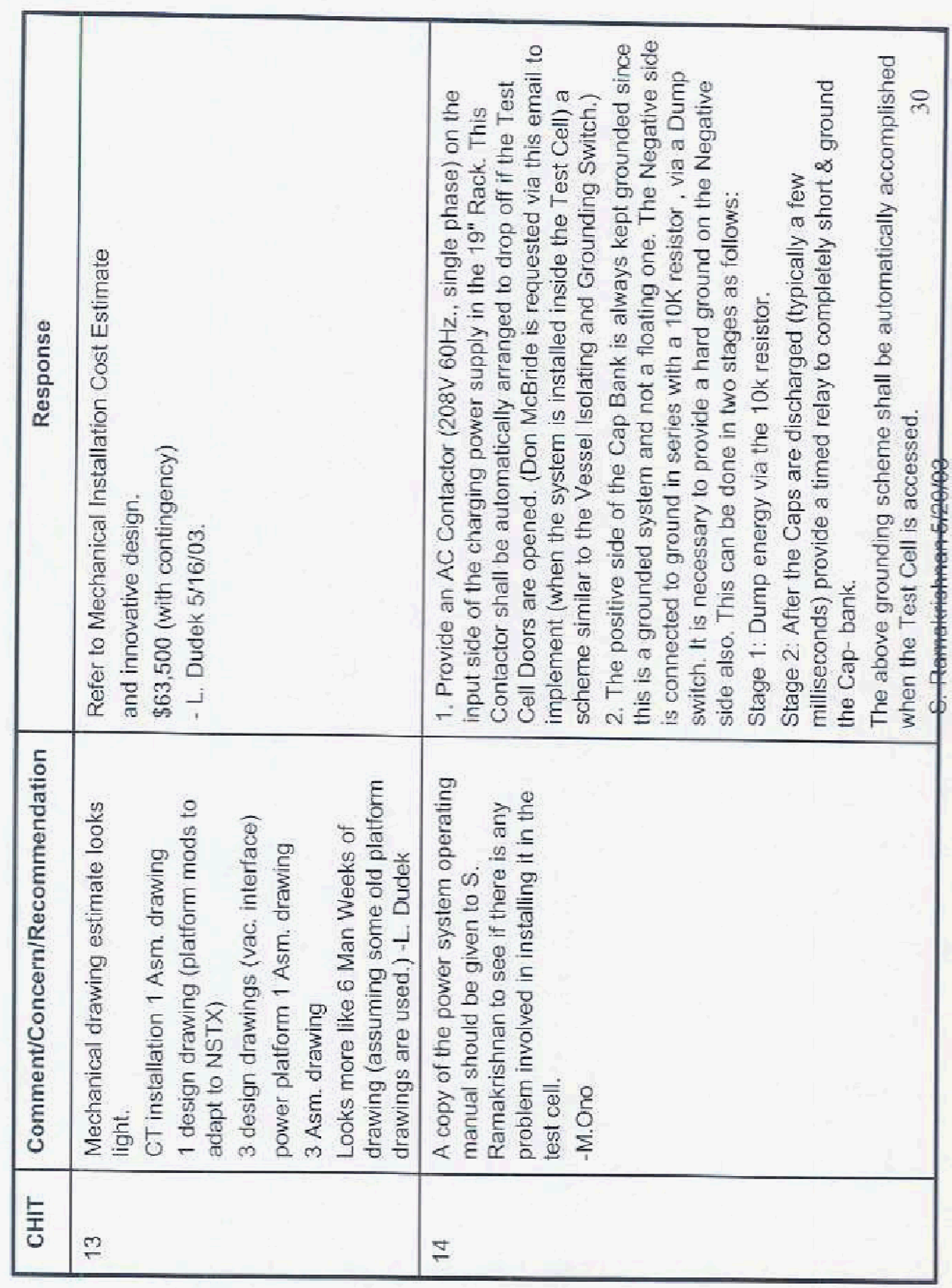




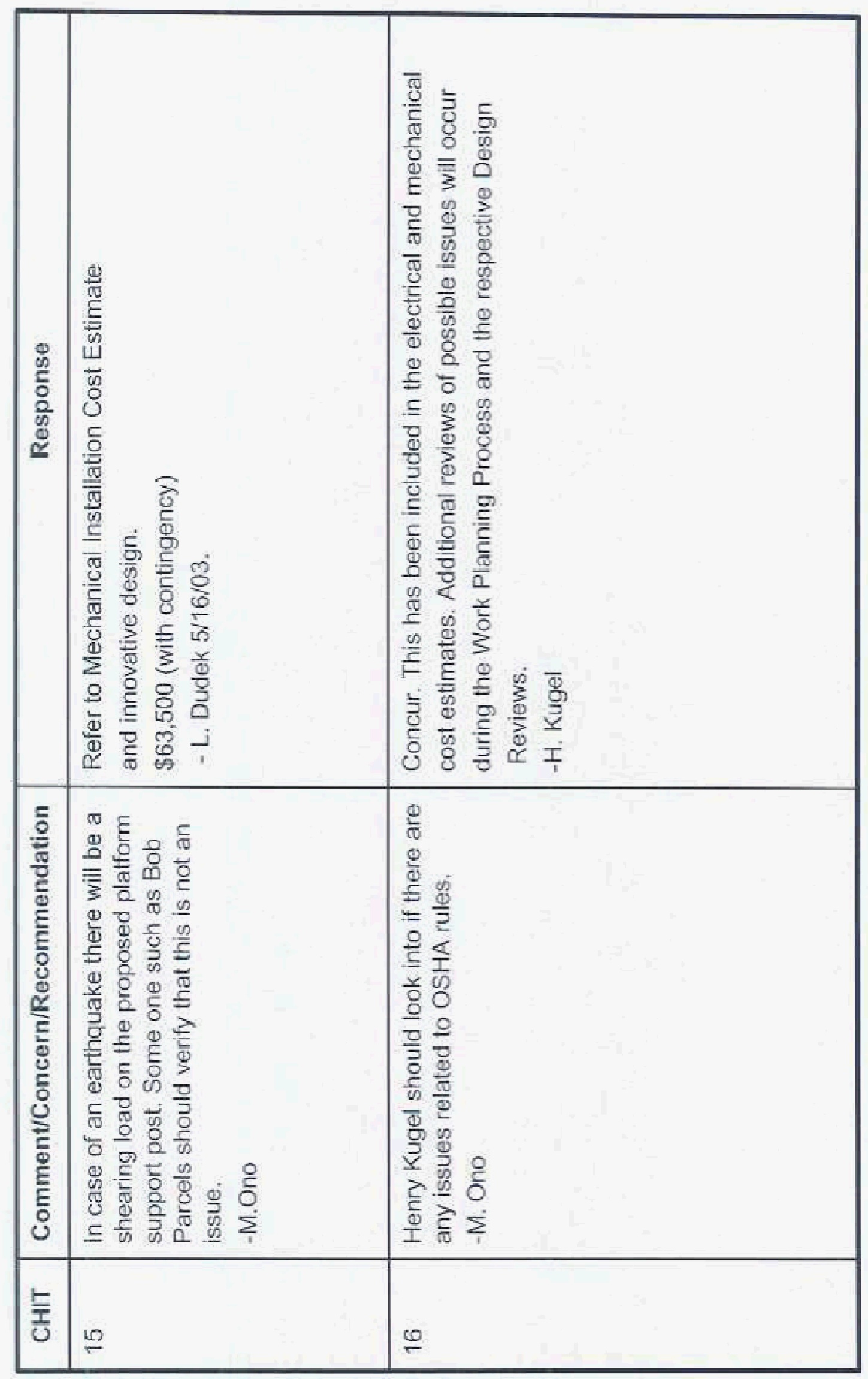




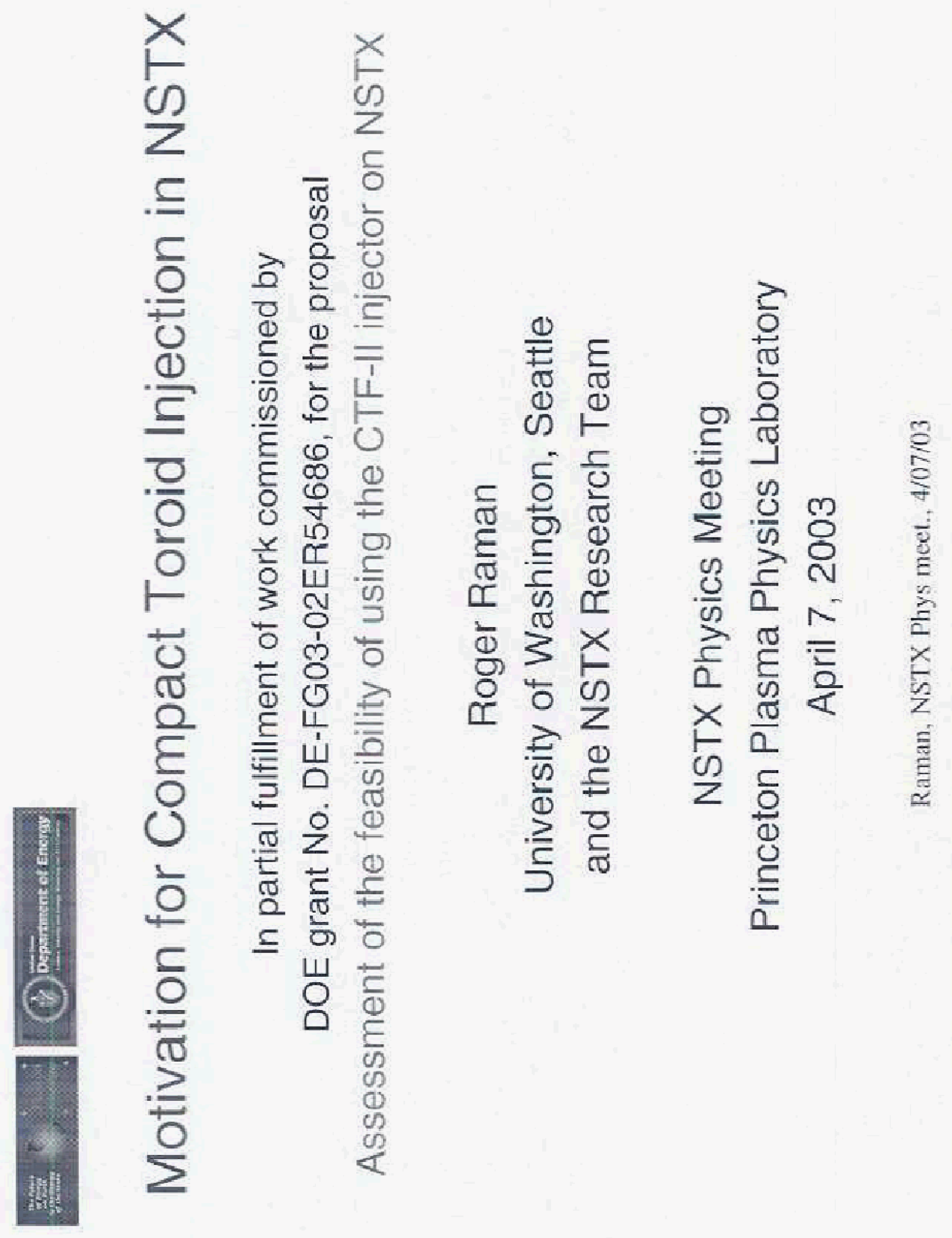




\section{Chronology of collaborator Compact Toroid Fueling presentations at NSTX Research Forums}

\begin{tabular}{|c|c|c|}
\hline & $U$ - Washington & UC-Davis \\
\hline Dec, 1997 & $\begin{array}{l}\text { R.Raman-1st pres. } \\
\text { Action: submitted } \\
\text { proposal to DOE }\end{array}$ & $\begin{array}{l}\text { D.Hwang-1st pres. } \\
\text { Action: submitted } \\
\text { proposal to DOE }\end{array}$ \\
\hline Jan. 1999 & R.Raman -2nd pres. & D.Hwang-2nd pres. \\
\hline Jan. 2000 & $\begin{array}{l}\text { R.Raman - 3rd pres. (in } \\
\text { Advanced Concepts) }\end{array}$ & \\
\hline Jan. 2001 & $\begin{array}{l}\text { R.Raman - 4th pres. (in } \\
\text { Heat., CD \& Fueling) \& } \\
5 \text { th pres. (in Transport \& } \\
\text { Turbulence) } \\
\text { Action: submitted 2nd } \\
\text { proposal to DOE }\end{array}$ & \\
\hline Nov. 2001 & $\begin{array}{l}\text { R.Raman - 6th pres. (in } \\
\text { Boundary Physics) }\end{array}$ & \\
\hline $\begin{array}{l}\text { June. } 2002 \\
\text { 5yr Res. } \\
\text { Plan. Meet. }\end{array}$ & $\begin{array}{l}\text { R.Raman - } 7 \text { th pres. (in } \\
\text { Boundary Physics) } \\
\text { R.Raman - 8th pres. (in } \\
\text { Integrated Senario Dev.) }\end{array}$ & \\
\hline July. 2002 & $\begin{array}{l}\text { Action: submitted 3rd } \\
\text { proposal to DOE. } \\
\text { Result: Approved by DOE } \\
\text { for CT injector Relocation } \\
\text { \& Evaluation }\end{array}$ & \\
\hline
\end{tabular}




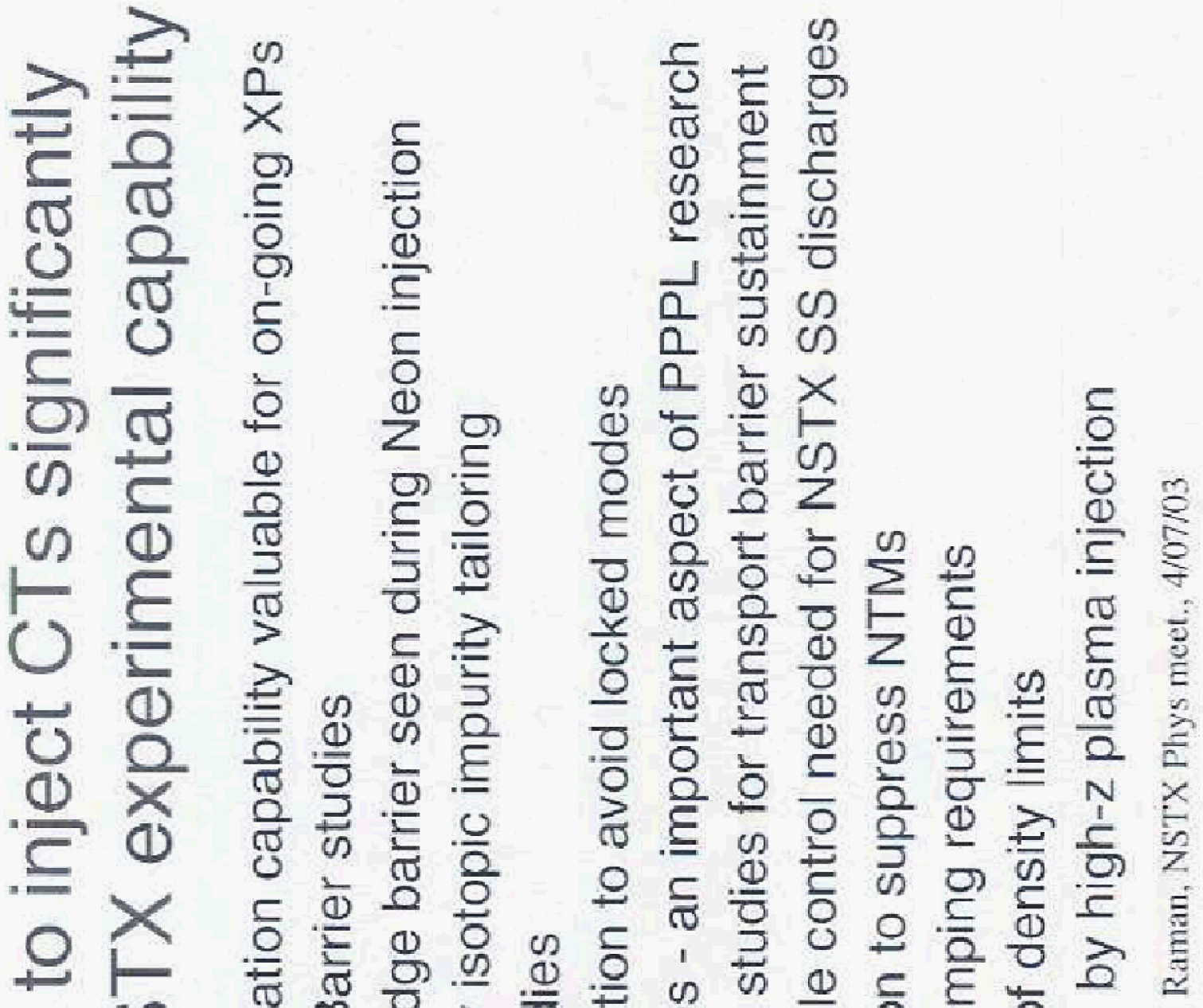

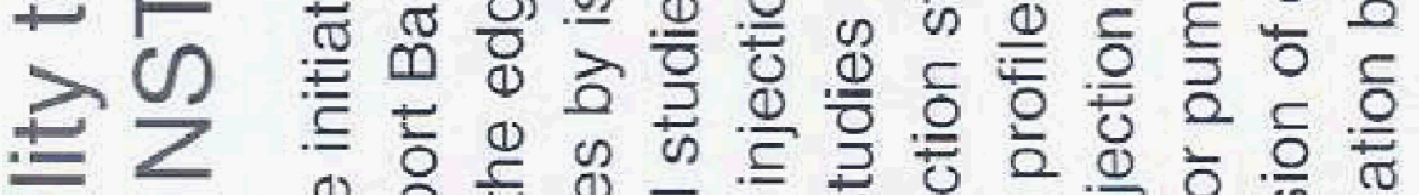

年

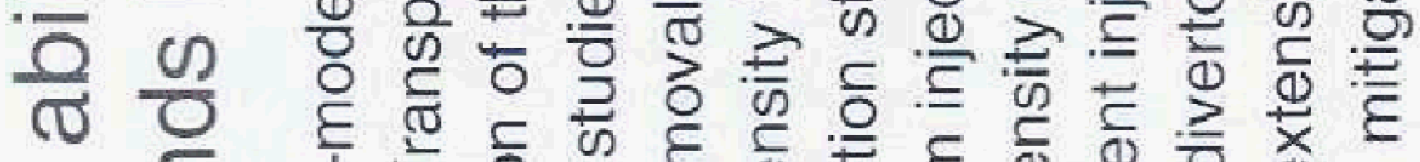

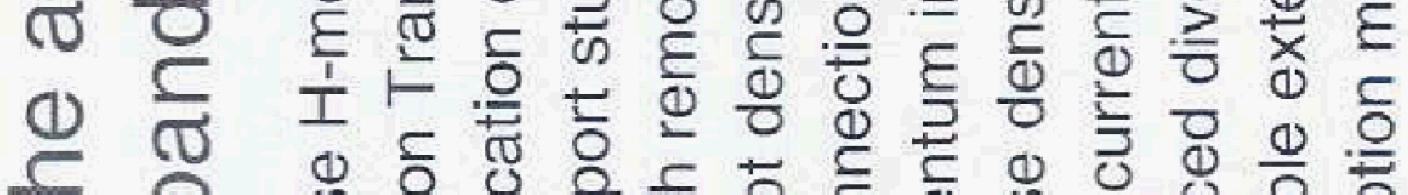

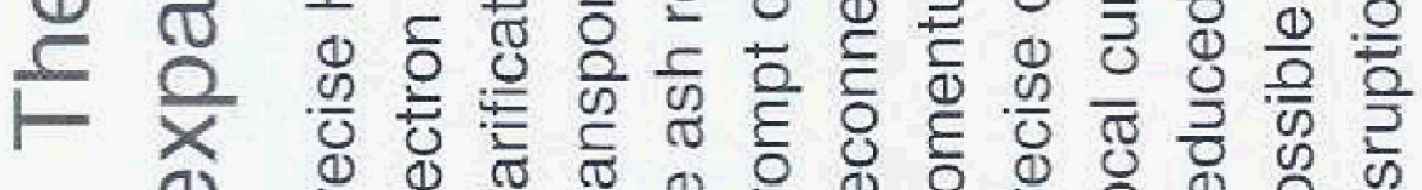

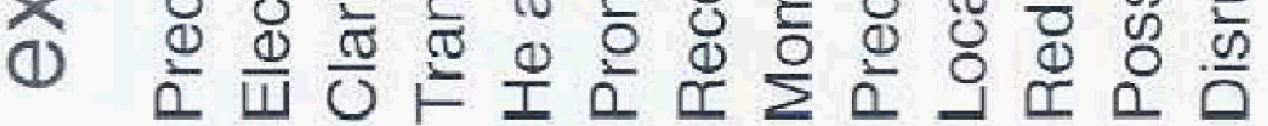




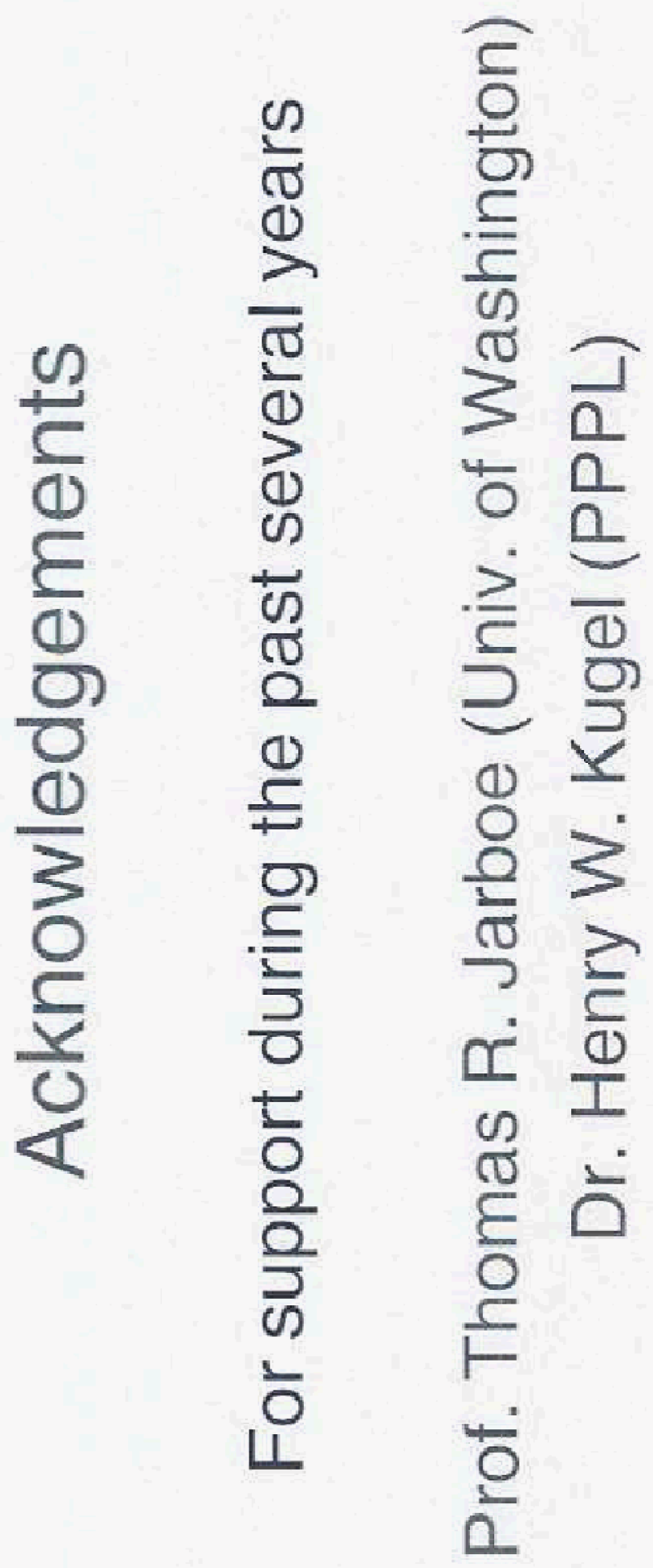




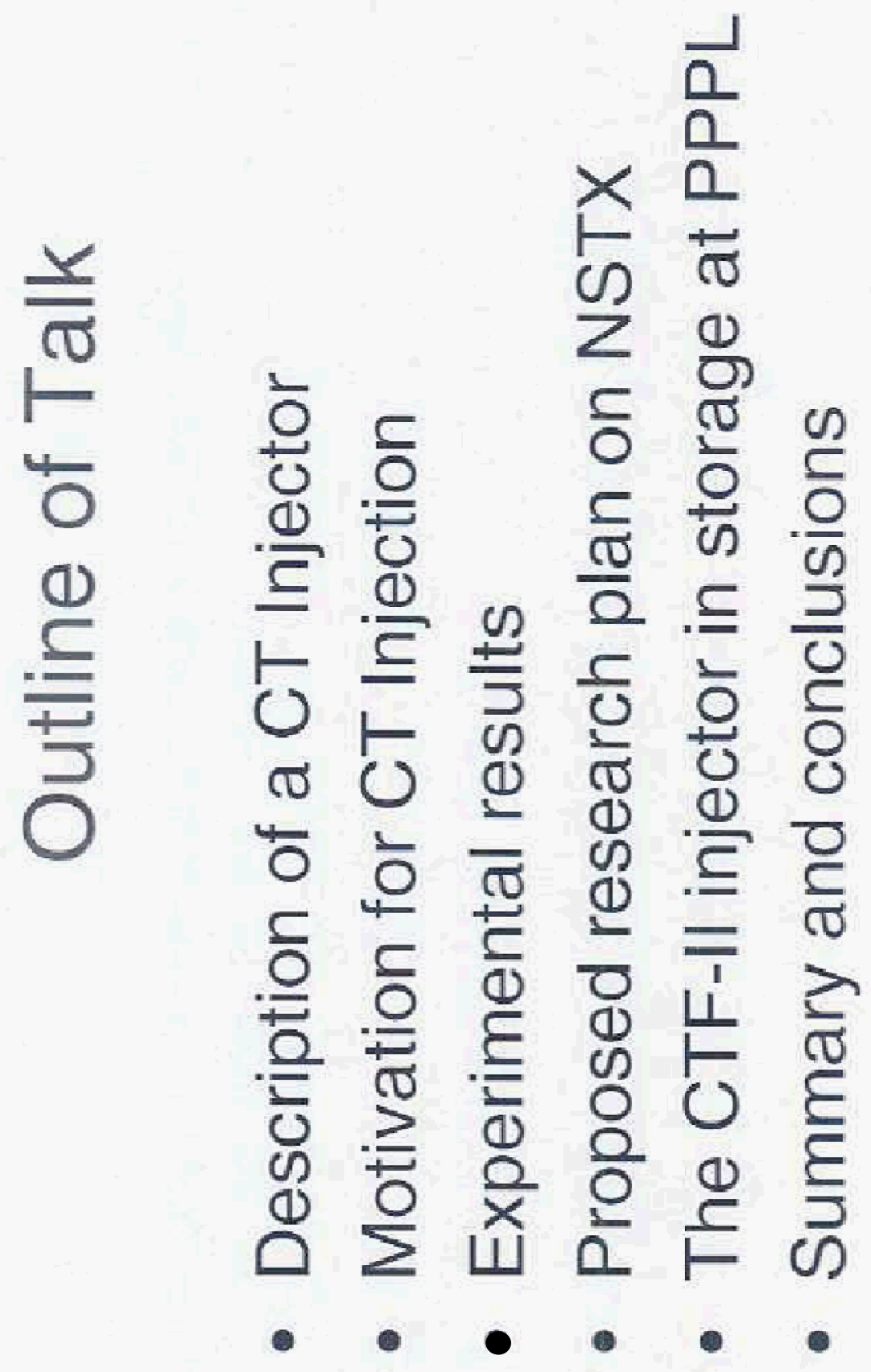



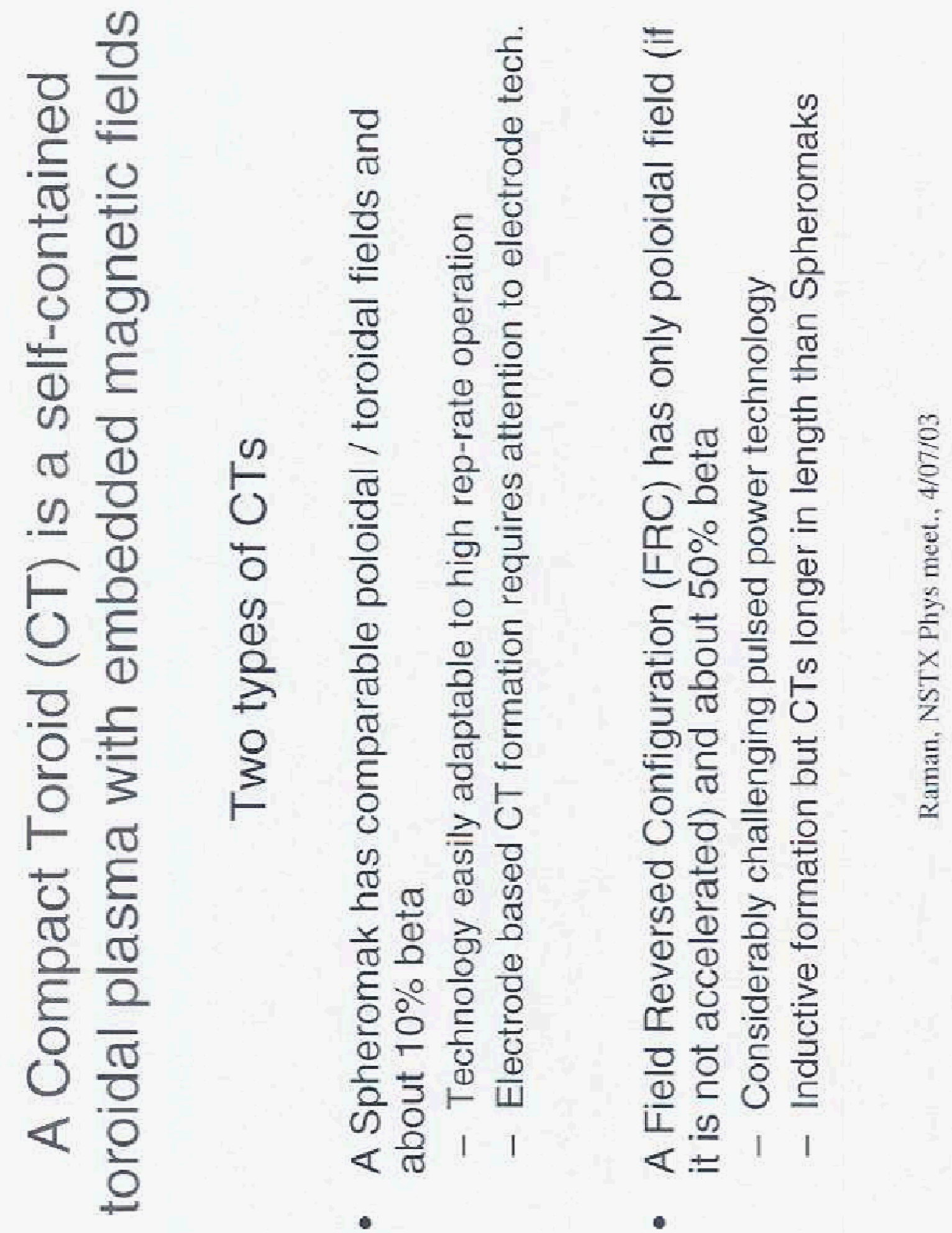

Oᄋ $\overline{\bar{\sigma}}$

웡 $\frac{5}{0}$

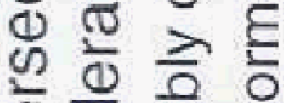

힝 뜽

む) 웜

흐흥ㄷㅇ 궁

등

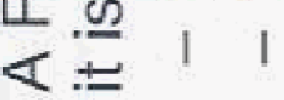




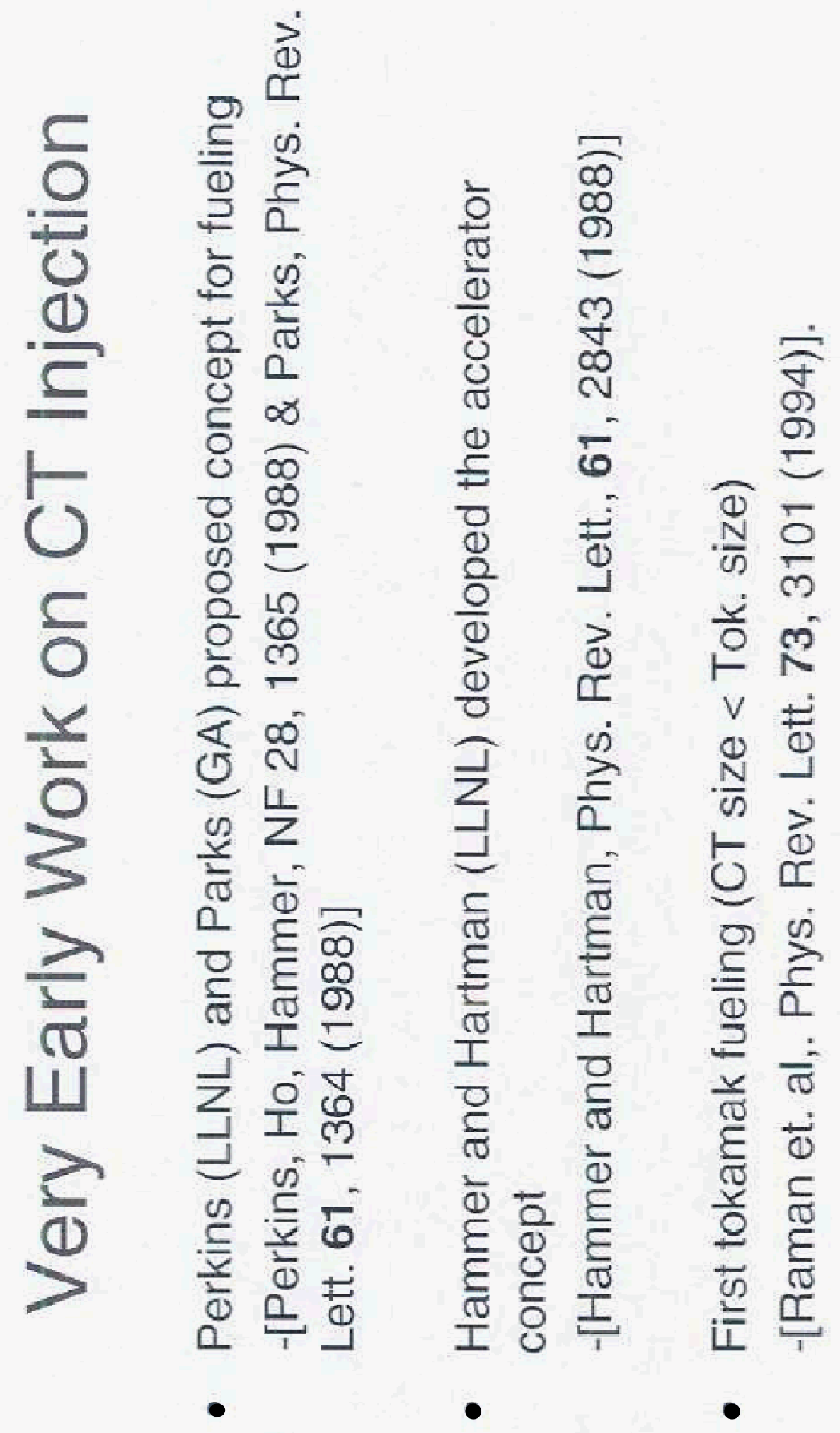



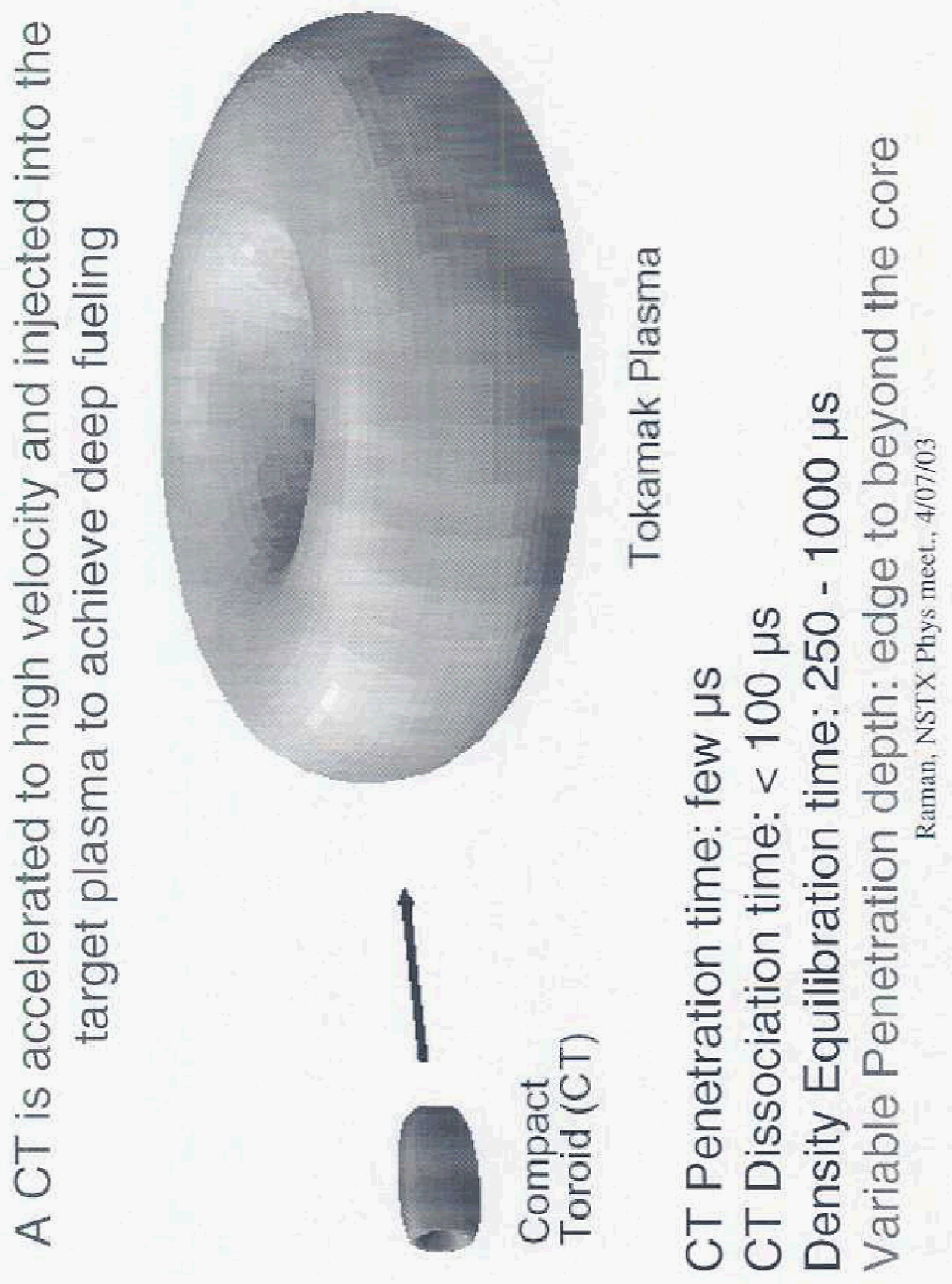


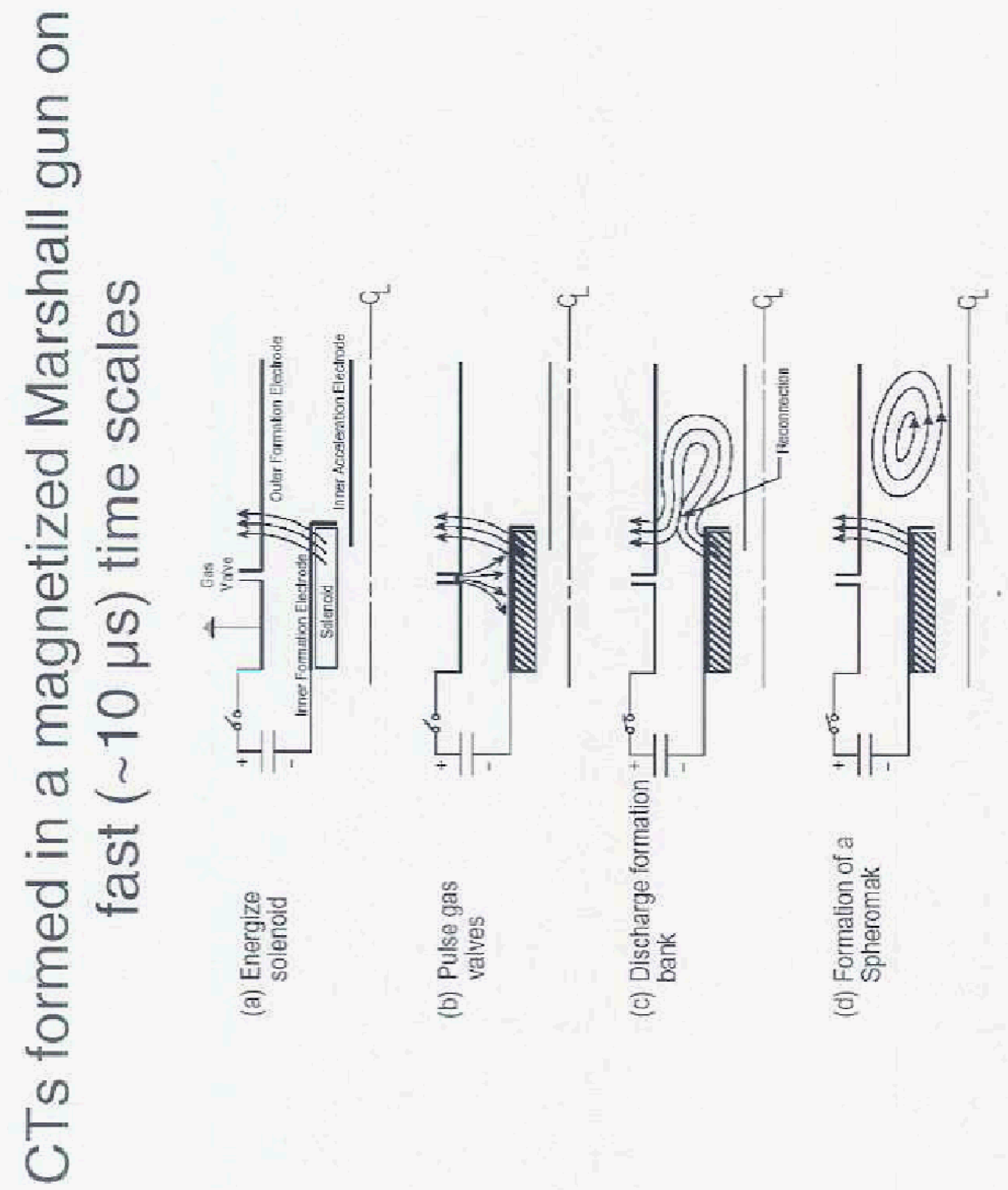



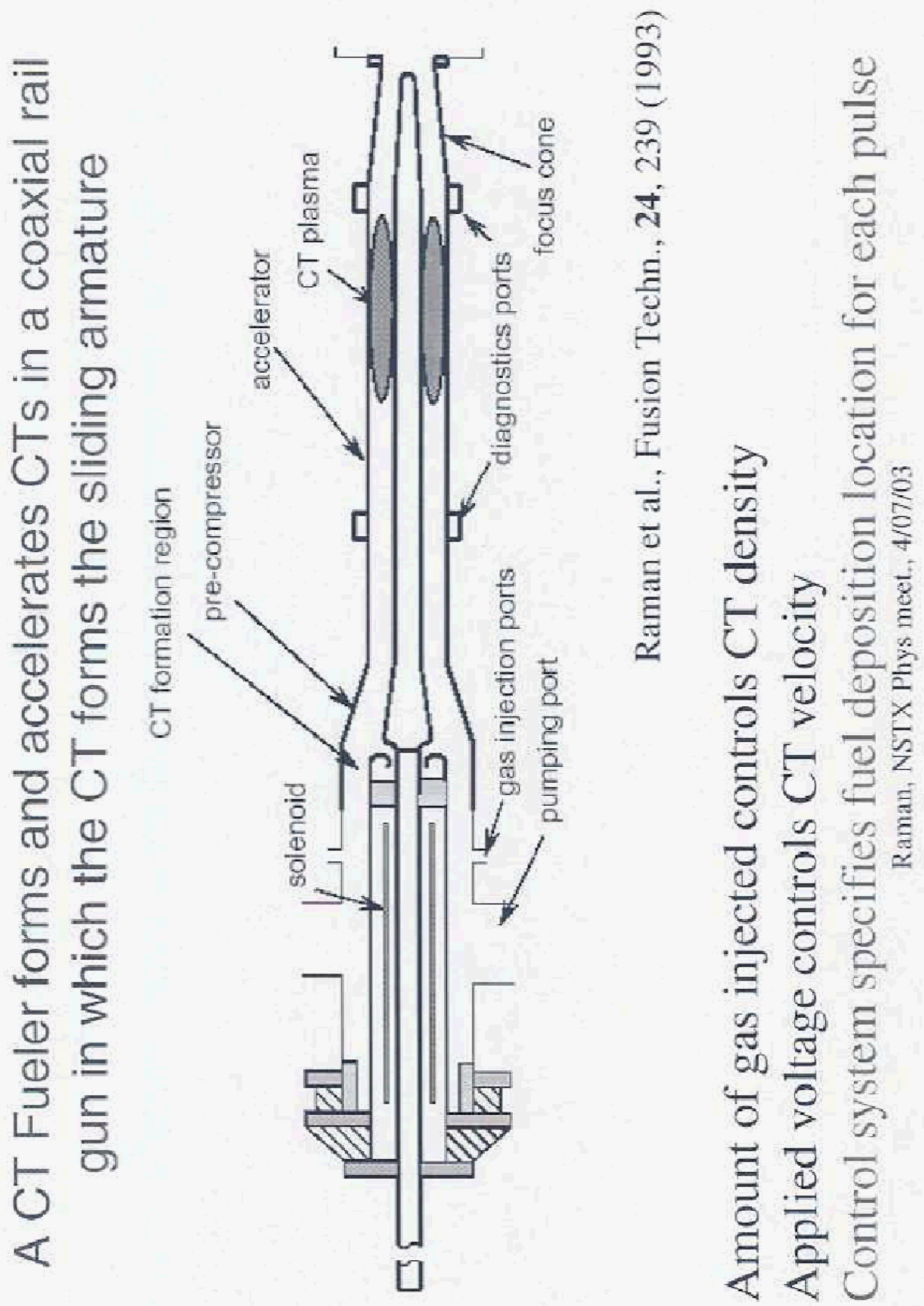


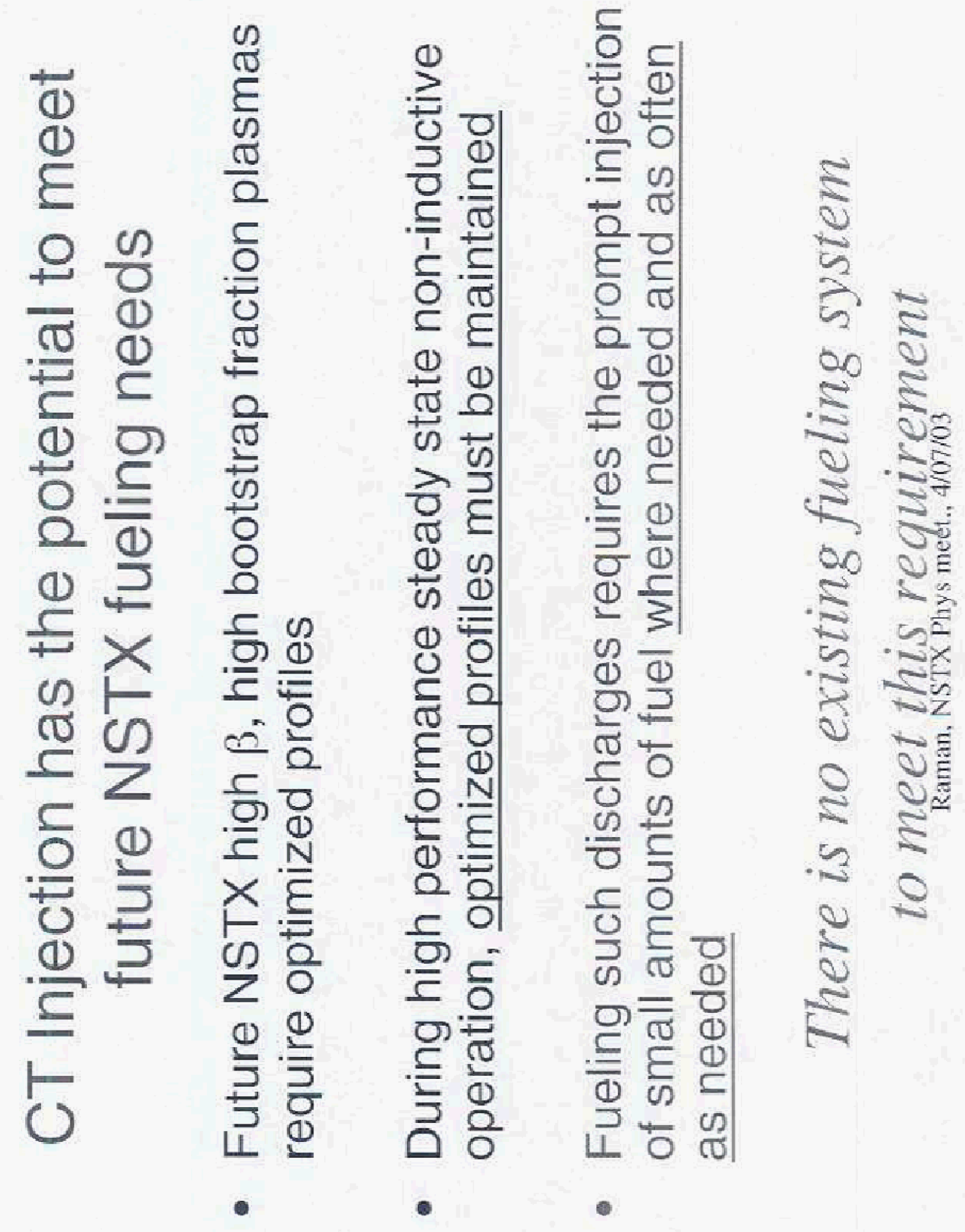




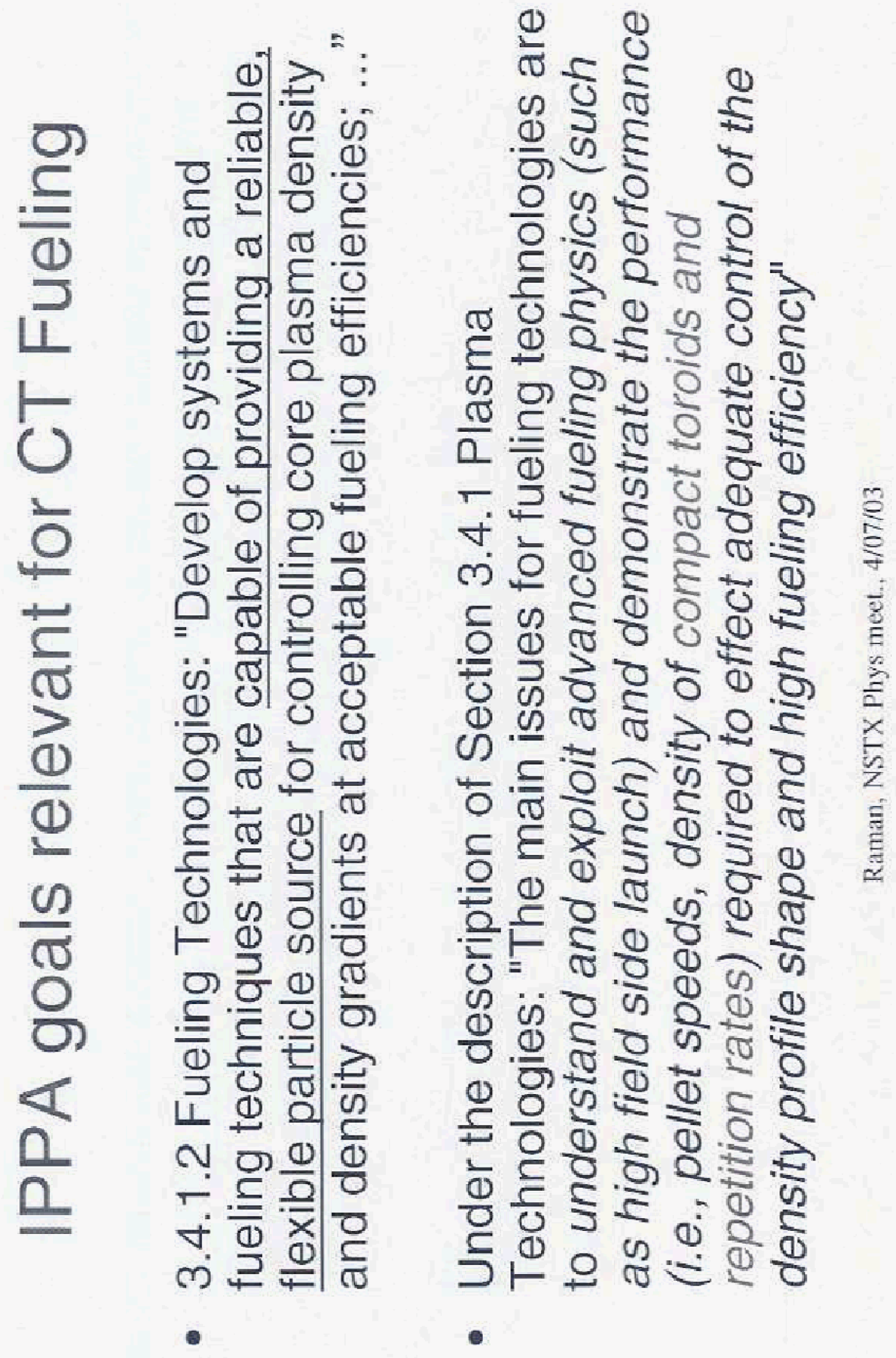



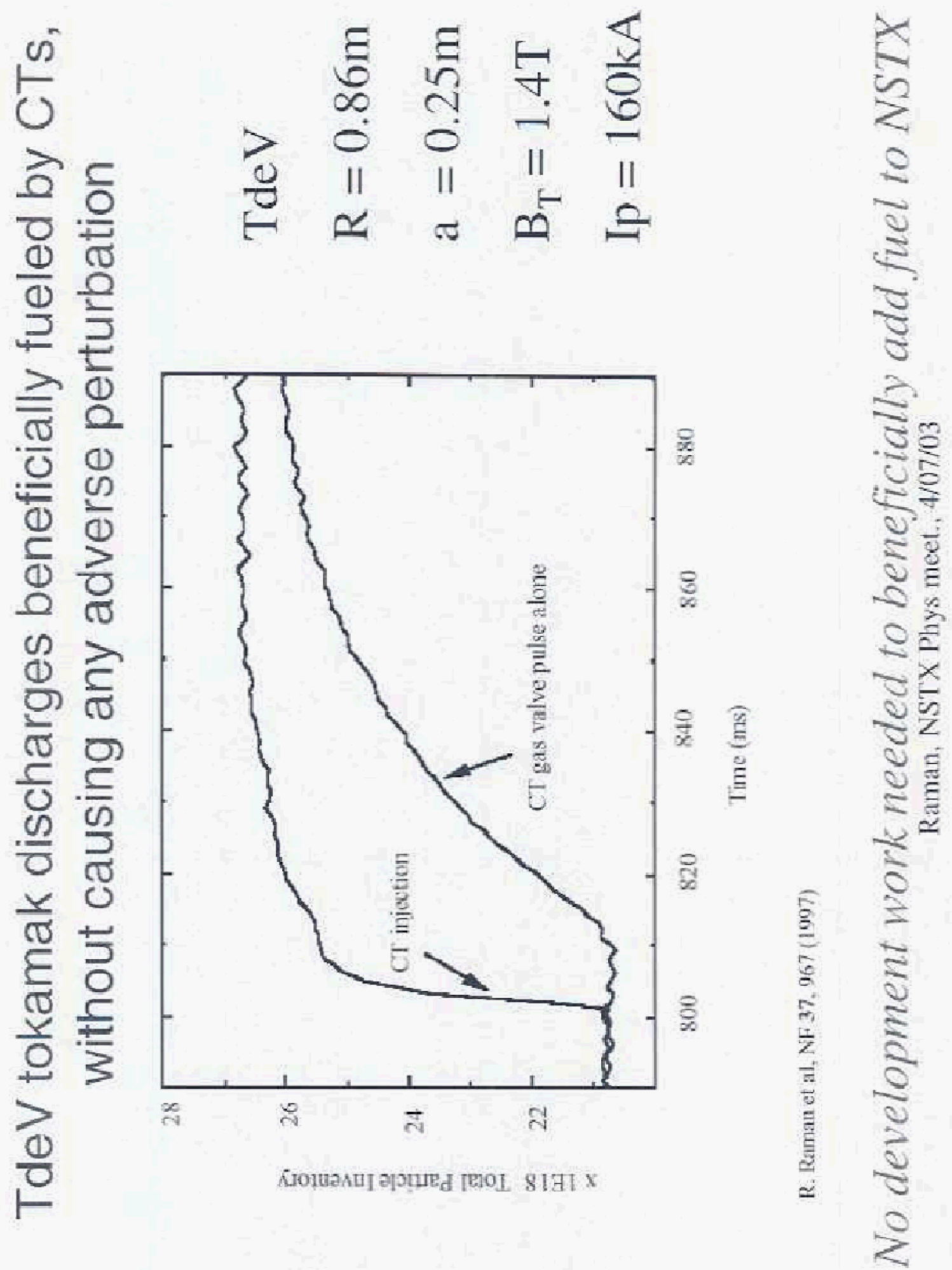


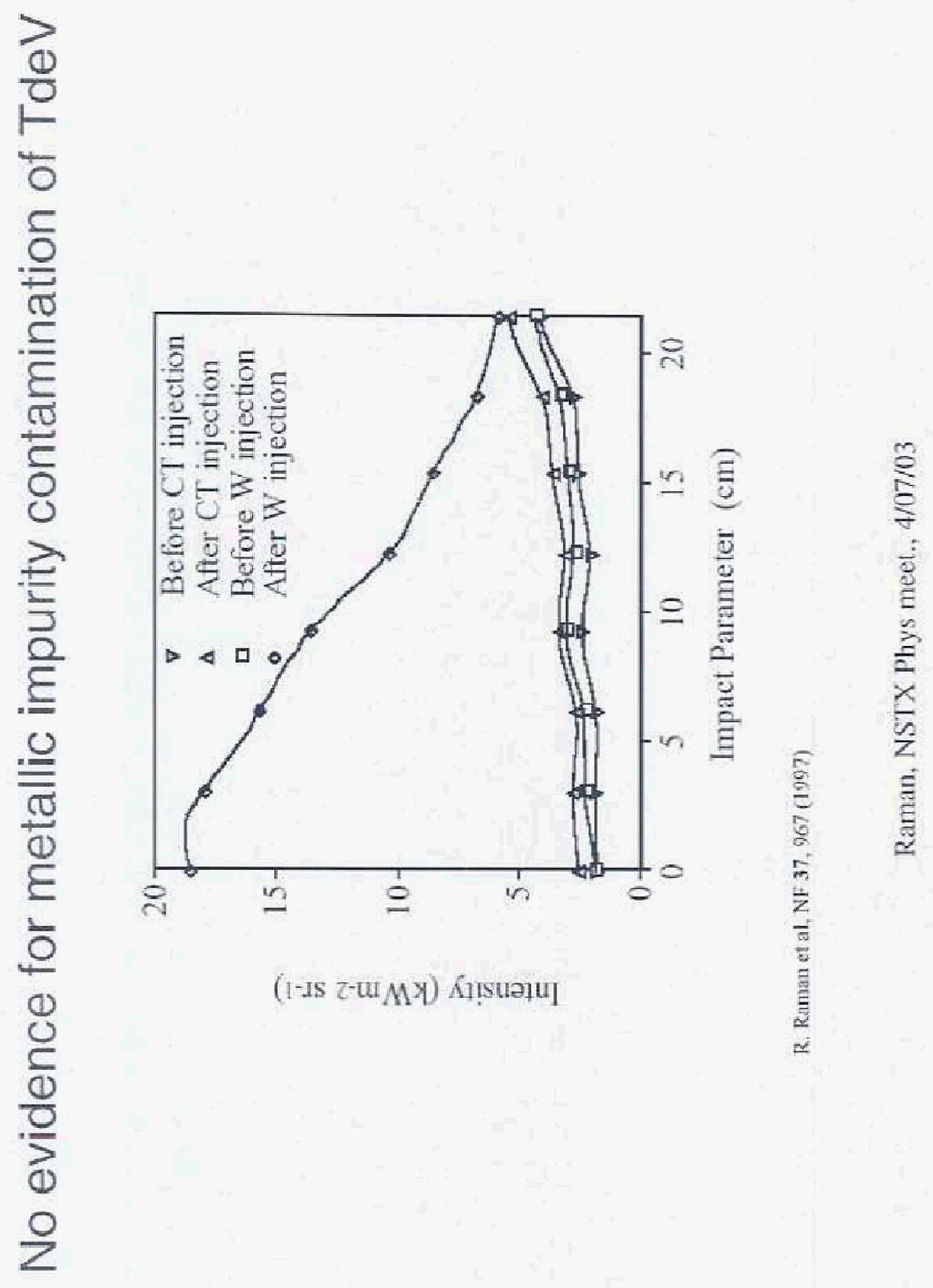




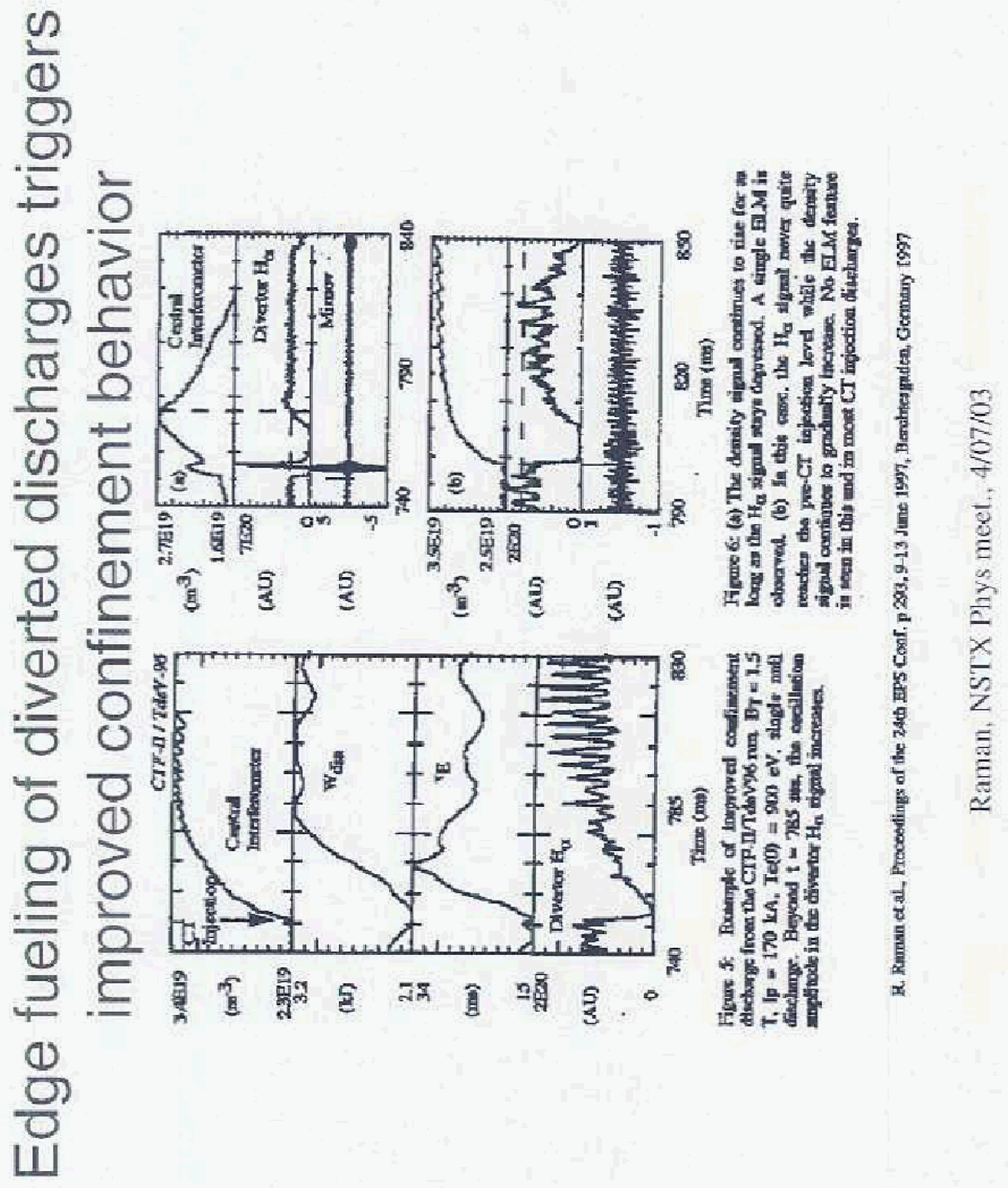




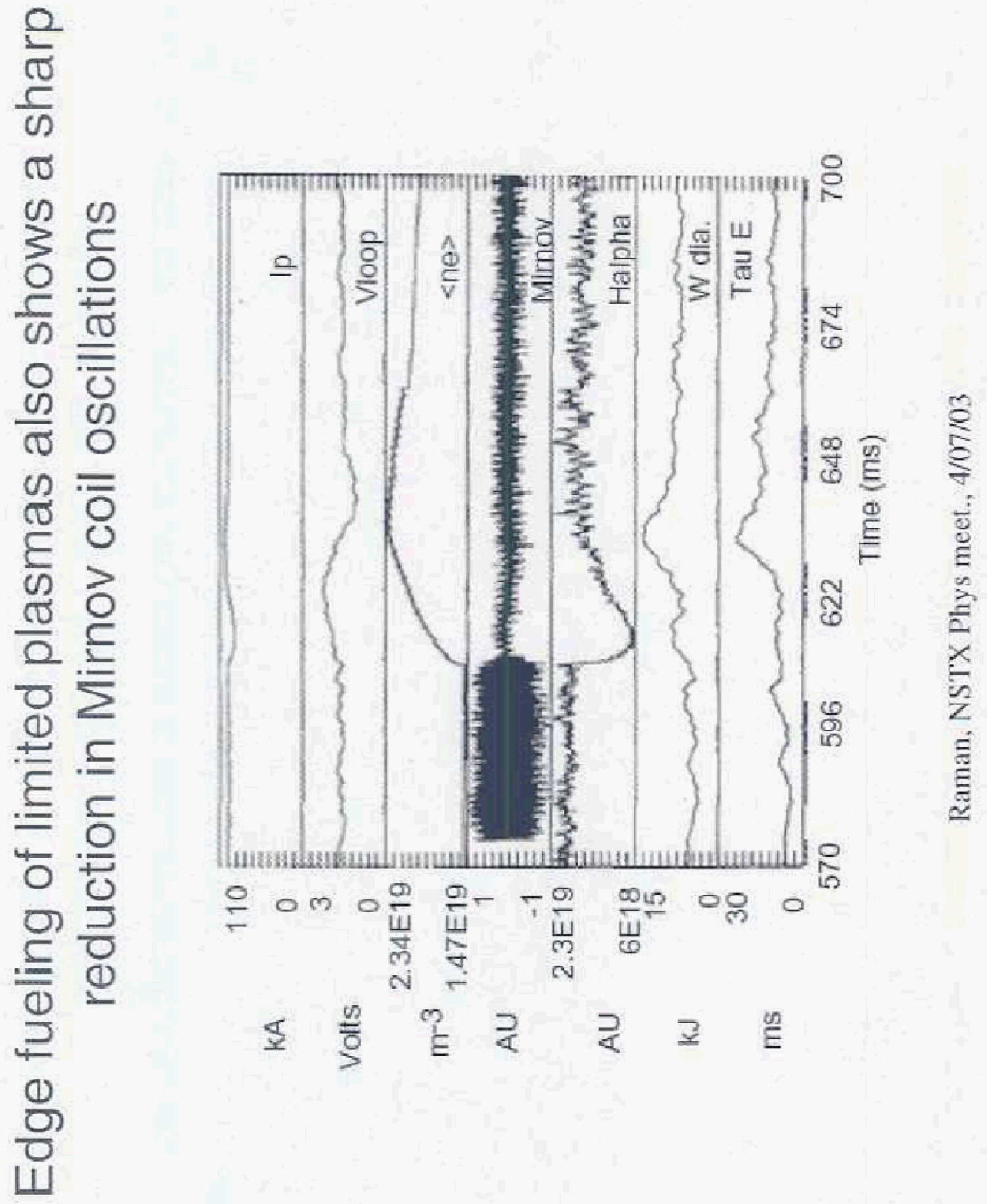




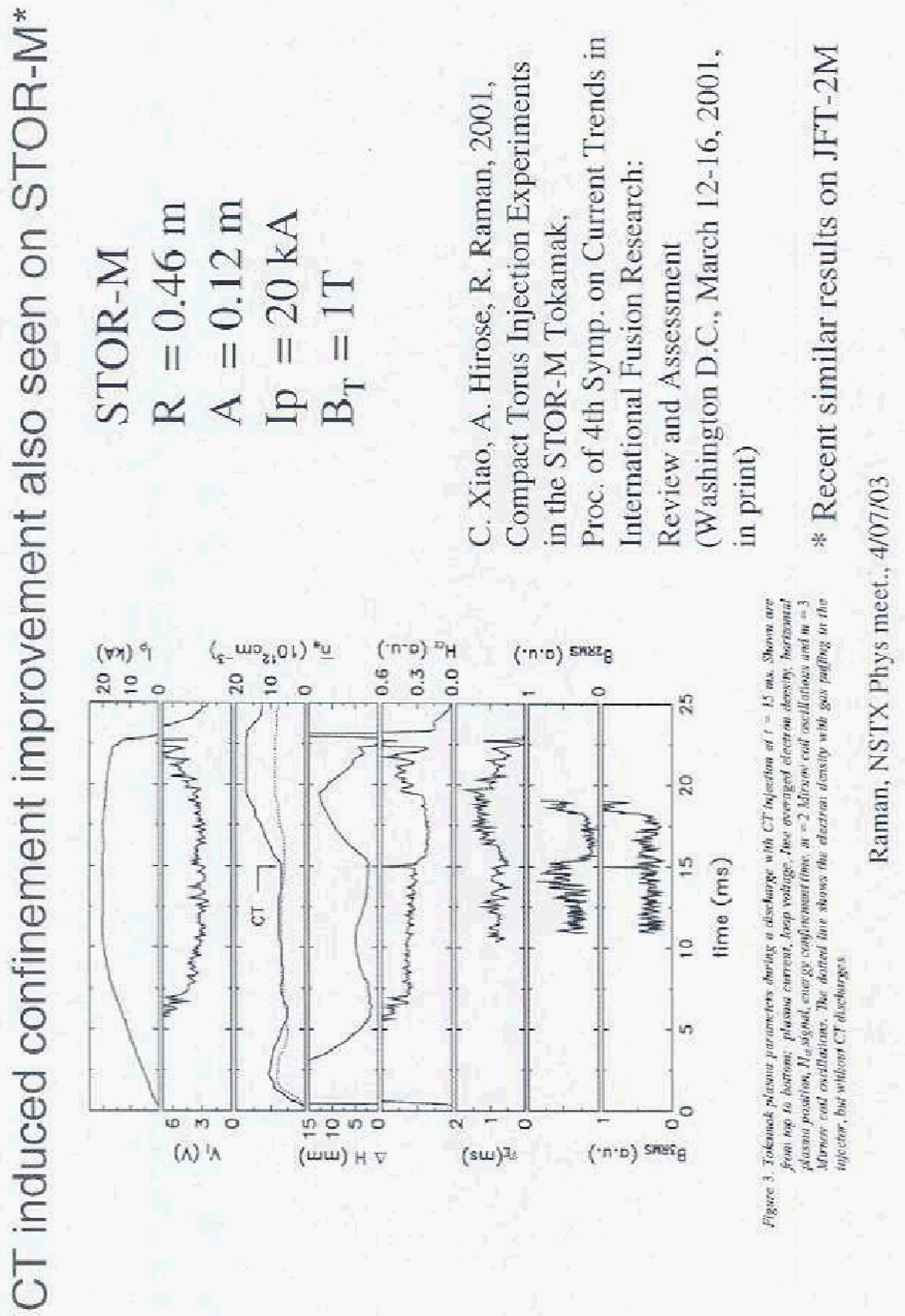




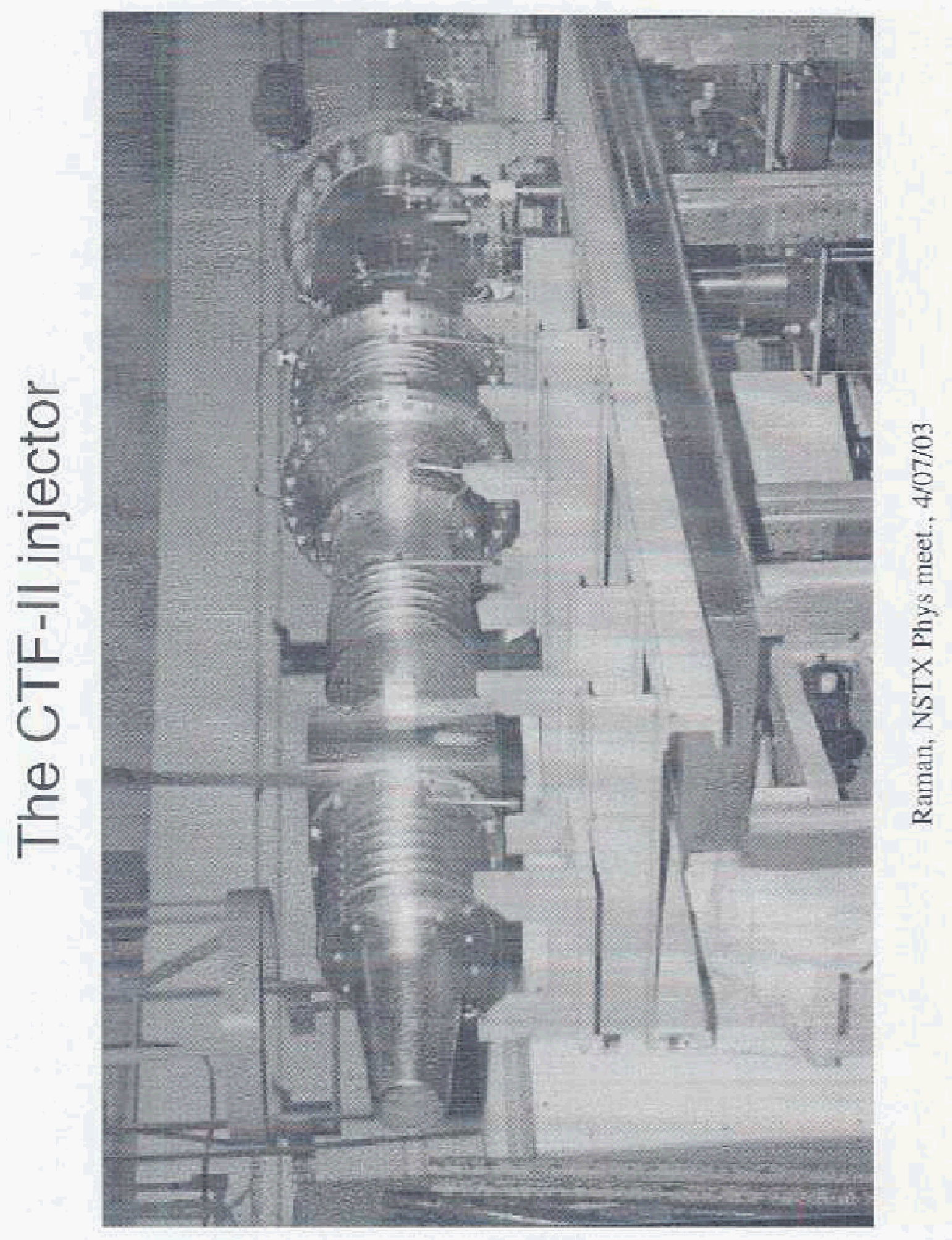




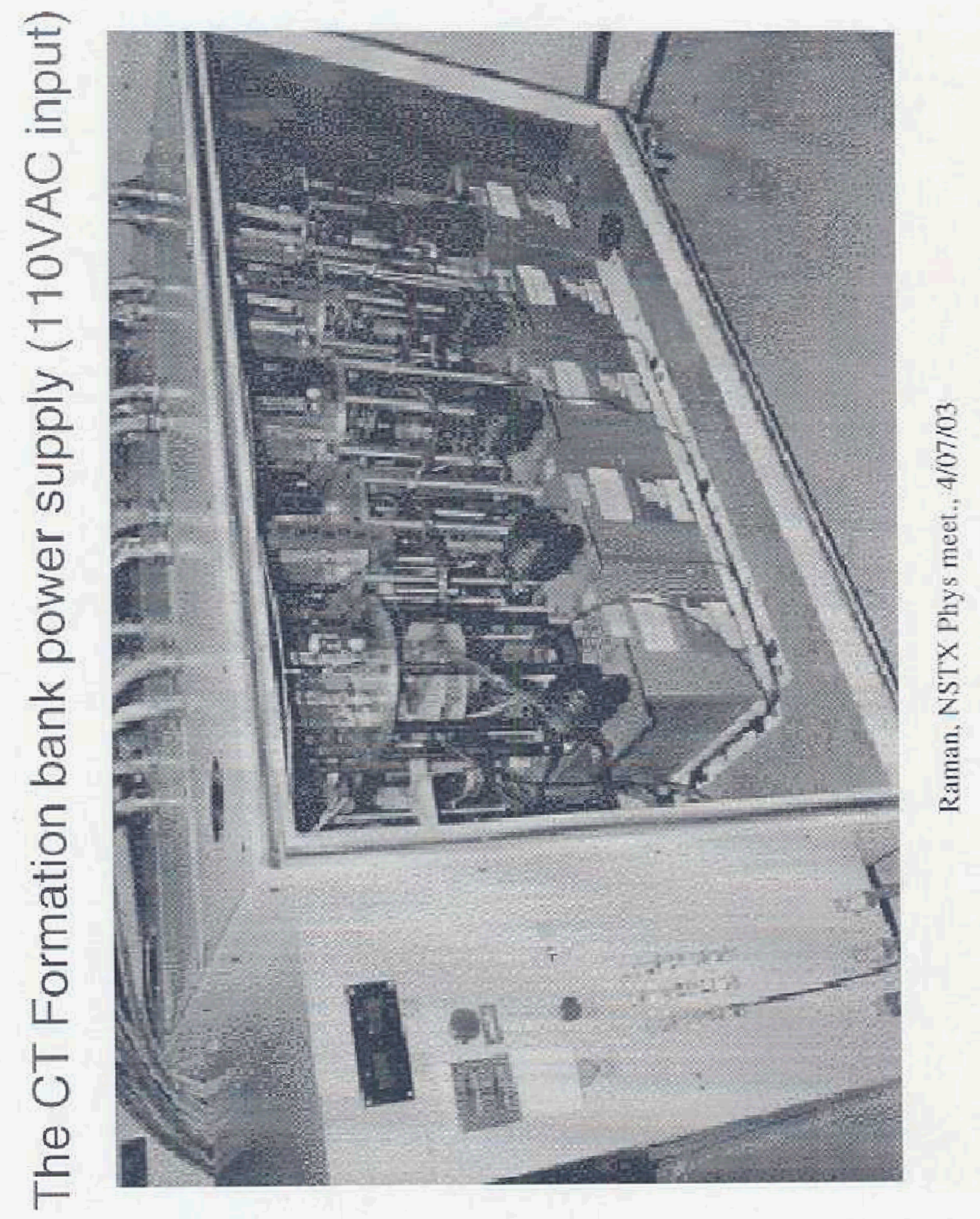




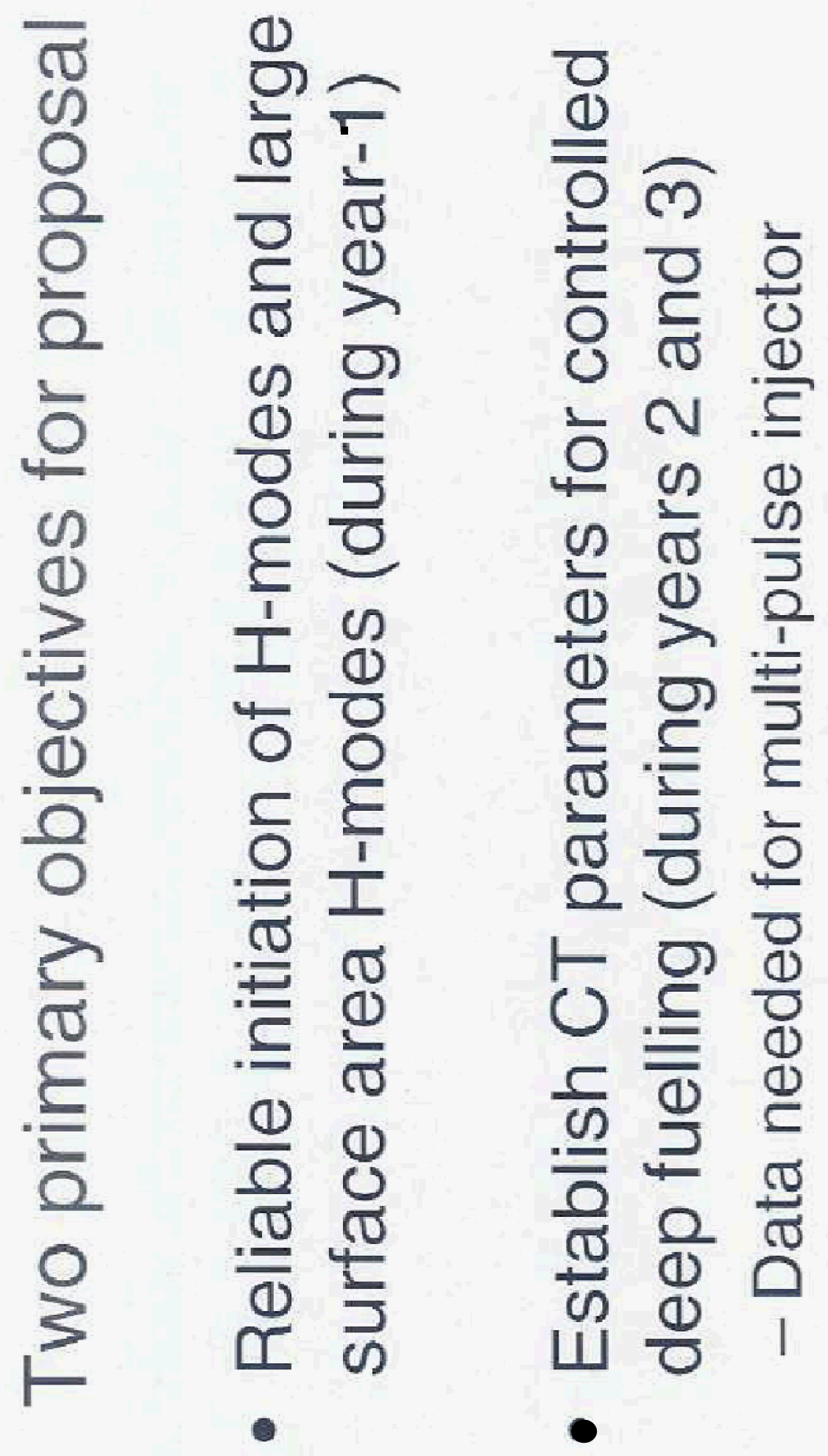




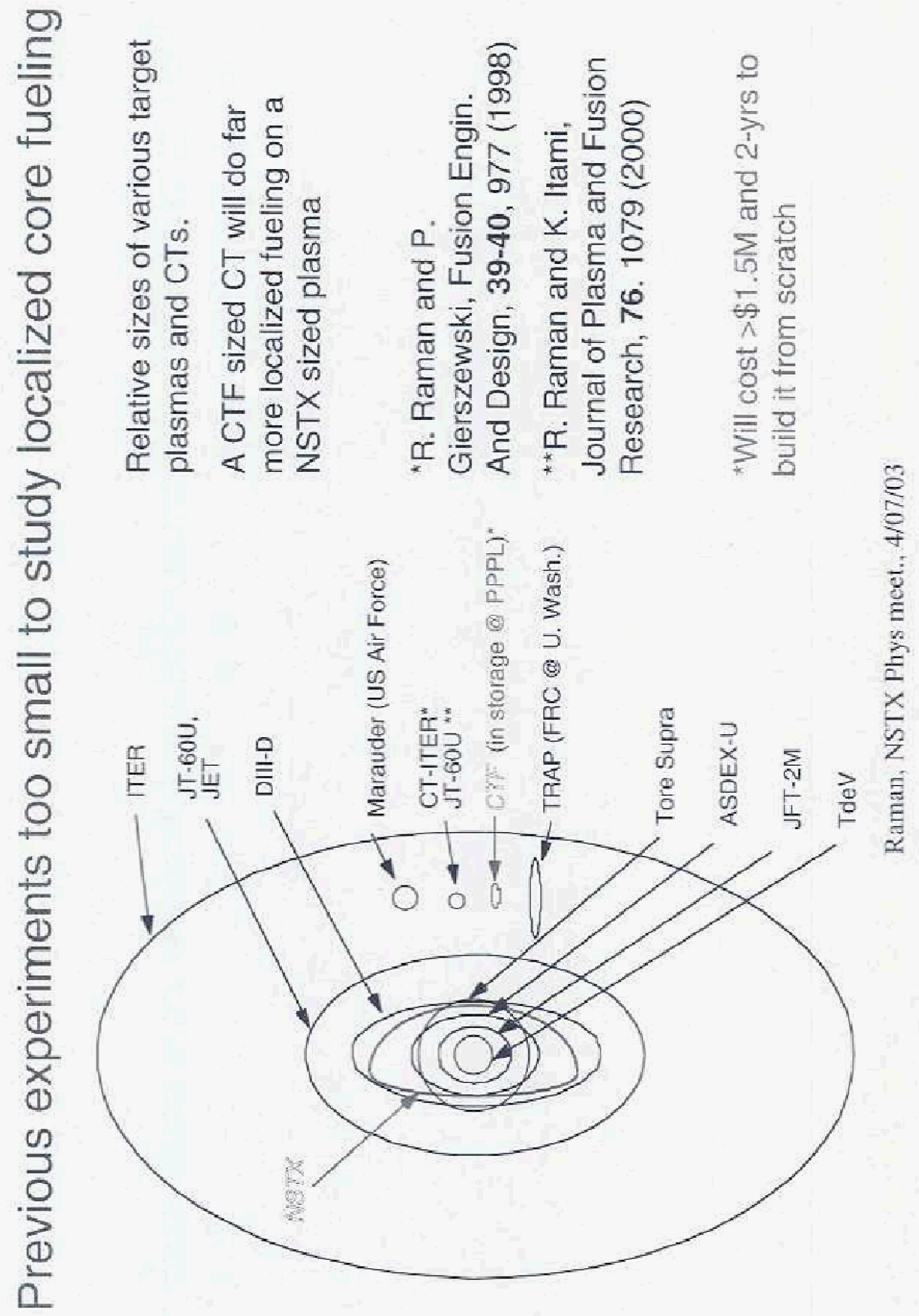




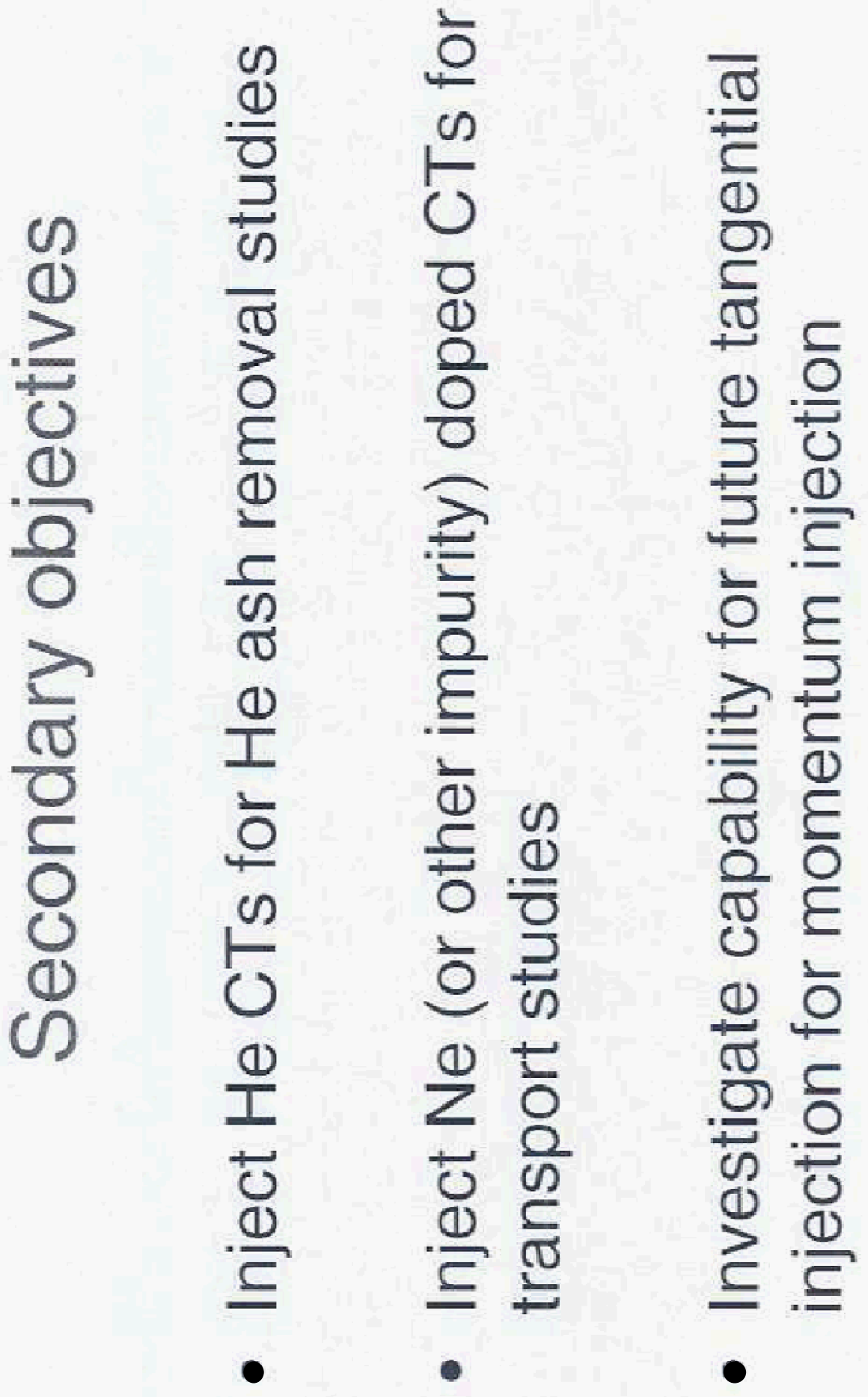




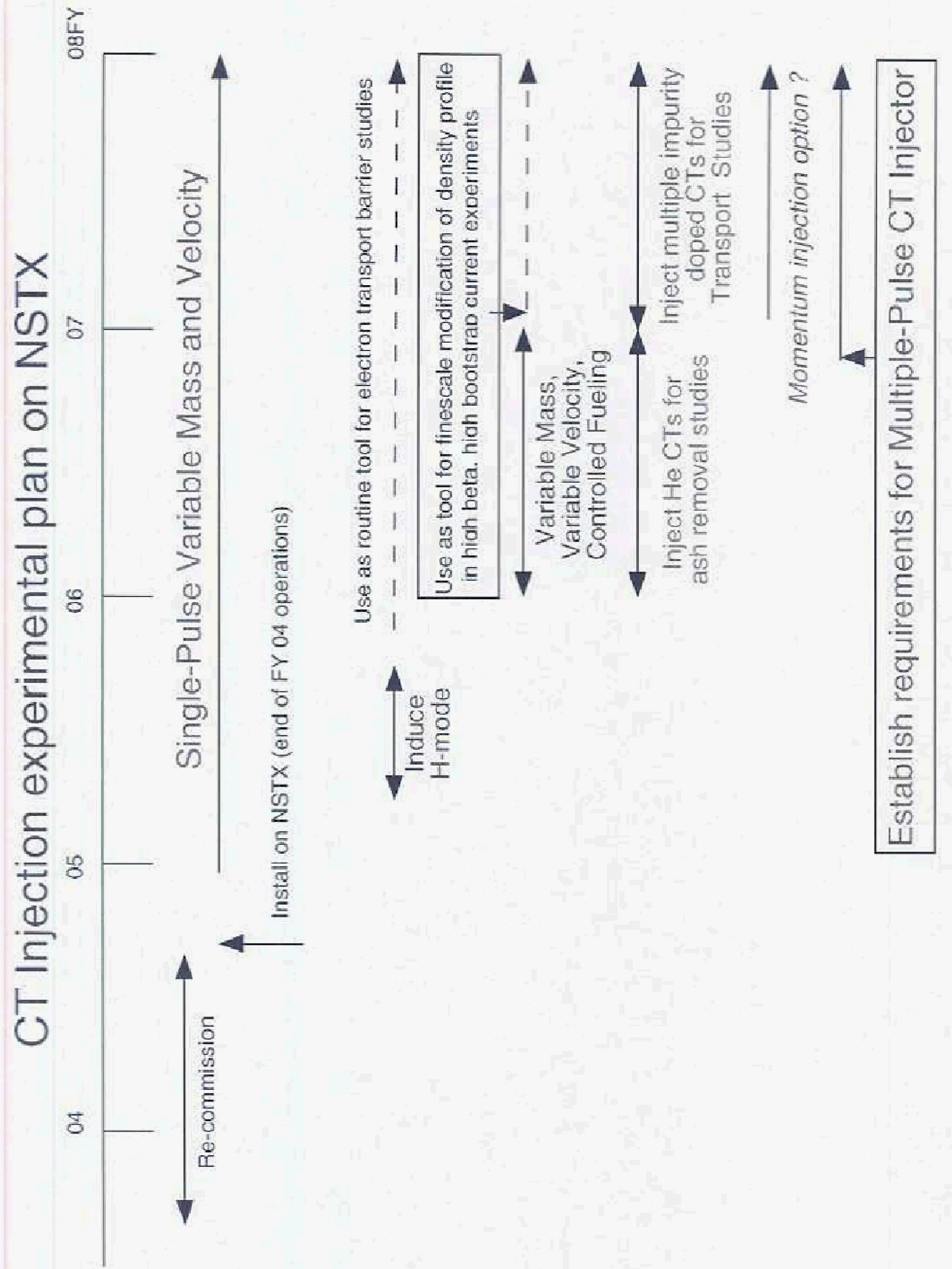

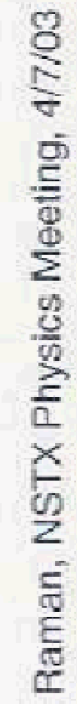




\section{Installation Concept}

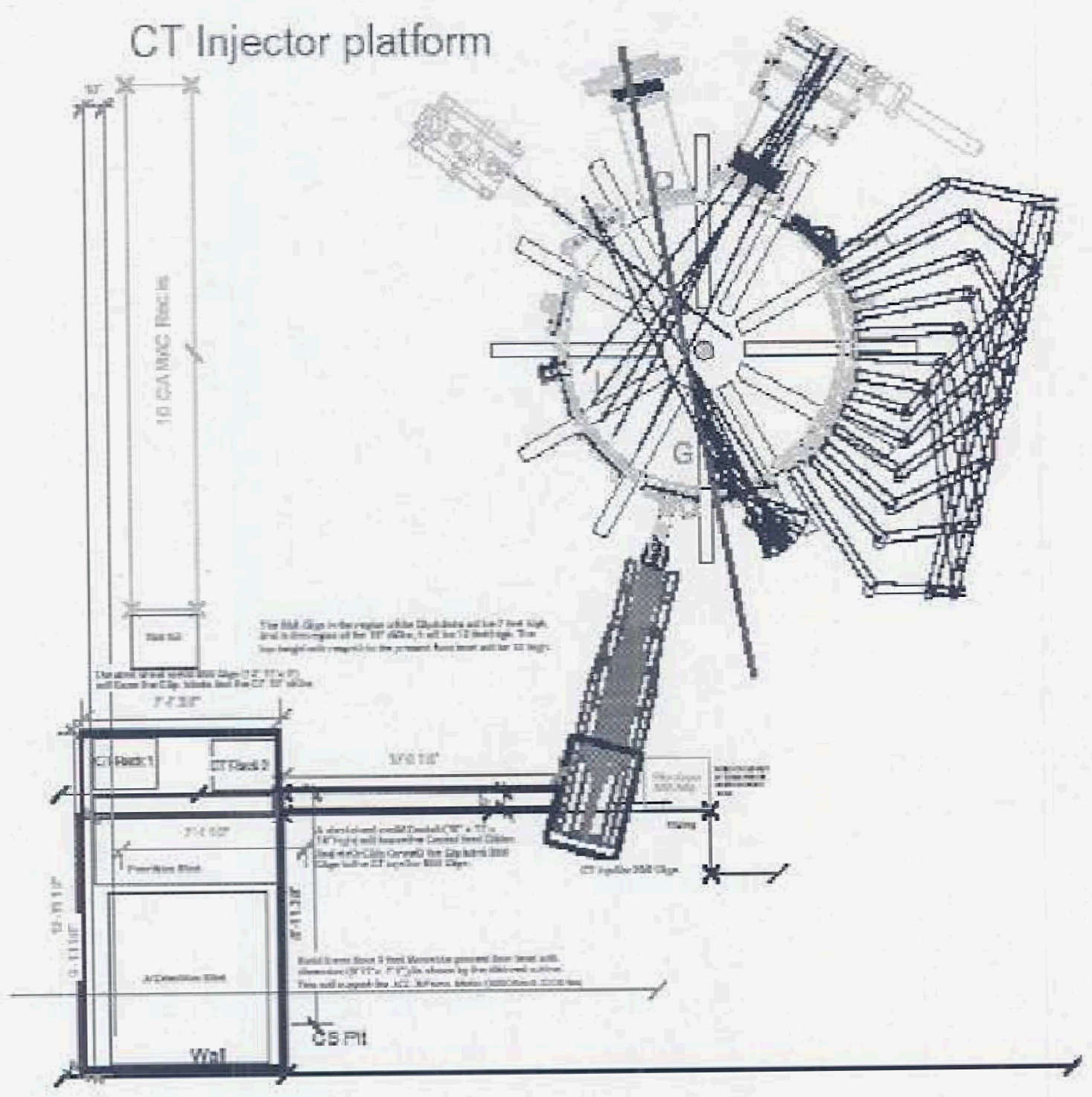

Raman, NSTX Phys Meet.

4/7/03 


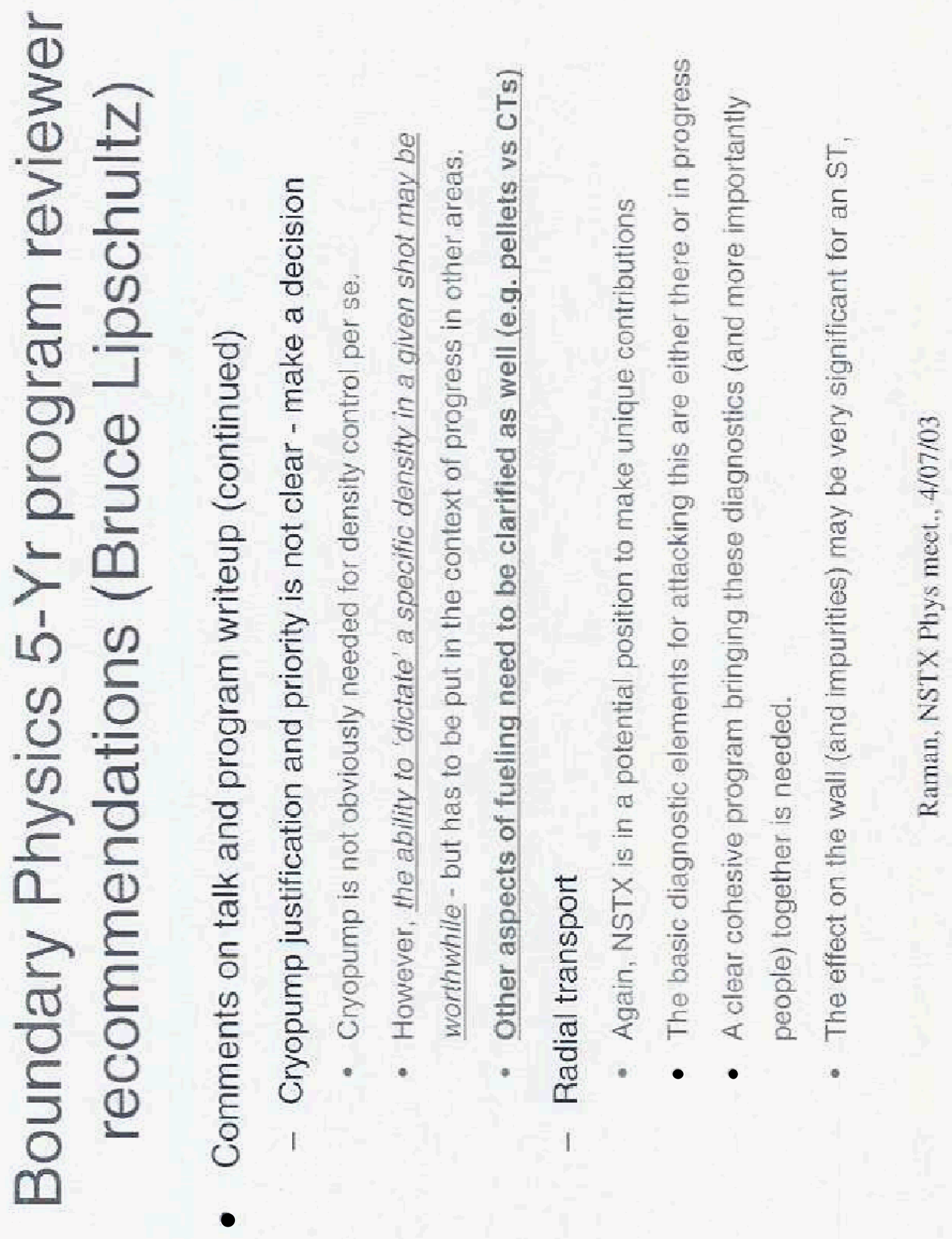




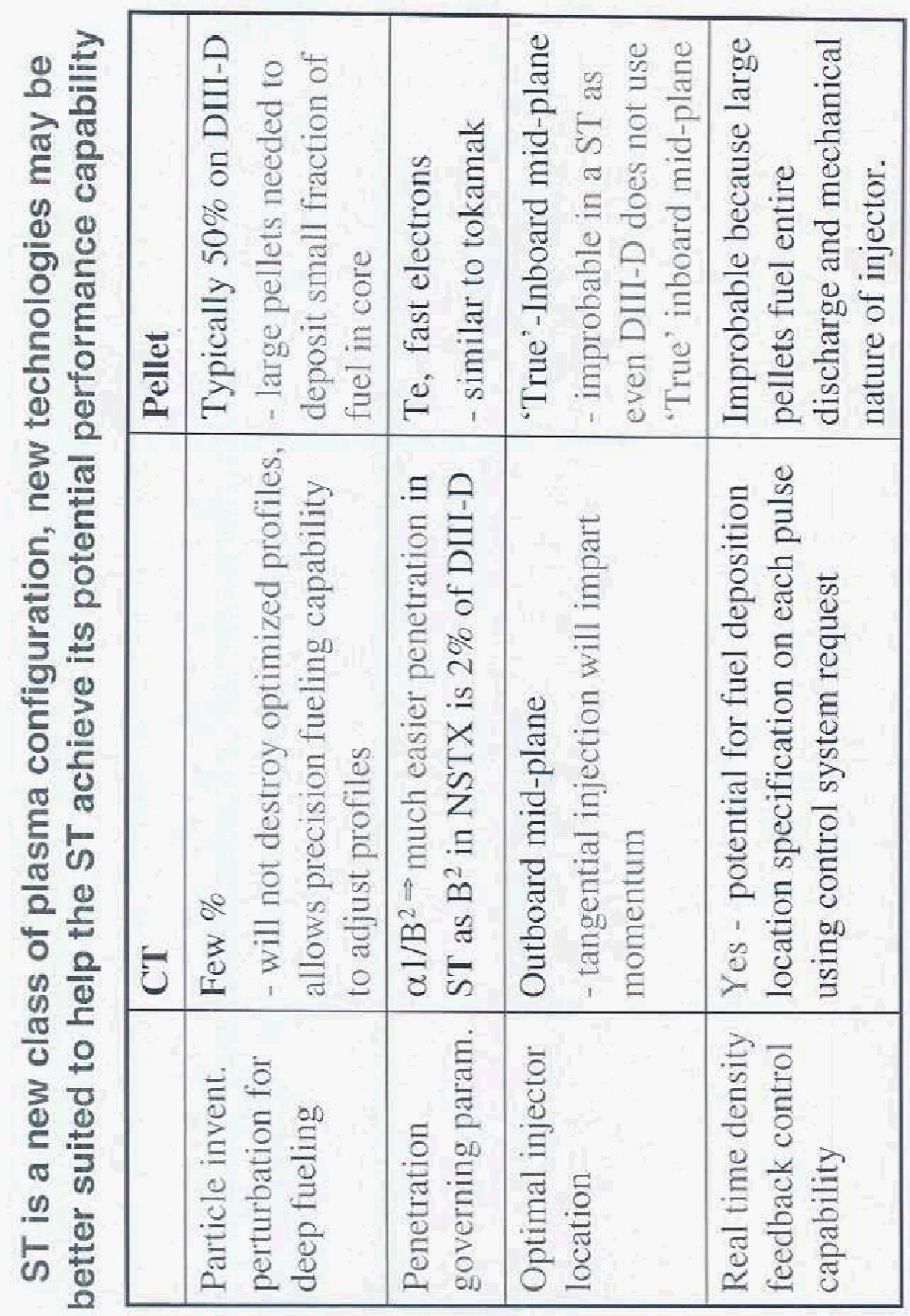



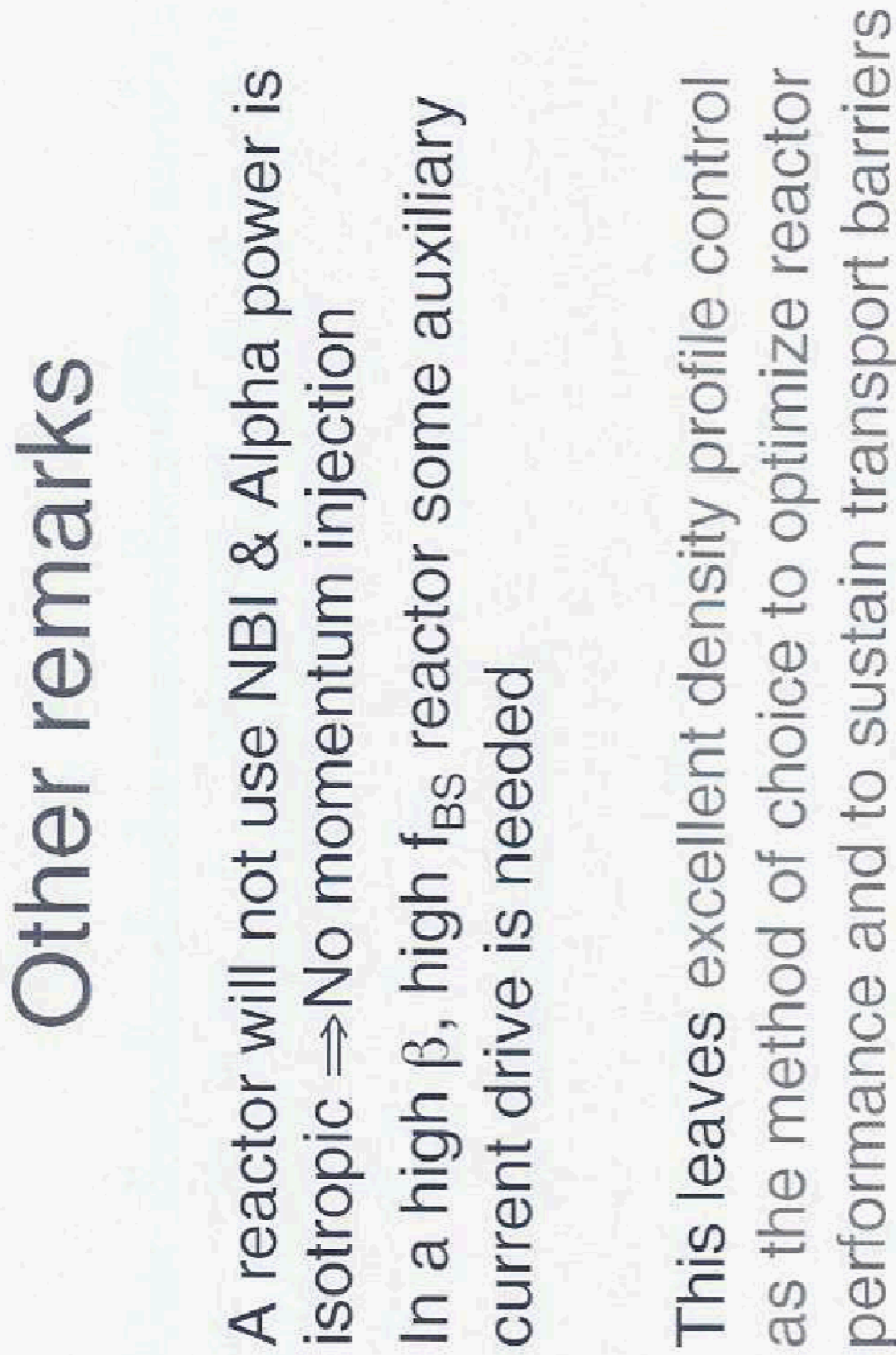


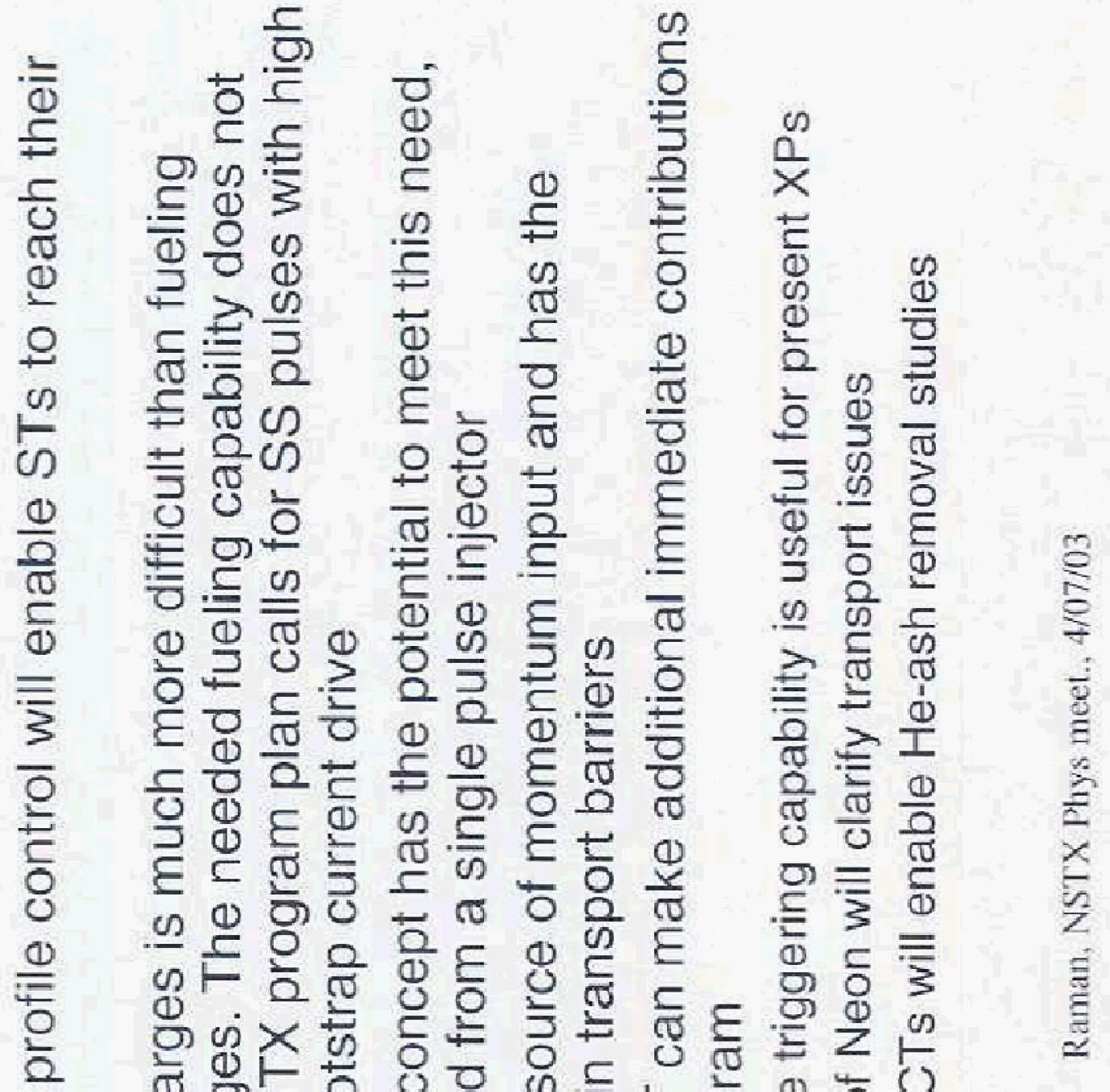

